Illinois State University

ISU ReD: Research and eData

Theses and Dissertations

7-7-2016

\title{
An Examination Of The First-Generation Student Experience At A Small, Private Institution
}

Joshua Erik Hayes

Illinois State University, jhayes185@gmail.com

Follow this and additional works at: https://ir.library.illinoisstate.edu/etd

Part of the Higher Education Administration Commons, and the Higher Education and Teaching Commons

\section{Recommended Citation}

Hayes, Joshua Erik, "An Examination Of The First-Generation Student Experience At A Small, Private Institution" (2016). Theses and Dissertations. 616.

https://ir.library.illinoisstate.edu/etd/616

This Dissertation is brought to you for free and open access by ISU ReD: Research and eData. It has been accepted for inclusion in Theses and Dissertations by an authorized administrator of ISU ReD: Research and eData. For more information, please contact ISUReD@ilstu.edu. 


\title{
AN EXAMINATION OF THE FIRST-GENERATION STUDENT EXPERIENCE AT A SMALL, PRIVATE INSTITUTION
}

\author{
Joshua Erik Hayes
}

\section{Pages}

The postsecondary completion gap - the differential between those who access postsecondary education and those who complete a postsecondary credential - is a complex crisis that permeates U.S. higher education. One postsecondary student segment that continues to lag behind other segments in terms of degree completion is firstgeneration students, or those who are the first in their immediate families to attend college. The current study explores first-generation students' experiences of their postsecondary environment viewed through unique lenses shaped by external contexts and prior experiences. Through a qualitative investigation of the experiences and perceptions of first-generation students at a private, residentially-based institution, the study explores how external forces influence first generation students' experience of the case study institution; how first generation students interpret the functional aspects of the case study institution's culture; and what these interpretations mean for the students' desire and ability to navigate their collegiate environment. As a group, the firstgeneration participants describe pre-college dispositions, family contexts, and educational experiences that serve as critical precursors to postsecondary achievement. Upon 
matriculation at the case study institution, participants describe experiencing a sense of care through the value of community, a sense of inclusion through the value of individuality, and a sense of achievement through the value of challenge. Participants' experiences of the case study institution's culture facilitates adjusting to an unfamiliar environment, overcoming social and academic challenges, and discovering purpose in their collegiate endeavors. The study concludes with a discussion of the role that institutional culture plays in the success of all student populations and with implications for college and university leaders interested in leveraging institutional culture to support degree completion.

KEYWORDS: First-Generation Students, Degree Completion, Organizational Culture 


\section{AN EXAMINATION OF THE FIRST-GENERATION STUDENT EXPERIENCE}

AT A SMALL, PRIVATE INSTITUTION

JOSHUA ERIK HAYES

A Dissertation Submitted in Partial

Fulfillment of the Requirements

for the Degree of

DOCTOR OF PHILOSOPHY

Department of Educational Administration and Foundations

ILLINOIS STATE UNIVERSITY

2016 
Copyright 2016 Joshua Erik Hayes 


\section{AN EXAMINATION OF THE FIRST-GENERATION STUDENT EXPERIENCE}

AT A SMALL, PRIVATE INSTITUTION

JOSHUA ERIK HAYES

COMMITTEE MEMBERS:

Dianne Gardner-Renn, Chair

Phyllis McCluskey-Titus

Mohamed Nur-Awaleh

Wendy Troxel 


\section{ACKNOWLEDGMENTS}

My heartfelt thanks to my supportive family and friends, who believed in me when I didn't believe in myself.

J. E. H. 


\section{CONTENTS}

Page

ACKNOWLEDGMENTS $\quad$ i

$\begin{array}{ll}\text { CONTENTS } & \text { ii }\end{array}$

TABLE vii

FIGURE viii

CHAPTER

I. INTRODUCTION 1

Statement of the Problem 1

Purpose of the Study \& Research Questions 6

Definition of Terms $\quad 7$

Significance of the Study $\quad 9$

Delimitations and Limitations $\quad 10$

$\begin{array}{ll}\text { Summary } & 10\end{array}$

II. REVIEW OF LITERATURE 13

The Postsecondary Completion Gap $\quad 13$

Gender \& Completion $\quad 16$

Race, Ethnicity \& Completion 16

Socioeconomic Status \& Completion 17

Other Student-Related Characteristics Related to Completion 18

Institutional Characteristics \& Completion $\quad 19$

First-Generation Status \& Completion 21

Implications of the Completion Gap 23

Economic Implications $\quad 23$

Institutional Implications $\quad 24$

Critical Implications 25 
First-Generation Students \& the Interactionalist Model

of Persistence

Overview of the Interactionalist Model 30

First-Generation Student Entry Characteristics 34

First-Generation Student Educational Goals \& Commitments 36

First-Generation Students, External Environments \&

Institutional Characteristics $\quad 38$

First-Generation Students \& Academic and Social Integration 39

First-Generation Students \& Other Sociological Models

of Persistence

First-Generation Students \& Institutional Theory

First-Generation Students \& Theories of Social Reproduction/ Cultural Capital

First-Generation Students \& Social/Ecological Theories of Persistence

First-Generation Students \& Family Systems Theory

First-Generation Students \& Psychological Theories of Persistence

First-Generation Students \& Student Involvement Theory

Attitudes, Intentions, Behavior \& First-Generation Student Persistence

Coping Behavioral Theory \& First-Generation Student

Persistence

Self-Efficacy \& First-Generation Student Persistence

Attribution Theory \& First-Generation Student Persistence

61

Identity, Role Theory \& First-Generation Student Persistence

First-Generation Student Persistence \& Economic Theory

First-Generation Student Persistence \& Student Engagement

First-Generation Student Persistence \& Critical Theories

Societal Oppression \& First-Generation Student Persistence $\quad 73$

Neoliberalism \& First-Generation Student Persistence

Organizational Culture \& Postsecondary Education

Definitions of Organizational Culture 
The Origin of Organizational Culture in Postsecondary Institutions

The Elements of Organizational Culture in Postsecondary Institutions

The Function of Organizational Culture in Postsecondary Institutions

Conceptual Framework for the Current Study

III. REVIEW OF METHODS

Study Purpose \& Research Questions

Philosophical \& Methodological Frameworks

Selection of the Case Study Institution

Selection of Participants

Brief Description of Participants

Collection of Evidence

Analysis of Evidence

Ensuring Trustworthiness of Evidence

Ethical Safeguards

120

Summary

IV. FINDINGS

Research Question \#1: External Influences 126

Sources of Strength Common to All Students 126

Sources of Strength Unique to First-Generation Participants 128

Areas of Challenge Common to All Students 135

Areas of Challenge Unique to First-Generation Participants 137

Summary

Research Question \#2: Interpretations of Institutional Culture

Care through the Value of Community

Inclusion through the Value of Individuality

Achievement through the Value of Challenge

Summary

Research Question \#3: Navigation of Institutional Culture

Adjusting to an Unfamiliar Environment 
Overcoming Social Isolation

Overcoming Academic Challenges 171

Discovering Deeper Purpose 181

Summary

Conclusion

Summary

First-Generation-Specific Assets

First-Generation-Specific Obstacles

First-Generation Participants' Interpretations of Institutional

Culture

First-Generation Participants' Navigation of Institutional

Culture

Adjusting to the Institutional Environment

Overcoming Social Isolation

Overcoming Academic Challenges

Discovering Deeper Collegiate Purpose

Summary

Channeling the Strength of Cultures of Origin

Leveraging the Allure of the Culture of Immersion

Capitalizing on the Potency of Organizational Culture

Channeling the Power of Cultural Windows

Harnessing the Power of Cultural Ambassadors

Fostering Cultural Enclaves

Reimagining the Campus Visit

Revitalizing Orientation Programming

Revamping Communication Strategies

Reinforcing Cultural Ambassadors

Rediscovering Institutional Culture 
REFERENCES

APPENDIX A: Survey Invitation

APPENDIX B: Survey Protocol

APPENDIX C: Interview Invitation

APPENDIX D: Interview Protocol

APPENDIX E: Statement of Informed Consent 
TABLE

Table

Page

1. Summary of Participants

113 


\section{FIGURE}

Figure $\quad$ Page

1. Conceptual Model of First-Generation Persistence at Performance University 


\section{CHAPTER I}

\section{INTRODUCTION}

\section{Statement of the Problem}

Postsecondary outcomes have long been issues of public scrutiny. Beginning in the mid-twentieth century, public discourse and policy emphasis on postsecondary outcomes centered on access, or opening the doors of higher education beyond the privileged classes with initiatives like the GI Bill and the Pell Grant (Thelin, 2004). In the new millennium, the emphasis shifted away from postsecondary access and to a focus on postsecondary completion. At the local level, states like Illinois, for example, have advanced the Illinois Public Agenda for College and Career Success, a policy framework for increasing the number of state residents who hold a postsecondary credential (State of Illinois Board of Higher Education, 2009). At the national level, the Obama administration has advanced an ambitious goal of ensuring that the U.S. leads the world in the number of college-educated citizens by the end of the current decade, calling for an increase in six-year college completion rates from forty percent to sixty percent and the addition of ten million new degree holders by 2020 (Kanter, Ochoa, Nassif, \& Chong, 2011). The emphasis on postsecondary completion is more critical than ever. With most jobs of the twenty-first century requiring at least some type of postsecondary training, a workforce lacking the skills acquired within formal degree and certificate programs

threatens the United Stats' position as a global economic leader (U.S. Department of 
Education, 2014). Furthermore, a lack of focus on postsecondary degree completion has devastating consequences for individual students and for the future of democratic participation. Ensuring that a critical mass of students who access postsecondary education persist to degree completion is paramount to the continued dominance of the U.S. writ large and to the prosperity and freedom of its citizenry.

One postsecondary student segment facing lagging completion rates is firstgeneration status, defined as students who are the first within their immediate families to pursue education beyond the secondary level (Choy, 2001; Chen, 2005). Accounting for over one-third of all first-year students enrolled in U.S. colleges and universities (Stuber, 2011), first-generation students are less likely to earn a postsecondary credential than continuing-generation students (Chen, 2005; Ishitani, 2006; Cataldi et al., 2011). Further exacerbating the completion gap, first-generation students tend to enroll in public institutions (Choy, 2001) and for-profit institutions (Engle \& Tinto, 2008) where the likelihood of completing a postsecondary credential is reduced. Most troubling, firstgeneration student degree completion lags within postsecondary environments where their continuing-generation counterparts are more likely to find success, namely private universities (Pascarella \& Terenzini, 2005) and smaller institutions (Lohfink \& Paulsen, 2005). Given the urgency of closing the completion gap for a sizeable student population, further investigation of first-generation student degree completion is warranted. Specifically, additional research is needed to determine what factors influence first-generation degree completion at the individual level and what role colleges and universities play in fostering degree completion among this population. Further investigation into the unique ways that first-generation students experience their 
postsecondary institutions - particularly small, privately-controlled institutions highlights critical issues that institutional leaders must address in order to close the completion gap for this population and to ensure the continued relevance of these traditional institutions in a rapidly changing postsecondary environment.

The differential between those who access postsecondary education and those who complete a postsecondary credential - the completion gap - is a complex crisis that permeates U.S. higher education. The completion gap is characterized by differing segments of the U.S. population (e.g., male, non-majority, low-income, first-generation) failing to complete postsecondary credentials at comparable rates. Even as diverse populations make incremental strides in postsecondary access, a stubborn completion gap remains between majority students and students from racial and ethnic minorities (Kena et al. 2016) students from the lowest socioeconomic levels (Horn \& Carroll, 2007; Mortenson, January 2012), and first-generation students (Chen, 2005). Student characteristics alone, however, do not explain the completion gap. Institutional characteristics such as type of control (e.g., public vs. private) play a role in degree completion. For example, four-year private institutions enjoy a consistent completion advantage over their publically-controlled peers with graduation rates higher than the postsecondary institutional average (Kena et al., 2016). In addition, institutional characteristics such as size, residential status and selectivity influence degree completion, with smaller residential institutions (Pascarella \& Terenzini, 2005; Bowen, Chingos, \& McPherson, 2009) and more selective institutions (Kena et al., 2016) demonstrating higher graduation rates for some - but not all - student populations than larger, less selective commuter institutions. 
Acknowledgement of the completion gap between different postsecondary populations coupled with acknowledgement of the role that institutional factors play in degree completion behavior warrants a distinction between two related constructs: persistence and retention. Persistence can be conceptualized as completion behavior at the individual level. Students make progress toward completing a postsecondary credential, or persist, as the result of a myriad of interwoven internal and external factors: primary and secondary schooling experiences; family involvement in education; commitment and motivation to earning a degree; the quality of campus life; level of financial resources; the quality of interaction with faculty; and outside obligations relating to family and work, just to name a few. Because no two students travel the same path to degree completion, persistence is a discrete, highly complex phenomenon. In contrast, retention can be conceptualized as degree completion at the organizational level. Over the course of their histories, college and university leaders make intentional and unintentional decisions that have implications for students' desire and ability to remain enrolled through degree completion. These decisions relate to institutional mission; curricula; the organizational climate; institutional priorities and how they are represented internally and externally; the elements of the physical plant, and inclusive policies and procedures. These organizational factors influence whether students who pass through the doors of the academy have the desire and ability to complete a degree. Retention and persistence are interrelated constructs that link institutions'

Retention and persistence are inter-related constructs that link institutions' ability to retain students with students' desire and ability to persist through degree completion. In short, students persist to graduation while colleges and universities retain their students 
to degree completion. Institutional retention rates - the number of students who graduate relative to the number who enter - are common metrics that colleges and universities use to gauge institutional success (Braxton and Hirschy, 2005). In term of persistence, Tinto's interactionalist theory of student persistence (1993) is the most widely-accepted heuristic for conceptualizing the forces that influence degree completion behavior at the individual level. Tinto's interactionalist model postulates that student entry characteristics and their goals and commitments with regard to earning a degree interact with forces external to the institution to shape students' experiences and behaviors. Some institutional behaviors foster what Tinto deems social and academic integration. According to the interactionalist model, the more deeply students are integrated into the academic and social life of their institution, the more like that they will persist to degree completion.

While Tinto's (1993) interactionalist model remains a dominant theory in the persistence and retention literature, some scholars question its application to diverse student populations (Braxton \& Hirschy, 2005). Indeed, some empirical investigations suggest that the relationship between first-generation students' educational goals and the subsequent social and academic integration is more nuanced than Tinto's (1993) theory proposes. According to the interactionalist theory, educational goals and commitments work to strengthen or weaken the likelihood that students will engage in socially and academically integrating behaviors, with well-developed goals and stronger academic commitments promoting integration behavior that fosters degree completion. Paradoxically, research finds that first-generation students - who are collectively less likely to persist than continuing-generation students - report more certainty in their 
academic major upon enrollment (Terenzini, Springer, Yaegar, Pascarella, \& Nora, 1996; Engle \& Tinto, 2008). Clearly, something mediates the relationship between educational goals, commitment and integration for first-generation students.

As with educational goals and commitments, the relationship between institutional characteristics and integration behavior appears to be different for firstgeneration students relative to other students. Countering the conventional logic of Tinto's (1993) interactionalist model, first-generation students who attend small, private institutions are less likely to persist than first-generation students who attend larger schools (Pascarella \& Terenzini, 2005; Lohfink \& Paulsen, 2005). This convergence points to the need for additional research that explores the nuanced relationship among institutional context, environmental context and the persistence behavior of firstgeneration students.

\section{Purpose of the Study \& Research Questions}

This study explored first-generation students' experiences of a small, privatelycontrolled postsecondary environment viewed through unique lenses shaped by external contexts and prior experiences. Through a qualitative investigation of the experiences and perceptions of students at a private university who were the first in their immediate families to pursue postsecondary education, the study addressed the following research questions:

1. How do external forces (e.g., family, prior educational experiences) influence first generation students' experiences of a small, privately-controlled institution?

2. How do first-generation students interpret the functional aspects of their institution's culture? 
3. What do these interpretations mean for first-generation students' ability to navigate the functional aspects of their institution's culture?

\section{Definition of Terms}

The following list identifies and defines key terms and concepts utilized in current study:

- Academic integration - Students' desire and ability to establish membership within the academic communities of their institution (Tinto, 1993).

- Artifacts - Observable manifestations of organizational values and beliefs (Kuh \& Whitt, 1988; p. 65).

- Continuing-generation students - Students who are not the first in their immediate families to pursue education beyond the secondary level (Choy, 2001; Chen, 2005).

- Cultural capital - The interpersonal skills, habits, language patterns, prior learning, and/or lifestyle that students possess that affect their understanding of the expectations of postsecondary education and their ability to navigate the organizational culture of their institution (Kuh \& Love, 2000).

- Cultural distance -The difference in attitudes, beliefs values and/or assumptions between a student's culture of origin and her culture of immersion (Kuh \& Love, 2000).

- Cultural enclaves - Subgroupings of individuals within a larger organizational culture that possess similar attitudes, beliefs, values and/or assumptions (Kuh \& Love, 2000).

- Cultural stress - The tension that a student experiences when there is discord 
between the attitudes, beliefs, values and/or assumptions of her culture of origin and those of her culture of immersion (Kuh \& Love, 2000).

- Culture of immersion - The dominant norms, values, practices, beliefs and assumptions of a student's college or university (Kuh \& Love, 2000).

- Culture of origin - The dominant norms, values, practices, beliefs and assumptions inherent is student's family, community and/or prior life experiences (Kuh \& Love, 2000).

- Enactment - The conscious and unconscious manner in which students create meaning of their colleges or universities through the process of social construction (Weick, 1988).

- First-generation student - Students who are the first in their immediate families to pursue education beyond the secondary level (Choy, 2001; Chen, 2005).

- Organizational culture - "The collective, mutually shaping patterns of norms, values, practices, beliefs, and assumptions that guide the behavior of individuals and groups in an institute of higher education and provide a frame of reference within which to interpret the meaning of events and actions on and off campus" (Kuh \& Whitt, p. 12-13).

- Persistence - Related to "retention," persistence is continuous enrollment at a postsecondary institution from the student's point of view; student behavior that facilitates progress toward degree completion.

- Retention - Related to "persistence," retention is continuous enrollment at a postsecondary institution from the institution's point of view; the organizational context and organizational behavior that facilitates student progress toward degree 
completion.

- Rituals - A “window" of organizational culture; actions or ceremonies that represent cultural values in action (Masland, 1985).

- Sagas - A "window" of organizational culture: a narrative of important events and individuals in an institution's history (Masland, 1985).

- Social integration - Students' desire and ability to establish membership within the social communities of their institution (Tinto, 1993).

- Subculture - A subgrouping of organizational members who come to share a common set of norms and values as the result of persistent interaction and who exert control over organizational members in an attempt to guarantee conformity to those norms and values (Bolton \& Kammeyer, 1972).

- Symbols - A "window" of organizational culture; "concrete examples" that "represent implicit cultural values and beliefs, thus, making it tangible" (Masland, $1985 ;$ p. 148).

- Values - Shared beliefs about the worth of institutional goals, activities, relationships and feelings (Schein, 2010).

\section{Significance of the Study}

In addition to providing policymakers and postsecondary leaders with practical considerations in fostering institutional environments that promote first-generation student success through retention, this study addressed gaps in the scholarship on firstgeneration degree persistence at the individual level. Specifically, the study explored how postsecondary goals and commitments for first-generation students were shaped by external forces (e.g., family members, prior educational experiences) and how first- 
generation students' experiences of their institutional environment influenced those goals and commitments. The study also explored first-generation students' experiences of the elements of a small, private university, an institutional environment in which continuinggeneration students thrive but in which first-generation students overall struggle with respect to degree completion. Most critically, the study explored what first-generation students' experiences of their postsecondary environment viewed through unique lenses shaped by external contexts and prior experiences meant for their desire and ability to complete a degree, with implications for the continued viability of privately-controlled institutions within a rapidly changing postsecondary landscape.

\section{Delimitations and Limitations}

The current study utilized Choy (2001) and Chen (2005)'s definition of firstgeneration status: students who reported that they are the first in their immediate families to pursue education beyond the secondary level. In order to explore the unique degree completion patterns of first-generation students relative to continuing-generation students within small, private colleges and universities (Pascarella \& Terenzini, 2005; Lohfink \& Paulsen, 2005), the study was delimited to a privately-controlled small institution, defined as an undergraduate student body of no more than 5,000.

\section{Summary}

Representing a shift in discourse and policy emphasis away from postsecondary access, emphasis on closing the postsecondary completion gap is an attempt to address a pervasive issue within U.S. higher education, with historically under-represented populations like first-generation students experiencing the consequences of noncompletion more poignantly. Though a dominant theoretical model for explaining degree 
completion behavior at the individual level, Tinto's (1993) interactionalist model lacks explanatory power for first-generation students, who as a group do not fare as well in terms of degree completion within small, privately-controlled institutions in which continuing-generation students generally thrive (Pascarella \& Terenzini, 2005; Lohfink \& Paulsen, 2005). This study explored first-generation students' experiences of a small, private university, including how pre-matriculation influences and experiences shaped first-generation students' postsecondary goals and commitments and their interpretations of the institutional environment. Finally, the study offered insight into what firstgeneration students' experiences of a small, private university meant for their desire and ability to complete a degree within a traditional institution entrenched within a dynamic postsecondary environment as well strategies college and university leaders should consider to promote the success of all student populations.

After an examination of the relevant literature and the study's theoretical framework in the Review of Literature chapter, the Review of Methods chapter outlines the study's methodology, including the theoretical and methodological frameworks; selection of the case study institution and sampling frames; collection and analysis of evidence; and strategies for ensuring trustworthiness, credibility and ethical standards. The Findings chapter synthesizes inquiry within the study's research questions, while the Connecting Findings to the Literature chapter offers a conceptual model of firstgeneration persistence that links the findings of the study to the empirical and theoretical literature on student persistence and organizational culture. Finally, the Discussion and Implications chapter presents theoretical insights relating to first-generation degree completion as well as practical considerations for college and university leaders seeking 
to improve degree completion within small, privately-controlled institutions. 


\section{CHAPTER II}

\section{REVIEW OF LITERATURE}

The following chapter outlines the empirical and theoretical literature relating to the degree completion of first-generation students, framing a qualitative study that explored how first-generation students experienced their postsecondary institution and what these experiences meant for degree completion. The chapter begins by describing the postsecondary completion gap between majority and non-majority student populations (including first-generation students) and by outlining the institutional, economic and critical implications of this gap. Next, the chapter addresses theoretical models of degree completion behavior beginning with Tinto's (1993) seminal interactionalist theory of student persistence. After applying the constructs of the interactionalist theory specifically to first-generation students, the chapter moves to the application of other persistence theories (i.e., sociological, psychological, student engagement, and critical theories) to first-generation students. The chapter concludes with a discussion of organizational culture, a promising framework for examining how students experience college and university settings and for exploring what these experiences mean for first-generation student degree completion.

\section{The Postsecondary Completion Gap}

Ensuring that students who access higher education ultimately complete a degree is critical to internal stakeholders (e.g., students, faculty and administrators) as well as 
external stakeholders (e.g., parents; employers; local, state and federal policymakers, and society writ large). The growth in students participating in higher education in the U.S alone has generated increased interest in postsecondary degree completion. According to the Department of Education's National Center for Education Statistics, enrollment in degree-granting institutions in the U.S. grew from 16.9 million in 2003 to 20.4 million in 2013. Within that time frame, the enrollment of 18 - to 24-year olds increased from 28.9 million to 31.5 million (Snyder, de Brey, \& Dillow, 2016 ). Although enrollment growth is projected to slow, the U.S. Department of Education estimates postsecondary enrollment growth of 15 percent over the next decade (Hussar \& Bailey, 2013). The explosion of enrollment has generated considerable research and policy interest in ensuring that those who access postsecondary education persist to degree completion, other sociopolitical and economic influences aside.

Overall, access to postsecondary access in the U.S. has steadily improved, with just over one-third (38.3 percent) of Americans age 25 to 64 holding a two-year or fouryear postsecondary credential (Matthews, 2012). However, degree completion rates vary by postsecondary sector. The six-year graduation rate of first-time students starting at private not-for-profit institutions in 2008 higher was 65 percent, compared to a 58 percent rate for students attending public institutions and a 27 percent rate for students attending private for-profit institutions (Kena et al., 2016). However, despite considerable research and policy attention in matters relating to degree access, national completion rates have remained stagnant since the 1980s (Seidman, 2005). This increase in access without a corresponding increase in completion warrants a continued investigation of students' degree completion behavior, or persistence, as well as the degree to which postsecondary 
institutions purposively foster degree completion behavior among students, or retention.

Additional research and policy focus on postsecondary completion is critical, particularly given the economic and sociopolitical environment of the early twenty-first century. For example, the last decade has seen increasing interest in open access institutions. Enrollment growth in open access for-profit institutions exploded at the height of the Great Recession, dwarfing growth in the public and private non-profit sectors (Knapp, Kelly-Reid, \& Ginder, 2012). However, degree completion within these institutions falls significantly short of completion rates within non-profit institutions (Kena et al., 2016). Similarly, the Obama administration has focused additional emphasis on open-access community colleges as part of a broader economic recovery effort (Kanter, et al., 2011). Not surprisingly, this sector experienced sizable growth during the height of the Great Recession (Mortenson, January 2012). But like completion rates at for-profit institutions, community colleges do not maintain the completion rates of baccalaureate institutions (Kena et al., 2016).

This focus on open-access absent a comparable focus on degree completion has national economic implications. With most jobs of the twenty-first century requiring at least some postsecondary training, a workforce lacking the skills acquired within formal degree and certificate programs threatens the United States' position as a global economic leader (Matthews, 2016). Most critically, a lack of focus on postsecondary degree completion has devastating consequences for individual students and for the future of democratic participation. Generally speaking, students lacking postsecondary credentials earn significantly less over the course of their lifetime, relegated to the lowest socioeconomic class (Carnevale, Jayasundera, \& Cheah, 2012). More devastatingly, 
fewer students earning formal postsecondary education means fewer citizens exposed to a critically-based education that encourages civic participation and challenges those forces that work to maintain the social, political and economic domination of the middle and upper classes (Freire, 2000). Clearly, ensuring that students who enter the doors of postsecondary education leave with a credential in hand is crucial not only to the students, but also to the health of the community and the nation.

\section{Gender \& Completion}

Nationally, growth in postsecondary access among women has outpaced growth in access among men over the last decade (Horn \& Carroll, 2007; Snyder \& Dillow, 2011), with women comprising $56 \%$ of total undergraduate enrollment at the start of the 2014-2015 academic year (Kena et al., 2016). Moreover, national six-year degree completion rates are five percentage points higher for women than men who attend public and private non-profit institutions, but lower than for men at for-profit institutions (Kena et al., 2016).

\section{Race, Ethnicity \& Completion}

Like gender, participation in postsecondary education differs by race and ethnicity. In terms of access, growth in non-White student enrollment, particularly Hispanic student enrollment, has exploded in recent decades, while enrollment of White students has fallen (Snyder, de Brey, \& Dillow, 2016). This growth in postsecondary access among non-White students, however, has not coincided with growth in degree completion rates, with six-year graduation rate for Caucasian students ten percentage points higher than completion rates for Hispanic students and twenty percentage points higher than completion rates for African-American students (Snyder \& Dillow, 2011). 
The degree completion gap between Caucasian students and African-American students grew from thirteen to nineteen percentage points between 1980 and 2011, and the degree completion gap between Caucasian students and Hispanic students grew from seventeen percentage points to twenty-six percentage points (Aud, et al., 2012).

\section{Socioeconomic Status \& Completion}

In addition to race and ethnicity, socioeconomic status influences postsecondary access and degree completion. Growth in postsecondary access for students from the lowest income quartile has improved from 28.2 percent in 1970 to 46.5 percent by 2010 compared to just an 8 percent growth among students at the highest income quartile (Mortenson, January 2012). However, socioeconomic status appears to mitigate the types of postsecondary institutions that students access, with even high achieving students from lower socioeconomic levels less likely to attend selective institutions than their more affluent counterparts (Radford, April 2013). Beyond postsecondary access, degree completion rates for low-SES students reveal an alarming trend. While bachelor's degree completion rates for students age 24 years and younger at the highest income level rose from 54.6 percent in 1970 to an impressive 96.8 percent in 2010, completion rates for this age group from the lowest income quartile remained flat, growing just a single percentage point (21.9 percent to 22.9 percent) between 1970 and 2010 (Mortenson, January 2012). The relationship between socioeconomic status and degree completion is consistent across institutions at all levels of selectivity, with those institutions with higher proportions of low-income students (with the exception of highly selective historically Black colleges and universities) seeing lower degree completion rates than institutions with fewer low-income students (Horn \& Carroll, 2007). 


\section{Other Student-Related Characteristics Related to Completion}

Beyond demographics like race, ethnicity and socioeconomic status, other student-related differences are associated with disparate postsecondary completion rates. For example, students who delay postsecondary enrollment are less likely to complete a degree than students who enroll immediately after high school (Attewell, Heil, \& Reisel, 2012). In addition, students who attend part-time and live off-campus are less likely to persist to degree completion than students who live on-campus. Most saliently, students' levels of academic achievement prior to postsecondary enrollment are linked to postsecondary degree completion (Pascarella \& Terenzini, 2005). Students with lower previous academic achievement (i.e., lower high school grade point average) and lower scores on the SAT are less likely to persist beyond the first college year than their more accomplished peers (Astin, 1993). Moreover, students requiring postsecondary remediation are far less likely to earn a degree than their more prepared peers (Bailey, Jeong, \& Cho, 2010; Complete College America, April 2012). In contrast, students who complete a rigorous secondary curriculum in the areas of English, mathematics, natural science and social sciences are more likely to persist toward degree completion than students who simply complete the minimum secondary core (Horn, Kojaku, \& Carroll, 2001). Similarly, postsecondary students participating in postsecondary developmental education programs fueled by Networked Improvement Communities (Bryk, Gomez, \& Grunow, 2011) are more likely to complete credit-bearing college coursework than students taking traditional remedial coursework (Strother, Van Campen, \& Grunow, 
2013).

\section{Institutional Characteristics \& Completion}

In addition to differences in postsecondary access and completion across student characteristics, differences across institutional type are also evident. Although the majority of postsecondary students continue to enroll in public institutions (Snyder, de Brey, \& Dillow, 2016), enrollment at private institutions has grown at a faster rate (Knapp, et al., 2012). In addition to increasing enrollment growth, four-year private institutions also enjoy a completion advantage over their publically-controlled peers. While completion rates within public institutions remain stagnant or decline, completion rates within private non-profit institutions continue to be higher than the postsecondary institutional average (Kena et al, 2016). Contrasting their public and non-profit counterparts, for-profit institutions lag behind in enrollment and degree completion. Although for-profit institutions saw an increase in enrollment during the height of the economic downturn of the late 2000s, enrollments have leveled as the nation has entered economic recovery (Knapp, et al., 2012). More critically, degree completion rates within for-profit institutions are far below their public and non-profit counterparts, (Kena et al., 2016).

Postsecondary access and degree completion also differ by the highest institutional credential. Enrollment in public baccalaureate institutions comprise nearly two-thirds of all postsecondary enrollment and continues to grow faster at 34 percent than enrollment at private baccalaureate institutions at 22 percent and public two-year institutions at 26 percent (Aud, et al., 2012). However, while the proportion of students attending full-time within baccalaureate institutions has declined slightly since the 1990s, 
full-time enrollment at two-year institutions has remained stable (Baum, Little, \& Payea, 2011). Enrollment in two-year institutions is linked to students' socioeconomic status, with two-year institutions historically providing access to postsecondary education for low-income students. Indeed, when enrollment in two-year institutions exploded between 2005 and 2010, this growth was particularly noticeable among lower-income students, with nearly half (44.9 percent) of students enrolled in two-year institutions hailing from the bottom quartile of the U.S. income distribution compared to just a quarter (24.6 percent) from the top income quartile (Mortenson, January 2012). However, the Great Recession that began in 2007 has shifted more mid- and high-income students into the two-year sector, with implications for access at over-crowded and under-funded associate degree institutions (Rhoades, 2012). More critically, degree completion rates differ dramatically between two-year and four-year institutions, with degree completion rates at baccalaureate institutions significantly higher than completion rates at institutions awarding associate's degrees (Kena et al., 2016).

Other institutional factors such as size, selectivity and residential status also influence postsecondary access and student degree completion behavior. While the number of small postsecondary institutions outnumbers larger institutions, the majority of postsecondary students continue to enroll in larger institutions (i.e., 10,000 or greater students), accounting for sixty percent of U.S. postsecondary enrollment (Snyder, de Brey, \& Dillow, 2016). However, small campuses - particularly small residential campuses - enjoy higher degree completion rates than their larger counterparts (Pascarella $\&$ Terenzini, 2005; Bowen et al., 2009). In addition, more selective institutions (i.e., institutions with lower acceptance rates) also boast higher degree completion rates than 
their less selective peers (Kena et al., 2016).

\section{First-Generation Status \& Completion}

One important variable linked to college student persistence is first-generation status, defined as students who are the first within their immediate families to pursue education beyond the secondary level (Choy, 2001; Chen, 2005). During the mid-1990s, nearly one-half (47 percent) of all beginning postsecondary students in the U.S. were first-generation students (Choy, 2001). Although the proportion of first-generation students has declined as national educational levels have improved, over one-third of all first-year students enrolled in U.S. colleges and universities are the first in their families to attend college (Stuber, 2011). National studies on first-generation students undertaken by the Department of Education's National Center for Education Statistics reveal distinct differences in postsecondary access and degree completion between first-generation students and continuing-generation college students, defined as students for whom one or both parents has pursued a degree beyond the secondary level (Choy, 2001; Chen, 2005). Choy and Chen's analyses of the National Education Longitudinal Study (NELS) cohort reveal that over one-fourth (28 percent) of the cohort who graduated high school in 1992 are first-generation students. Ultimately, first-generation students from the NELS sample are less likely to complete a postsecondary degree after eight years than their continuinggeneration counterparts. Just over half (57 percent) of the first-generation high school seniors from the NELS sample earn a postsecondary credential by 2000 compared to nearly two-thirds (61 percent) of students whose parents completed some college and 80 percent of students who parents completed a bachelor's degree (Chen, 2005). Other more recent investigations substantiate the completion gap between first-generation and 
continuing-generation students (Pascarella \& Terenzini, 2005; Ishitani, 2006; Saenz, Hurtado, Barrera, Wolf, \& Yeung, 2007; Cataldi et al., 2011). Although the completion gap widens when first-generation students are also low-income and non-White (Engle \& Tinto, 2008) and academically under-prepared (Terenzini, Springer, et al., 1996;

Warburton, Bugarin, \& Nunez, 2001; Ishitani, 2006), the disparity between firstgeneration students and continuing-generation students remains even when demographic and other pre-enrollment characteristics are held constant (Nunez \& Cuccarco-Alamin, 1998; Ishitani, 2003).

As with other demographic groups, first-generation status interacts with institutional characteristics to yield disparate levels of access and degree completion. However, these differences are not always in the expected direction. For example, firstgeneration students are more likely to enroll in public institutions (Choy, 2001) and twoyear and for-profit institutions (Engle \& Tinto, 2008; Cataldi, et al., 2011) where the likelihood of completing a postsecondary credential is reduced. Those first-generation students who do attend private four-year institutions, however, do not exhibit the same degree completion behavior as other student segments. Instead, first-generation students who attend private institutions are less likely to persist to their second year than firstgeneration students attending public institutions (Pascarella \& Terenzini, 2005). In addition, first-generation students who attend smaller institutions are less likely to persist beyond their first-year than first-generation students who attend larger institutions (Lohfink \& Paulsen, 2005). Clearly, the relationship between institutional characteristics (e.g., size and public vs. private) and degree completion behavior (e.g., persistence) is different for first-generation students relative to their continuing-generation counterparts. 


\section{Implications of the Completion Gap}

The differential between those who access postsecondary education and those who complete a credential has significant consequences, including material implications for state and federal economies and postsecondary institutions; institutional implications for colleges and universities; and critical implications for individual students.

\section{Economic Implications}

From a cost-benefit standpoint, students' failure to earn a credential represents a dismal return on public investment in postsecondary education. Recent annual estimates of what state and federal taxpayers spend educating first-year students who do not complete a credential run as high as $\$ 9$ billion (Schneider, 2010). This waste translates to 1) sunk costs for cash strapped federal and state governments who have made a tremendous investments in postsecondary education in the form of appropriations and financial aid dollars; 2) diminished wages for individual students over the course of their lifetime; 3 ) and a lost source of revenue for increasingly tuition-driven postsecondary institutions. However, dismal completion rates represent more than wasted public and private dollars that could have been invested elsewhere.

Failure to close the postsecondary degree completion gap for all students has implications for the dominance of the U.S. economy and for the nation's role as a leader among first-world nations. Given that just over one in three Americans currently holds a postsecondary degree, the current skills gap is steep, and its impact is potentially crippling (Matthews, 2012). In Illinois, the number of jobs requiring a postsecondary credential in 2020 is even larger, at nearly two in three (Complete College America, September 2011). Clearly, if the United States does not educate its citizenry for the jobs 
required by the regional and state economies of the future, it will fall behind other industrialized nations and surrender its leadership in the global economy.

\section{Institutional Implications}

Failure to close the degree completion gap for all students also has implications for postsecondary institutions seeking to operate in accordance with their missions. Assuring that the bulk of students who enter an institution persist to degree completion is important to postsecondary institutions who value knowledge creation and dissemination, student learning and development, support for the local and national economy, and informed democratic participation. To these ends, many colleges and universities have invested considerable resources in curricular and co-curricular programs and services that promote persistence and degree completion (Valentine, et al., 2011). The most notable institutional investment in student persistence is in course remediation. This expenditure has been tremendous, with an estimated $\$ 3.6$ billion dollars in direct remedial education costs incurred by states and by postsecondary institutions during the 2007-2008 academic year (Alliance for Excellent Education, May 2011). Yet this tremendous investment has been tremendously inefficient and ineffective. Nationally, over half of all students enrolled in two-year institutions require some form of course remediation. Sadly, just over one in five of these students have completed these remedial courses two years later, with less than one in ten projected to complete an associate's degree three years later (Complete College America, April 2012). And while the proportion of students requiring remediation within four-year institutions is smaller than the proportion at two-year institutions (19.9 percent versus 51.7 percent), these students do not fare significantly better, with just over one-third (35.1 percent) of four-year institution students requiring 
remedial courses projected to complete a bachelor's degree after six years (Complete College America, April 2012). In Illinois, the three-year associate's degree graduation rate of students starting in remedial courses is a dismal 14.0 percent, and the six-year completion rate for Illinois students requiring remedial courses is only 27.3 percent (Complete College America, April 2012).

Beyond idealistic concerns related to educational mission, institutional efforts to improve student persistence toward degree completion are also grounded in more pragmatic concerns. Clearly, students who accumulate credits but do not complete a degree represent a waste of precious financial and human capital for postsecondary institutions (Johnson, 2012). However, lagging degree completion also represents a threat to future revenue streams. With performance-based funding for postsecondary education increasingly tying metrics like first-year persistence and completion rates to state appropriations, institutional stakeholders have a vested interest in assuring that the majority of students walk in their doors walk out with a postsecondary degree (Hermes, 2012).

\section{Critical Implications}

Beyond the impact on the national economy and postsecondary institutions, failure to close the degree completion gap has implications for individuals' striving to achieve material prosperity, to engage in democratic action, and to pursue lives of meaning and purpose. Economically, a postsecondary credential remains the most accessible and most effective path to the middle class for millions of Americans. On average, earning potential is inescapably tied to level of postsecondary education, with adults holding a bachelor's degree or higher earning nearly twice that of adults holding 
only a high school diploma (Carnevale et al., 2012). In addition to access to higher paying jobs, a postsecondary credential also affords increased job security. While job losses across all education levels were significant during the Great Recession, unemployment rates were much steeper for high school graduates. Moreover, nearly all of the job recovery continues to be concentrated in occupational areas that require at least some postsecondary training (U. S. Department of Education, 2014). Non-completers face crippling student loan debt, paying more per credit hour completed than those who ultimately earn a credential (Wei \& Horn, 2013). This student debt burden for noncompleters is especially onerous for those non-completers attending for-profit institutions (Wei \& Horn, 2013). In addition, non-completers are likely to incur greater credit card debt (Young Invincibles, May 2013), are less likely to own a home as young adults, and are less likely have access to affordable healthcare (Consumer Financial Protection Bureau, May 2013). In this way, failure to support the persistence of those who access higher education regulates those do not complete their degrees to a life of diminished earning potential, limited and unstable employment opportunities, and membership within the lowest socioeconomic levels.

Given the central role that higher education plays in securing material security, reducing the benefits of postsecondary degree completion to personal economic gain is both logical and powerful. However, couching the value of higher education in purely material terms marginalizes its other externalities, including the power of a transformative higher education to challenge the power of a material-obsessed culture and promote democratic action. Under the Obama administration, the U.S. Department of Education has couched the benefits of improved college completion as almost exclusively 
economic, all but guaranteeing increased lifetime earnings for those who complete a postsecondary credential while assuring degree holders will be well-trained for the jobs that will drive future national economic growth (Kanter et al., 2011; Rodney \& Stephan, 2012).Viewed through a Freirean lens (Freire, 2000), this economic, material focus reinforces a neoliberal view of higher education that minimizes the non-monetary benefits associated with higher education, namely education as preparation for democratic citizenship and a life of meaning and value. By touting the increase to personal income that generally accompanies increased education, the Department of Education reinforces the neoliberal ideal of happiness through consumerism. More sinisterly, this view of higher education as job training suggests a tacit motive in the college completion agenda: ensuring that degree holders are well-prepared for jobs that service the economy and create additional wealth for existing capital holders. Freire conceptualizes this sinister, material-obsessed system as an oppressive world order in which capital, largely concentrated in the hands of the few, becomes "the measure of all things" (p. 58). In this system, higher education is beneficial to those who mean to perpetuate material inequity (whom Freire characterizes as oppressors) while benefiting students (whom Freire characterizes as the oppressed) only in its ability to increase the likelihood of capturing an elusive share of the capital. In this system, postsecondary students are passive vessels of job training information, resigned to their place in the socioeconomic pecking order without critical examination of their circumstances and without realizing their potential to improve their standing.

Over the last three decades, a shift in financial aid policy at the federal, state and institutional level has maintained an oppressive world order in which the opportunities 
afforded by postsecondary education remain concentrated within the privileged class. Beginning with the Higher Education Act of 1965 and the Educational Opportunity Grant program (a precursor to the Pell grant established in the 1970s), federal financial aid in the U.S. had its origin in helping low- and middle-income students access postsecondary education and persist to degree completion (Lingenfelter, 2008). Since the 1970s, however, the federal government has shifted its focus away from need-based grants for low-income students and toward guaranteed loans and tax credits. Clearly, absorbing additional debt and taking advantage of tax credits is largely sustainable only to students hailing from middle and upper-income families. As a result, low-income students are increasingly unable to capitalize on federal subsidies for higher education (Mortenson, January 2012).

As the federal government has shifted away from need-based, state support for higher education has declined dramatically, most saliently during the most recent economic downturn. Indeed, every state except for North Dakota and Wyoming spending less per student since the start of the Great Recession (Oliff, Palacios, Johnson, \& Leachman, 2013). The result is exploding tuition costs that prohibited most lowincome students from accessing and persisting within public institutions (Mortenson, January 2012).

Partly in response to shifts in state and federal policies, postsecondary institutions - both public and private - have become increasingly focused on improving their perceived status and increasing their revenue streams. This focus has translated into merit-based financial aid policies that focus on recruiting and retaining well-prepared students from affluent families at the expense of providing opportunities for lower- 
income students (Mortenson, January 2012). This shift in federal and institutional financial aid policies has worked to preserve postsecondary opportunities for the privileged socioeconomic class while restricting opportunity for low-income students, many of whom are minority and first-generation students.

In summary, failing to bridge the persistence gap for segments like firstgeneration students has profound implications for the national and regional economies, for postsecondary institutions, and for individual students. Given that the jobs of the future continue to require at least some training beyond the secondary level, failing to produce a critical mass of postsecondary graduates relative to other developed countries threatens federal and state leadership within the global economy. In light of increasingly scarce resources and the rise of performance-based federal and state funding, ensuring that the bulk of students who access higher education persist to graduation is vital not only to the mission of postsecondary institutions but also to their continued viability. Ultimately, failing to close the persistence gap threatens the material position of noncompleters, banishing them to low-skill, low-paying jobs while saddling them with crippling debt and limited housing options. More sinisterly, maintaining an underclass of non-completers perpetuates an oppressive neoliberal ideology in which higher education is reduced to professional training and networking for the privileged class and lacks truly transformative power for all others.

\section{First-Generation Students \& the Interactionalist Model of Persistence}

In order to close the completion gap for student segments like first-generation students, educational researchers and practitioners must understand the unique forces that influence individual student behavior (i.e., persistence) as well as the institutional factors 
that foster - or hinder - degree completion (i.e., retention). Moreover, the most powerful insights into closing the completion gap result from understanding institutional degree completion behavior within the context of students' individual experiences.

\section{Overview of the Interactionalist Model}

Tinto’s (1993) “near paradigmatic” (Braxton \& Hirschy, 2005, p. 61) interactionalist model of persistence provides a useful framework for examining the factors that contribute to individual degree completion behavior, or persistence. Grounded in the sociological tradition, Tinto's model details how student characteristics (e.g., family background, skill and ability levels, prior educational experiences), educational goals and educational commitments serve as precursors to persistence. Student characteristics, educational goals and educational commitments interact with the characteristics of the students' external environment and institutional environment to influence integration within the social and academic communities of the institution. It is the interaction of these elements - student characteristics, goals, commitment, institutional characteristics and experiences, academic/social integration, and the external environment- that determine persistence. Tinto's classic interactionalist theory has been utilized in a plethora of empirical investigations of student persistence, including the persistence of non-White students (Lee, Donlan, \& Brown, 2010-2011; Strayhorn, 2012), students attending two-year institutions (Karp, Hughes, \& O'Gara, 2010-2011) and firstgeneration students (Longwell-Grice \& Longwell-Grice, 2008; Woosley \& Shepler, 2011).

Tinto's (1993) interactionalist model of student persistence outlines the constructs that converge to influence students' desire and ability to remain enrolled through 
graduation. For example, Tinto highlights the importance of student entry characteristics to persistence. These entry characteristics include family and community background, personal attributes, skills, financial resources and dispositions. Entry characteristics also include prior educational experiences and achievements, such as high school grades and standardized test scores: In turn, pre-college entry characteristics influence students' educational goals (e.g., level of education desired, type of career desired) and commitments (e.g., the obligation that students experience for achieving their educational and career goals and the loyalty that they feel to their institutions). These goals and commitments serve as resources that orient students to academic and social behaviors that promote persistence.

The interface of student entry characteristics, intentions and commitments does not occur in a vacuum, but rather within a multi-layered context that contains elements that are both internal and external to the institution. The external environment encompasses forces unique to individual students (e.g., pre-college relationships, family responsibilities, off-campus employment) as well as forces in the broader public sphere (e.g., the economic and political environment, state and federal funding of higher education, public discourse relating to higher education). Combined with pre-entry characteristics and educational goals and commitments, the external environment provides a context for interaction between the student and the institution. In turn, institutional characteristics (e.g., two-year vs. four year; type of control; size; institutional quality and prestige) provide added context for student persistence in the interactionalist model, strengthening or weakening students' educational goals, level of commitment, and integration within the academic and social community of the 
institution. Institutions with lower levels of prestige (e.g., two-year institutions, oncompetitive public institutions) attract a student body that, as a whole, has lower educational goals and weaker institutional commitment. As a result, students attending less prestigious institutions are less likely to engage, or integrate, with the academic and social communities of the institution than students attending more prestigious institutions. In addition, Pascarella \& Terenzini (1991) cite institutional processes, policies and philosophies that hinder, two-year students' ability to continue on to four-year institutions as well as problematic inter-institution transfer processes (e.g., gaining admission, securing financial aid, transferring credits) as reasons why two-year students depart postsecondary education before earning a degree. Ongoing research on the impact of institutional characteristics on student persistence, however, reveals that the relationship between these phenomena is more complex than first imagined. Indeed, in their later meta-analysis that spanned the research of the 1990's, Pascarella and Terenzini (2005) assert that, although many of their conclusions about the negative impact of attending a two-year institution on degree attainment hold true, this relationship is mitigated by other factors, including whether two-year students actually transfer to a four-year institution (i.e., student entry characteristics), the economic climate, and state policies relating to institutional structure (i.e., the external environment).

A central construct within Tinto's (1993) interactionalist model, academic and social integration is broadly conceptualized as students' ability to establish membership within the academic and social communities of their institution. Tinto's (1993) construct of integration can be traced to the work of Spady (1971), who utilized Durkheim's (1951) sociological theory of egotistical suicide as a lens through which to examine departure 
behavior. According to Durkheim's social integration theory, an individual commits suicide if she perceives no affiliation with other members of society (social integration) or if her values are not congruent with other members of society (intellectual integration). Applied to persistence behavior, an individual might voluntarily depart if she does not perceive membership, or integration, with the social and/or academic communities of the institution. This lack of integration may take the form of incongruence. In other words, a student may depart if she perceives coursework to be too challenging or too easy (academic incongruence), if her intellectual values are not in the line with the values of community (intellectual incongruence), or if she is dissatisfied with the day-to-day interaction with her peers and/or faculty (social incongruence). Lack of integration with the social and academic community may also take the form of isolation, or the absence of significant relationships with others within the institution. Within the Tinto's (1993) model, academic integration is manifested through academic performance, interaction with faculty, and participation in the formal and informal intellectual life of the institution. Social integration is manifested through interaction with peers as well as formal and informal participation in campus activities.

The construct of integration interacts with the interactionalist constructs of educational goals and commitment. That is, as students become more integrated within the social and academic communities of their institutions, their desire to meet academic goals increases, as does their level of commitment to their education and their institution. In this way, academic and social integration is shaped not only by experiences upon enrollment but also by student entry characteristics, institutional characteristics, educations goals, commitment levels, and external demands. 


\section{First-Generation Student Entry Characteristics}

A number of researchers uncover salient differences between the entry characteristics of first-generation college students and the characteristics of students whose parents attended a postsecondary institution. Demographically, first-generation students are more likely to be of lower socioeconomic class, more likely to be from racial and ethnic minority groups, and more likely to be older (Terenzini, Springer, et al., 1996; Nunez \& Cuccarco-Alamin, 1998; Choy, 2001; Saenz et al., 2007). Low-income firstgeneration students are also more likely to have dependent children (Liu, 2011). In addition to demographic differences, research suggests that first-generation students also differ from continuing-generation students intellectually. Specifically, first-generation students are more likely to possess significantly lower mathematic abilities (Choy, 2001; Chen, 2005) and significantly lower critical thinking and social abilities (Terenzini, Springer, et al., 1996). Finally, first-generation students differ from continuing-generation students in their enrollment decisions and in their enrollment patterns. Although more recent investigations point to familial influences that are more supportive of collegegoing behavior (Saenz et al., 2007), first-generation students historically report less encouragement to attend college from their high school teachers (Terenzini, Springer, et al., 1996) and family members (London, 1989; Choy, 2001). In addition to studying demographic differences between first-generation students and continuing-generation students, researchers also focus on how disparate characteristics within this population contribute to persistence. Specifically, researchers conclude that first-generation students who are female, married, Hispanic and of lower socioeconomic status are less likely to persist to the second year than first-generation students who are male, unmarried, White, 
and of higher socioeconomic status (Lohfink \& Paulsen, 2005).

A number of studies point to a preparation gap between first-generation and continuing- students in the areas of math, reading and critical thinking (Fenske, Porter, \& DuBrian, 2000; Ishitani, May, 2005; Pascarella, Pierson, Wolniak, \& Terenzini, 2004). This lack of preparation is most salient in the area of mathematics (Terenzini, Springer, et al., 1996; Terenzini, Pascarella, et al., 1996; Strayhorn, 2006) and is particularly problematic given the link between completion of college-level math courses, persistence and degree completion (Offenstein, Moore, \& Shulock, 2010). Richardson and Skinner (1992) expand the construct of academic preparation beyond content knowledge to include accurate expectations of postsecondary course content as well as precise knowledge of the academic skills that will be required for collegiate success. This includes accurate expectations surrounding time management, collegiate finances, institutional bureaucracy, and the navigation of the physical and temporal spaces of college or university campus. These inaccurate expectations relating to postsecondary education can lead first-generation students to experience greater levels of disorientation and force them to "double" their cognitive efforts relative to their continuing-generation peers.

The entry characteristics of first-generation students have implications for persistence according to the interactionalist model (Tinto, 1993). Specifically, differences in demographics, academic and cognitive preparation, level of family support, and enrollment preferences between first-generation and continuing-generation students situate these populations differently through their influence on postsecondary academic achievement and educational goals and commitments as described below (Tinto, 1993). 
As a result, first-generation students are less integrated to the social and academic community of the institution than their continuing-generation counterparts, thereby increasing their likelihood of departure from postsecondary education.

\section{First-Generation Student Educational Goals \& Commitments}

Educational goals and commitments serve as antecedents to persistence through their effects on integration within the interactionalist model. Specifically, students' educational aspirations as well as their dedication to meeting those aspirations serve as precursors to their willingness to seek membership within the social and academic communities of their institution (Tinto, 1993). Researchers have uncovered important differences relating to educational goals both between first-generation and continuinggeneration students as well as among the first-generation population. Historically, firstgeneration students report lower degree aspirations than students whose parents have postsecondary educational experiences (Terenzini, Springer, et al., 1996; Choy, 2001). However, degree aspirations among first-generation students have been on the rise since the 1970s (Saenz et al., 2007), with internal motivation to pursue higher education even higher among students who are the first in their families to complete secondary education and among Hispanic first-generation students (Próspero, Russell \& Vohra-Gupta, 2012). Still, those first-generation students who aspire to less than a bachelor's degree are less likely to persist to the second year than first-generation students who aspire to a bachelor's degree or higher (Lohfink \& Paulsen, 2005). In addition to personal orientations to goal setting, external support for setting postsecondary goals is different for first-generation students relative to their continuing-generation counterparts, with first-generation students reporting less encouragement to continue their education from 
their secondary teachers (Terenzini, Springer, et al., 1996). In contrast, perceived parental support for postsecondary education, while historically lower than support from parents of continuing-generation students (London, 1989; Choy, 2001), has increased significantly since the 1970s (Saenz, et al., 2007; Irlbeck, Adams, Akers, Burris \& Jones, 2014).

In addition to alternate goal orientation, first-generation and continuinggeneration students differ in their initial commitment to postsecondary study. Firstgeneration students are more likely to delay postsecondary enrollment after high school (Nunez \& Cuccarco-Alamin, 1998; Choy, 2001; Chen, 2005). Once enrolled, firstgeneration students are more likely to attend part-time and to reside off-campus (Nunez \& Cuccarco-Alamin, 1998; Choy, 2001). When choosing an institution, first-generation students are more likely to select institutions based on finances and on proximity to home (Saenz et al., 2007), suggesting commitments relating to cost and family that differ from the commitments of continuing-generation students. Aligned with these commitments, first-generation students are also more likely to select public and two-year institutions (Nunez \& Cuccarco-Alamin, 1998; Choy, 2001) and to work while attending (McCormick, Moore, \& Kuh, 2010). The distinctive goal and commitment levels of firstgeneration student can also be conceptualized as a function of what Richardson and Skinner (1992) coin opportunity orientation, or beliefs about the role of postsecondary education in increasing life opportunities. In other words, relative to continuinggeneration students, it may be that first-generation students do not perceive how setting high postsecondary goals and committing limited resources to degree completion will translate to increased opportunities later in life. 
The differences in educational goals and commitment between first-generation and continuing-generation students have implications for persistence. Because they have distinctive educational aspirations, are more likely to select institutions based on the ability to meet financial and family obligations, and have alternate commitments to degree completion, first-generation students may be less likely to seek out integrating social and academic opportunities (Tinto, 1993) than their continuing-generation counterparts. This lack of integration within the academic and social communities of the institution, according to the interactionalist model, translates to increased likelihood of postsecondary departure.

\section{First-Generation Students, External Environments \& Institutional Characteristics}

Although confronted with a similar broad external context as continuinggeneration students (e.g., local and national economic conditions, public subsidies for postsecondary education, political discourse surrounding higher education), firstgeneration students face unique circumstance within their external environments that have implications for persistence. First-generation students are more likely to have significant extra-collegiate responsibilities, such working more than twenty hours per week (Saenz et al., 2007) and dependent children (Liu, 2011). The time and effort required by these responsibilities may leave limited time and energy for engaging in collegiate activities that help foster academic and social integration (Tinto, 1993). Faced with diminished opportunities for academic and social integration, first-generation students are less likely to persist according to the interactionalist model.

Institutional characteristics influence persistence through their effect on commitment and integration, with students selecting more prestigious institutions 
experiencing an increased level of commitment and students selecting residential institutions finding more opportunities for social integration (Tinto, 1993). In support of this assertion, the persistence literature points to a relationship between educational attainment and two-year/four-year status, with students who start at more prestigious, residential, four-year institutions more likely to persist to degree completion than students who start at less prestigious, two-year institutions (Pascarella \& Terenzini, 1991; 2005; Bowen et al., 2009). Because first-generation students are over-represented at two-year institutions (Nunez, Cucarro-Alamin, 1998; Choy, 2001), one might conclude that the persistence gap between first-generation and continuing-generation students is a function of their increased likelihood of enrolling at less prestigious, non-residential institutions. However, research suggests that institutional characteristics do not influence firstgeneration persistence in the same way as they influence continuing-generation students. In their meta-analyses of the persistence literature Pascarella \& Terenzini (1991; 2005) find that first-generation students who attend private institutions are less likely to persist to their second year than first-generation students attending public institutions. In addition, other researchers find that first-generation students who attend smaller institutions are less likely to persist beyond the first-year than first-generation students who attend larger institutions (Lohfink \& Paulsen, 2005). Plainly, the relationship between institutional characteristics and the integration that bolsters persistence is more nuanced for first-generation students relative to their continuing-generation counterparts.

\section{First-Generation Students \& Academic and Social Integration}

As with other constructs within the interactionalist model of student persistence (Tinto, 1993), researchers uncover differences in the formal and informal social and 
academic integration of first-generation and the integration of their continuing-generation counterparts. Given the link between integration (i.e., establishing membership within the academic and social communities of institutions) and persistence within the interactionalist model, the implications for first-generation students are clear. As a group, first-generation students spend less time on campus, are more likely to work a significant number of hours off-campus (Choy, 2001; Engle \& Tinto, 2008; Grayson, 2011) and are more likely to live off-campus (Nunez \& Cuccarco-Alamin, 1998). While on campus, research suggests that first-generation students are less likely to engage in formal and informal activities that help them establish the membership within the academic and social communities that facilitates persistence. In terms of formal academic integration, first-generation students spend less time studying (Saenz et al., 2007), attend fewer non-required academic and career-related lectures (Grayson, 2011), meet less frequently with advisors about academic plans (Nunez \& Cuccaro-Alamin, 1998), and report less participation in formal study groups than continuing-generation students (Nunez \& Cuccaro-Alamin, 1998). In terms of formal social integration, firstgeneration students are less likely than continuing-generation students to participate in collegiate experiences that foster membership within the social community, such as orientation programs (Terenzini, Springer, et al., 1996) student organizations, organized athletics and cultural events (Grayson, 2011; Stebleton \& Soria, 2012). In terms of informal academic integration, first-generation students report negative perceptions of faculty relating to the view of faculty as concerned about student development (Terenzini, Springer, et al., 1996; Longwell-Grice \& Longwell-Grice, 2008) and the view of faculty as available for help outside of class (Longwell-Grice \& Longwell-Grice, 
2008; Grayson 2011). First-generation students also report less informal contact with faculty relating to academic matters than continuing-generation students (Nunez \& Cuccaro-Alamin, 1998; Stebleton \& Soria, 2012), with those first-generation students who report more informal social contact with faculty outside of class more likely to persist to their second year than first-generation students who report less of this contact (Lohfink \& Paulsen, 2005). Finally, first-generation students exhibit less evidence of informal social integration. Compared to continuing-generation students, they are less likely to report "going places" with college peers (Nunez \& Cuccaro-Alamin, 1998), are less likely to report positive peer relationships including encouragement from friends to continue enrollment (Terenzini, Springer, et al.,1996), and less likely to make new friends (Grayson, 2011). Those first-generation students reporting greater satisfaction with the social aspect of institutions are more likely to persist to their second year than those reporting less satisfaction (Lohfink \& Paulsen, 2005).

The notion of "fit" between students and the institutions in which they enroll can be conceptualized as the degree to which students feel that they are members of the social and academic communities of the institution (Tinto, 1993). As such, choosing a college or university that "fits" can be conceptualized as a function of integration within the interactionalist model of persistence. Although information related to institutional size and academic reputation is readily available to prospective students, information relating to the informal social and intellectual life of the campus is not as easily obtained (Tinto, 1993). For their part, first-generation students are less likely to select postsecondary institutions based on the academic and social opportunities they afford. Instead, this population is more likely to select institutions based on factors such as cost and the 
ability to live at home (Nunez \& Cuccarco-Alamin, 1998; Saenz et al., 2007). In other words, first-generation students are less likely to select institutions with regard to integrating academic and social experiences, thereby selecting institutions that may not "fit" and increasing their likelihood for attrition.

\section{First-Generation Students \& Other Sociological Models of Persistence}

While acknowledging the myriad of interwoven factors that shape degree completion behavior, Tinto's (1993) interactionalist theory of persistence emphasizes institution-specific structures and social processes to explain a complex phenomenon. Lacking in this model is a detailed explanation of the way that sociological phenomenon that originate outside of a college or university influence student outcomes inside the institution. To that end, other sociological frameworks explicate the ways that social structures and process in the external environment (e.g., forces in the larger postsecondary field, perpetuating social inequalities, family influences) impact students' desire and ability to persist to degree completion.

\section{First-Generation Students \& Institutional Theory}

Researchers have utilized the constructs of institutional theory to problematize postsecondary student persistence. According to Zucker (1987), the institutionalization of an organization can be broadly conceptualized along two dimensions. First, the institution is conceptualized as a collection of structures (e.g., credit hours), processes (e.g., registration) and group behaviors (e.g., marching at commencement) that evolve within organizations. Functioning to promote stability over time, these institutional structures work to instill shared values resulting from shared histories, shared senses of social reality, notions of what constitutes organizational clients (e.g., students), routines, 
and other systems. Individual institutions can be conceptualized as part of a larger field comprised of other organizations (Meyer \& Rowan, 1977). Institutionalization is a process whereby organizations, as the result of inhabiting a common regulatory, political and social field with other organizations and as a result of isomorphic pressure to be perceived as rational and legitimate (DiMaggio \& Powell, 1983), come to share common structural and cultural elements that instill shared values among organizational members (Laden, Milem, \& Crowson, 2000).

Mintzberg (1979) conceptualizes the common structure of academic institutions as a professional bureaucracy. Different from machine bureaucracies in which managers determine organization goals and control the work of the enterprise through formal authority, postsecondary institutions are organized around the expertise of the professionals within the organization's technical core, the faculty. Operating within a highly decentralized system of authority, these professionals are not controlled by organizational managers (e.g., the administration), but are guided largely by professional standards that originate outside of the organization. Within the professional bureaucracies of colleges and universities, the role of administrators is not to control the work of the faculty, but rather to provide the faculty with operational resources, address disturbances within the organization that thwart normal operations, and "buffer" the faculty from the outside world so that they may focus on their work. In addition to professional bureaucracies, academic institutions can also be conceptualized as loosely coupled systems (Weick, 1976), in which organizational structures (e.g., departments, positions, policies), processes (e.g., planning and implementation), and events (e.g., outcomes and reward/punishment), although weakly connected, retain their distinctive 
elements and can be separated during periods of organizational change or disturbance.

The common structural and cultural elements of the institutionalized academic institution have implications for student persistence, including first-generation student persistence. Although Laden, Milem and Crowson (2000) maintain that accessing postsecondary institutions is a well-institutionalized feature of U.S. culture, they question whether persistence behavior is as well-institutionalized. Instead, Laden, Milem and Crowson posit that attrition reflects a lack of institutionalization for those institutional forms that integrate students within the life of the organization (Tinto, 1993). Indeed, Laden, Milem and Crowson posit that attrition, not persistence, may be an institutionalized norm of postsecondary education that serves the function of selectivity. From this view, student departure serves to "[reflect] deep organizational cultures or after-admission selectivity and a negotiate thy-own-way tradition of socialization into the college community" (p. 251).

Like maladaptive institutionalized forms and process, academic institutions as professional bureaucracies and loosely-coupled systems have implications for firstgeneration student persistence. Mintzberg (1979) characterizes the professional bureaucracy of the academic institution as an "inflexible structure, well-suited to producing its standard outputs but ill-suited to adapting to the production of new ones" (p. 60). The highly decentralized, professionally-controlled nature of academic institutions allow for limited opportunities to impose corrective action on faculty members who do not wish to undertake the action of their own accord. Likewise, the implementation of academically-related persistence initiatives such as enhanced remedial education and active, learner-centered pedagogy are likely to meet resistance unless they 
originate from the faculty. Indeed, Mintzberg asserts that "change in the Professional Bureaucracy does not sweep in from new administrators taking office to announce major reforms, nor from government technocrats intent on bringing the professionals under control. Rather, change seeps in, by the slow process of changing the professionals" (p. 69). In this way, the success or failure of strategic change within an academic institution lies not in the vision of ambitious administrators, but in the decision of faculty members to embrace or reject it. In addition to barriers presented by the professional bureaucracy of academic institutions, their loosely coupled nature (Weick, 1976) presents obstacles to postsecondary leaders seeking to evoke structural changes in support of first-generation student persistence. By their nature, organizational forms, processes and events that are loosely coupled retain their essential elements during periods of change or disruption. While this can be beneficial during times of organizational crisis, it can slow - or even halt - the progress of strategic organizational change aimed at clearing the path to degree completion for first-generation students. Plainly, when the success of a critical mass of students is not an embedded assumption of colleges and universities (i.e., is not institutionalized), and when the institutional structure of the academy inhibits systemic change, closing the completion gap for first-generation students is a formidable task.

\section{First-Generation Students \& Theories of Social Reproduction/Cultural Capital}

Although acknowledging the role that external factors play in degree completion behavior, the interactionalist theory of student persistence (Tinto, 1993) does not explicate the ways in which pervasive societal forces function to maintain inequality in postsecondary outcomes among majority and non-majority student populations. To that end, Bourdieu (1979/1984) advances a model that describes how individuals acquire and 
utilize culturally-based resources and explains how social structure - and social inequality - are reinforced and reproduced. Within Bourdieu's model, cultural capital refers to the skills, abilities, tastes, preferences, and norms that serve as cultural currency within a given social system. Cultural capital is obtained either through one's social origin (i.e., family) or through formal schooling. The worth of cultural capital depends on the social context in which it is produced and valued, or the field. A field can make many forms (including a family and a school), and is a site of conflict and competition, with those occupying the field jockeying for control of its available resources (i.e., cultural capital). Bourdieu characterizes the social networks and connections through which resources are traded within a given field as social capital. Individuals with ample social capital (e.g., increased social connections) are able to access and utilize the resources within the field more effectively than those who lack social capital. Over time, individuals acquire an unconscious pattern of dispositions, norms and tastes that influence both their perception of social situations as well as their social action. Bourdieu classifies these unconscious patterns as individuals' habitus.

Taken together, Bourdieu's (1979/1984) matrix of cultural capital, field, social capital and habitus perpetuate the social order through the process of social reproduction. Certain types of cultural capital (e.g., a behavioral norm such as volunteering answers to questions posed by the teacher) are valued more than others within a given field (e.g., a school). In addition, those with greater social capital (e.g., parents who are actively involved in their children's schools) are more likely to leverage available cultural resources within the field. Those actors employing the field's preferred cultural capital often as the result of access to greater social capital - are rewarded, while those 
employing less preferred cultural capital are marginalized. Over time, individuals develop unconscious patterns of dispositions, norms and tastes (i.e., habitus) that influence their perceptions and actions. These unconscious patterns, coupled with the reinforcement of displays of preferred cultural capital, serve to reinforce, or reproduce, the social structure within a field. Utilizing the metaphor of a poker game, WinkleWagner (2010) describes the relationship between Bourdieu's (1979/1984) constructs and illustrates how these constructs reinforce social structure through a process of social reproduction. In this metaphor, the game (including the dealer and the casino) represents the field, the cards represent cultural capital, the players' individual positions in the game represent social capital, and the players' individual game playing strategies represent habitus. An individual's ability to leverage the hand she is dealt (cultural capital) hinges on her knowledge of the game, her relationship with the dealer/casino (field and social capital, respectively) and her learned strategy (habitus). If the cards held by other players are more valuable, then the cultural capital held by a single player is less meaningful. If certain players are "comped" by the casino, or if the dealer distributes cards differently to players based on prior relationships, then the game is biased to those who possess more social capital. And if a player has not learned the rules of the game over time, or if her strategy is inappropriate given the nature of the hand, then her habitus negatively influences her outcome. The result is similar to the advantage that "the house" enjoys over individual players: regardless of whether individual players weather "hot streaks" or “cold streaks," social structure and social inequality are maintained. Bourdieu (1979/1984) characterizes the ability to "win the hand" by utilizing culturally-based resources effectively within a given field as cultural competency. 
Higher education theorists and researchers adapt Bourdieu's (1979/1984) notion of cultural capital to explain variation in postsecondary student outcomes. In her review of the literature on the use of cultural capital in educational research, Winkle-Wagner (2010) identifies three broad conceptualizations of cultural capital: highbrow cultural capital, contextually-valued cultural capital, and non-dominant cultural capital. WinkleWagner channels Weber (1968) to characterize what she coins highbrow cultural capital, or the possession of skills, tastes, and preferences of social elites. According to this conception of cultural capital, individuals are exposed to the "finer things" (e.g., elite taste in art, music, and food) through their families (and to a lesser extent through formal schooling), ultimately incorporating a preference for these tastes into their own habitus. In turn, this preference for the "finer things" is recognized and rewarded within the social field, facilitating greater access to culturally-based resources for those who exhibit these preferences and reinforcing the existing social order. Indeed, researchers posit that postsecondary students who possess and exhibit high levels of highbrow culture enjoy an advantage in access to higher education (Tierney, 2002), selection of a degree that fosters upward social mobility (Goyette \& Mullen, 2006), and greater academic success (Aschaffenburg \& Maas, 1997; Roscigno \& Ainsworth-Darnell, 1999).

In addition to highbrow cultural capital, Winkle-Wagner (2010) reviews contextually-valued notions of cultural capital, in which a particular set of knowledge, competencies, skills or abilities may be valuable in some fields but not in others (Lareau \& Weininger, 2003). In this way, cultural capital is not "owned" by cultural elites, but rather can be accessed, developed and employed by those at all socio-cultural strata within a multitude of fields. Researchers uncover the relationship between contextually- 
valued cultural capital and institutional choice, with those possessing lower levels of cultural capital selecting less prestigious institutions (Astin \& Oseguera, 2004).

Researchers also uncover a link between contextually-based cultural capital and identity development, with-low income students who attend elite institutions reporting a negative self-concept as the result of their membership in their socioeconomic status (Aries \& Seider, 2005).

Finally, Winkle-Wagner (2010) reviews non-dominant notions of cultural capital. Tied closely to Bourdieu's (1979/1984) notion of field, the non-dominant view of cultural capital purports that cultural capital is comprised of shared skills, abilities, tastes, preferences, and norms that are valuable within non-dominant communities (e.g., racial and ethnic minorities, low-income communities). Non-dominant cultural capital is similar to contextually-valued cultural capital in that the construct is not "owned" by social elites or dominant communities (i.e., White, middle- and upper-income communities). Non-dominant cultural capital is distinct from contextually-valued cultural capital, however, in that it is a communal construct shared across non-dominant communities. For example, researcher find that Chinese-American students who possess forms of cultural capital that are distinctive to their home culture achieve a similar levels of educational attainment as White students who possess the forms of cultural capital generally prized within postsecondary institutions (Pearce \& Lin, 2005). In addition, Hispanic students who attend postsecondary institutions where no single racial or ethnic group dominates the campus culture experience increased self-confidence (Núñez, 2009), presumably resulting from the perceived legitimacy of their non-dominant cultural capital within certain fields. 
Other higher education scholars link cultural capital (Bourdieu, 1979/1984) to issues of first-generation student success. Students' level of highbrow cultural capital is often operationalized by level of parental education in the literature (Pascarella et al., 2004; Goyette \& Mullen, 2006). From a contextually-valued cultural standpoint, firstgeneration students experience a cultural mismatch within postsecondary institutions that emphasize the importance of independence over the interdependence that tends to permeate their home cultures, with negative implications for postsecondary success (Stephens, Fryberg, Markus, Johnson, \& Covarrubias, 2012; Stephens, Townsend, Markus, \& Phillips, 2012). From a non-dominant cultural standpoint, first-generation status is often framed as a cultural deficit by those within the academy (Valencia, 2010). In other words, the characteristics of the students' home culture (in the instance of firstgeneration college students, being raised parents who are unfamiliar with the norms and practices of collegiate life) are viewed as detrimental to student success. This detriment can be framed as a failure to equip students with elite tastes and preferences that are valued within the collegiate environment (i.e., highbrow cultural capital), or a failure to equip students with the cultural resources that foster success within a college setting (i.e., contextually-based cultural capital). Clearly, this view of first-generation students ignores the presence of non-dominant cultural capital that may bolster postsecondary success. In contrast to the historical notion that first-generation students lack family support for college-going (London, 1989; Choy, 2001), family support for participating in higher education among first-generation students continues to rise (Saenz et al., 2007). Non-dominant cultural capital in the form of family support is particularly important for non-White first-generation students, namely Hispanic students (Gloria \& Castellanos, 
2012), Asian students (Pearce \& Lin, 2005), and Israeli students (Gofen, 2009).

Social and cultural capital within the postsecondary context is not limited to individuals. Berger (2000) asserts that postsecondary institutions themselves possess and leverage social and cultural capital. Drawing on the work of Meyer (1970), Berger maintains that institutions possess social charters, or "socially constructed and legitimized definitions of the product [graduates with specific attributes]" (p. 104).” These social charters "represent the kind of education provided by the institution and quality of that education" and provided "socially agreed upon and legitimated assessments of the cultural capital of the institution" (p. 104). Because they tend to be selective and attract students with higher levels of cultural capital, institutions with stronger social charters will have the highest completion rates. Similarly, students with higher levels of cultural capital are more likely to persist than students with lower levels. Alignment in the level of institutional capital and a student's individual capital positively impacts persistence behavior. In other words, students with high levels of individual cultural capital are more likely to persist at institutions with correspondingly high levels of organizational cultural capital, and students with low levels of individual cultural capital are more likely to persist at institutions with correspondingly low levels of organizational cultural capital. Clearly, pervasive sociological forces work at the individual and institutional level to structure resources in ways that breed inequality in degree completion between majority (e.g., continuing-generation) and non-majority (e.g., first-generation ) student populations. 
First-Generation Students \& Social/Ecological Theories of Persistence

Expanding on the ways that the student characteristics, external forces and the internal institutional environment influence degree completion within Tinto's (1993) interactionalist theory, social/ecological models of persistence emphasize how postsecondary students' internal perceptions of their environments interact with the social structures of their college or university. Baird's (2000) social/ecological model emphasizes how students' cognitive assessments of their institutional environment and the institutional environment itself converge to influence academic and social integration (Tinto, 1993) and, ultimately, persistence:

[The social/ecological model] emphasizes the central role of students' appraisals of their environments. These appraisals represent students' personal understandings of the structures of the environments and their opportunities and constraints upon behavior. Applying this point to the [interactionalist model of persistence] suggests that it is students' perceptions of the opportunities and constraints within the academic and social systems that would lead them to various behaviors, which in turn would affect their levels of social and academic integration. (p. 67)

The notion that student behavior (e.g. persistence) is dependent upon students' interpretation of their environment is congruent with the notion of cultural enactment among college and university students (Kuh \& Whitt, 1988). In other words, it is not the actual structural forms of the institution, but rather students' construction of those forms, that are critical to shaping student experience. In turn, conceptualizing first-generation student degree completion behavior from the social/ecological standpoint hinges on 
understanding how this population experiences institutional environments (i.e., colleges and universities) with which they may have limited exposure.

Like Baird (2000), Kuh and Love (2000) offer a social/ecological model of persistence that acknowledges the importance of institutional environments as well the importance of students' home environments. First, Kuh and Love posit that all collegiate experiences, including decisions to leave or persist at an institution, are filtered through students' "meaning-making systems" (p. 201). According to this proposition, it is not institutions' actual structural properties, but rather the students' interpretation of those properties, that matter. Students" "meaning-making systems" are shaped by their cultures of origin, comprised of family influences, prior educational experiences, and community forces. As a result of the influence of their cultures of origin, first-generation students may possess "meaning-making systems" that contain inaccurate or incompatible assumptions about postsecondary education. Kuh and Love go on to assert that students' cultures of origin mediate the importance that students attach to participating in postsecondary education and persisting to degree completion. For example, members of first-generation students' families may actively encourage them to attend college, but they may also fail to understand the desire to earn a postsecondary degree, both of which have implications for these students' motivation to persist. As a result, Kuh and Love assert that knowledge of students' cultures of immersion-the overarching "norms, values, practices, beliefs and assumptions" (Kuh \& Whitt, 1988; p. 12) of academic institutionscoupled with knowledge of their cultures of origin is necessary for true understanding of students' ability to integrate within the communities of organizations. Central to this understanding of first-generation students' cultures of origin is knowledge of their 
cultural capital, which Kuh and Love (2000) conceptualize as the resources (e.g. interpersonal skills, habits, language patterns, prior learning, lifestyle) that students possesses that affect their understanding of the expectations of postsecondary education and their ability to navigate organizational cultures. Acknowledging that expectations of college completion are woven into the cultures of origin for some students but not for others, Kuh and Love assert that "the probability of persistence is inversely related to the cultural distance between a student's culture(s) of origin and the cultures of immersion" (p.204, emphasis added). Those students forced to travel great cultural distances must ultimately acclimate to their institution's dominant culture of immersion or, alternately, join cultural enclaves. The more time that students spend within their cultures of origin after matriculation in their cultures of immersion, the greater the degree of what Kuh and Love coin cultural stress, which decreases students' chances of persistence. Ultimately, the more cultural enclaves that students joins, the stronger their academic and social integration within the life of organizations (Tinto, 1993), and the more likely they are to persist.

\section{First-Generation Students \& Family Systems Theory}

Given the role that parental education plays in degree completion even when other variables are held constant (Nunez \& Cuccarco-Alamin, 1998; Ishitani, 2003), greater understanding of first-generation success requires consideration of family influences. London (1989) applies family systems theory in his qualitative investigation of the social histories and psychodynamics of first-generation students. Specifically, London explores how these first-generation students reconcile the roles of family member and "college woman" or "college man," applying the family theory of Helm Stierlin (1974) to 
investigate how first-generation research participants' relationships with family members influence their collegiate experience. Utilizing Stierlin's framework, London uncovers how first-generation students' relationship with their family members can be binding (i.e., family members attempting to keep students close to the familial context without regard for students' individual goals), delegating (i.e., family members encouraging students to separate from the familial context in pursuit of family goals while keeping them close via obligations of loyalty) or expelling (i.e., family members seeing the presence of students as antithetical to their own goals and forcing them away from the familial context ). Indeed, first-generation students who do ultimately achieve postsecondary success may experience a sense of survivor guilt for leaving family and friends in difficult situations (Tate, Williams, \& Harden, 2013).

Each of Stierlin's (1974) family relationships has implications for first-generation students' persistence. For first-generation students in binding family relationships, higher education can be a "vehicle of separation" (London, 1989; p. 147) between students and their family members, creating an added stressor that may discourage persistence. Although experiencing support for college going, first-generation students in delegating family relationships also shoulder the burden of achieving family goals relating to degree completion as well as the stress of pursing these goals while remaining loyal to family members. And although they are free from the responsibility of meeting family goals and remaining loyal to the family context, first-generation students in expelling family relationships lack a critical source of support for college going.

More recent empirical investigations of the connection between family dynamics and first-generation persistence reinforce the importance of family influences in the 
experience of higher education. In their study on family emotional and information support, Sy, Fong, Carter, Boehme and Alpert (2011-2012) find that first-generation students report less emotional and information support for college-going from their parents than their continuing-generation counterparts. Moreover, Sy et al. find that firstgeneration students reporting less emotional support for college-going experience higher levels of stress one month prior to matriculation. This relationship between perceived emotional support and pre-matriculation stress was not observed among continuinggeneration students.

In summary, a number of researchers and theorists working from the sociological tradition expand on Tinto's (1993) interactionalist theory of persistence to explain the external forces that influence degree completion behavior. These forces relate to normalizing structures and processes within the larger postsecondary field, to pervasive societal inequalities that maintain an inequitable status quo, and to students' interpretation of their institutional experiences informed by family influences. These forces have distinctive implications for first-generation student degree completion and highlight the need to examine degree completion behavior as a social construction that may be influenced by level of parental education.

\section{First-Generation Students \& Psychological Theories of Persistence}

While sociologically-based explanations of degree completion behavior emphasize those forces that are external to the student, some researchers and theorists maintain that degree completion is a highly individualized construct that is heavily influenced by student entry characteristics (Tinto, 1993). Working from this assumption, researchers and theorists from the psychological tradition operationalize degree 
completion as an amalgam of individual student behaviors that are reflections of internal processes (e.g., beliefs, attitudes, motivation, coping strategies, etc).

\section{First-Generation Students \& Student Involvement Theory}

The most widely-known psychological theory of student persistence is Astin's (1984) theory of student involvement. According to this theory, highly motivated students externally demonstrate their internal motivation by focusing energy on their studies, spending considerable amounts on time on campus, participating in extracurricular activities, and interacting with faculty inside and outside of the classroom. Within their meta-analyses of persistence research, Pascarella \& Terenzini $(1991 ; 2005)$ find that a number of student behaviors generally associated with involvement (e.g., participating in orientation, advising, and first-year seminars; living on campus; participating in intercollegiate athletics and other extracurricular activities; on-campus employment) are positively linked to persistence. Viewed through the lens of student involvement (Astin, 1984), the ways in which first-generation students express internal process through their behavior within their colleges and universities have implications for their persistence. First-generation students are less likely to report participating in the formal activities of the campus, including orientation programs (Terenzini, Springer, et al., 1996), student organizations (Nunez \& Cuccaro-Alamin, 1998), and support services (Stebleson \& Soria, 2012). In addition, first-generation students are also less likely to report living on-campus, further restricting their opportunities for campus involvement (Nunez \& Cuccaro-Alamin, 1998) According to Astin's (1984) model, first-generation students' lower levels of involvement relative to their continuing-generation peers is reflective of this segment's distinctive beliefs, attitudes, motivation, and coping strategies 
related to postsecondary education. In turn, this lower level of involvement among firstgeneration students translates to a lower probability of persistence to degree completion.

\section{Attitudes, Intentions, Behavior \& First-Generation Student Persistence}

Bean and Eaton (2000) utilize four cognitive theories to advance a psychologically-based model of student persistence. The first construct is attitudebehavior theory, which links intention to behavior. According to this theory, a belief constitutes the link that an individual establishes between an object or an activity and a particular attribute (e.g., this college is great) that is reinforced by prior experience and important others. Over time, reinforced beliefs lead to the formation of attitudes, or positive and negative assessments of objects and activities. In turn, attitudes shape intentions with regard to the object or activity, which ultimately prompt student behavior. In this way, persistence to degree behavior is predicted by students' initial and continuing intentions with regard to postsecondary education. As noted previously, first-generation students possess attitudes and intentions with regard to higher education that are distinct from their continuing-generation counterparts, including differences in degree aspirations (Choy, 2001), perceptions that faculty and staff are supportive of their success (Longwell-Grice \& Longwell-Grice, 2008) and perceptions regarding the opportunities of higher education (Skinner \& Richardson, 1992). Furthermore, these attitudes and intentions are reinforced by distinctive prior experiences and parental support (Terenzini, Springer, et al., 1996) among first-generation students. These postsecondary attitudes and intentions reinforced by the pre-college context translate to alternate persistence patterns for first-generation students. 


\section{Coping Behavioral Theory \& First-Generation Student Persistence}

In addition to attitude-behavior theory, Bean \& Eaton (2000) also apply coping behavioral theory to student persistence. According to this theory, students who successfully cope with the difficulties presented by postsecondary education experience less stress. As a result, these students "gain the attitudinal perspectives of successful academic and social integration" (p. 51) within their colleges and universities. Related to coping behavioral theory is the theory of approach and avoidance behavior. Applied to student persistence, students who actively engage in academic "approach" behaviors (e.g., participate in class, seek additional assistance) and social approach behaviors (e.g., join organizations) are more fully integrated to the institution - and therefore more likely to persist - than students who actively engage in "avoidance" behaviors. As noted previously, first-generation students differ from continuing-generations students in academic and social behaviors that could be conceptualized as "approach" behaviors. For example, first-generation students are less likely to seek out faculty informally and are less likely to participate in the formal and informal social life of their campuses (Terenzini, Springer, et al., 1996; Nunez \& Cuccaro-Alamin, 1998; Grayson, 2011; Stebleton \& Soria, 2012). Indeed, first-generation students do not show a preference for active coping strategies relative to other student populations (Mehta, Newbold \& O'Rourke, 2011). This proclivity for avoidance behavior and rejection of active coping strategies among first-generation students have implications for their ability to deal with difficulties, which in turn has implications for their ability and/or desire to persistent to degree completion. 


\section{Self-Efficacy \& First-Generation Student Persistence}

In addition to explicating how students' academic and social coping behaviors influence individual degree completion behavior, Bean and Eaton (2000) apply the psychological theory of self-efficacy to student persistence. Self-efficacy relates to individuals' perception of their abilities to succeed academically and socially (Bandura, 1997). As people come to recognize their competencies and gain self-confidence, they exhibit an increased desire to achieve tasks, set goals, and work toward goal completion. Applied to degree completion, as students come to realize their competencies in dealing with the events and situations that comprise higher education, they gain confidence in their ability to survive and adapt. This increase in self-efficacy manifests as persistence behavior.

As with other psychological constructs, first-generation students are distinct from continuing-generation students in their experience of self-efficacy as it relates to postsecondary education. Hellman (1996) points to a difference in academic self-efficacy between first-generation and continuing-generation community college students. Specifically, Hellman concludes that first-generation students have lower self-images of their academic abilities than continuing-generation students. More recent research substantiates the academic self-efficacy gap between first-generation and continuinggeneration students (Wang \& Castañeda-Sound, 2008; Jenkins, Miyazaki, \& Janosik, 2009). This self-efficacy gap may have implications for persistence, particularly when first-generation students encounter academic difficulty. If first-generation students perceive themselves as lacking the ability overcome academic challenges, they may not make the attempt and ultimately give up. Indeed, research suggests that first-generation 
status exacerbates the negative effects of low self-esteem on postsecondary academic performance (Aspelmeier, Love, McGill, Elliot, \& Pierce 2012).

\section{Attribution Theory \& First-Generation Student Persistence}

Identifying a third psychological construct linked to degree completion, Bean and Eaton (2000) review attribution theory and its application to student persistence.

Specifically, Bean and Eaton evoke the notion of locus of control, or the forces to which students attribute their collegiate success and failures, to persistence. Believing that successes and failures are the result of individual effort and competency is associated with an internal locus of control. In contrast, believing that outcomes are the result of forces outside of individual effort and competency is associated with an external locus of control. Applied to a model of persistence, students who maintain an internal locus of control in relation to social and academic matters are more motivated to engage in behaviors associated with integration (Tinto, 1993), which in turn positively influences their persistence behaviors.

Locus of control has implications for a host of first-generation collegiate outcomes, including persistence. First-generations students enjoy a modest advantage over continuing-generation students in the possession of an internal locus of control (Pascarella et al., \& Terenzini, 2004). However, researchers point to parental education as a variable that moderates the relationship between locus of control and collegiate outcomes. In other words, the influence of locus of control on collegiate outcomes is stronger for first-generation students relative to their continuing-generation counterparts, with an internal locus of control more strongly associated with positive outcomes and an external locus of control more strongly associated with negative outcomes for this 
population. This moderating effect of parental education is evident in the relationship between locus of control and collegiate achievement (Aspelmeier, Love, McGill. Elliott, \& Pierce, 2012) and mastery orientation (Strage, 1999). In this way, although firstgeneration students with an internal locus of control are more likely to experience positive collegiate outcomes that bolster persistence, first-generation students with an external locus of control are also more likely to experience negative collegiate outcomes that may hinder persistence.

\section{Identity, Role Theory \& First-Generation Student Persistence}

A final pair of psychological constructs implicated in degree completion generally and first-generation degree completion specifically is identity and role theory. Applied to student persistence, personal identity is conceptualized as the influence of meeting the demands presented by multiple life roles on students' desire and ability to persist to degree completion. As noted previously, first-generation students are more likely than their continuing-generation peers to be older (Choy, 2001), to work a significant number of hours (Saenz, et al., 2007), to have spouses and dependents (Engle \& Tinto, 2008), to be physically removed from the institution as the result of living off campus (Nunez \& Cuccarco-Alamin, 1998), and to forgo participation in campus activities (Grayson, 2011). In other words, first-generation students maintain a significant number of major life roles beyond the role of college student. In conceptualizing adults' capacity to meet the challenges of continuing education, McClusky (1974) advances a model in which an individual's margin (i.e., energy available to expend on additional endeavors such as postsecondary education) is a function of her load (i.e., the demands of maintaining an autonomous adult life) and of her power (i.e., the physical, psychological, and social 
resources available to meet the demands of adult life). According to McClusky's model, the capacity to tackle new challenges (i.e., margin) hinges either on managing life roles (i.e., load) or on increasing the physical, psychological and/or social resources to meet those demands (i.e., power). Before first-generation students experience more demands than their continuing-generation peers as the result maintaining multiple and significant life roles, their margin for exerting energy on persistence behavior becomes dependent upon the amount of resources at their disposal. When these resources are insufficient, first-generation students' ability to take on additional challenges such as completing a degree may be diminished.

In addition to maintaining multiple significant life roles, first-generation students encounter another identify-related challenge to persistence: the incompatibility of the role of "college student" to competing life roles, to critical others, and to previous life experiences. For some first-generation students, being a college student is not the most important - or even among the more important - "hats" that they wear. Accordingly, these students do no organize their time around being a college student, investing little time on campus life beyond attending classes and investing only as much energy as they can afford given their other demands (Richardson \& Skinner, 1992). More critically, "college student" is often not an identify that is valued by first-generation students' reference group (i.e., family members, friends, community members, employers), who might perceive little value in higher education or who might feel threatened or abandoned by those seeking a postsecondary credential (Richardson \& Skinner, 1992). This marginalization of the college student identity, both by important others and by students themselves, can have negative implications for first-generation student persistence. 
Furthermore, research suggests that first-generation students who do endeavor to embrace the role of "college student" face unique challenges. Pointing to greater incongruence between faculty expectations and student expectations for first-generation students, Collier (2008) hypothesizes that lower levels of cultural capital resulting from limited exposure to postsecondary education in the first-generation household present obstacles for comprehending collegiate expectations, making mastery of the role of "college student" more difficult for this population. As a result, even first-generation students committed to their "college student" role must increase their efforts to achieve success relative to their continuing-generation peers.

In summary, researchers and theorists approaching the completion gap from the psychological tradition emphasize the importance of student entry characteristics (Tinto, 1993) and conceptualize degree completion behavior as the manifestation of distinctive internal processes. For these researchers and theorists, closing the completion gap means focusing on involvement behaviors shaped by collegiate attitudes and intentions, improving students' coping strategies, building students' capacity for believing in their abilities and incorporating a "college student" identity. A substantial body of literature suggests that these psychological constructs are unique for first-generation students, and as such, institutional efforts to close the completion gap for this population must acknowledge the individualized nature of degree completion behavior.

\section{First-Generation Student Persistence \& Economic Theory}

Like those conceptualizing the issue from the sociological and psychological traditions, researchers and theorists approaching degree completion from an economic tradition expand Tinto’s (1993) interactionalist model of student persistence by 
describing the way that individual students intersect with external forces and institutional environments to influence persistence. Economic theories of student persistence build from the assumption that students operate as rational economic actors within a "marketplace" of colleges and universities. In turn, various "market forces" such as perception of cost and benefit have the potential to influence both student as well as institutional behavior.

St. John, Cabrera, Nora and Asker (2000) conceptualize models of persistence along three dimensions. Traditional price-response theories are purely economic models that characterize persistence behavior as the result of students weighing the social and economic costs and benefits of attending a postsecondary institution against the costs and benefits of pursuing life alternatives (e.g., entering the world of work). In contrast, student-institution fit theories (e.g., Tinto's interactionalist model) are largely void of financial and economic perspectives. A blend of these two perspectives, integrative approaches recognize that financial and economic forces, in addition to student characteristics, institutional characteristics, and student experience converge to influence persistence.

St. John et al. (2000) review two integrative approaches to student persistence that incorporate financial and economic theory into sociological models of persistence like the interactionalist model (Tinto, 1993). One such model, Cabrera, Nora and Castañeda's (1992) ability-to-pay model, postulates that economics impact student persistence both directly and indirectly at the student level. Directly, economics influence persistence through their impact on students' ability to meet the direct educational costs associated with collegiate attendance. Clearly, students unable to meet 
the financial obligations associated with tuition, fees and basic life maintenance will be unable to persist regardless of desire or other factors. In addition, economics influence persistence indirectly through their ability to facilitate - or threaten - students' full participation in the academic and social life of the institution. For example, students who must work a part-time or even a full-time job in order to cover the cost of tuition, fees and/or room and board possess less time to devote to extra-curricular activities that foster integration within an institution's academic and social communities. This lack of integration has negative implications for persistence according to the interactionalist model (Tinto, 1993). Inherent within the ability-to-pay model are objective measures of financial capacity (i.e., the actual resources that students bring to bear on educational expenses) as well as subjective judgments of this capacity (i.e., students' perception of the costs and benefits of higher education as well as their perception of their ability to meet costs and realize benefits). In this way, "ability-to-pay" is both an objective reality and a social construction comprised of students' real or perceived ability to meet the financial obligations of postsecondary attendance as well as their real or perceived ability to participate in the full range of collegiate activities.

Both the direct, objective effects of economics as well as the indirect, subjective effects of finances inherent within the ability-to pay-model (Cabrera et al., 1992) have implications for first-generation student persistence behavior. For example, firstgeneration student persistence is most certainly directly influenced by this population's actual socioeconomic status. As a group, first-generation students are more likely to hail from lower income levels that their continuing-generation counterparts (Engle \& Tinto, 2008), a reality that is likely tied to this population's likelihood of working a significant 
number of hours while enrolled in higher education (Choy, 2001). Clearly, having fewer resources to cover the cost of tuition, fees and basic life maintenance would increase any student groups" likelihood of "dropping out" or "stopping out" due to finances. However, there is evidence that first-generation student persistence may be indirectly affected by student and family members' perception of postsecondary economics. As a group, first-generation students are more price-sensitive with regard to postsecondary education and more likely to selecting postsecondary institutions based on their financial situation (Nunez \& Cuccarco-Alamin, 1998; Saenz et al., 2007). When this real or imagined perception of first-generation students" "ability-to-pay" leads to the selection of a less-prestigious institution (i.e., a two-year institution or non-selective four-year institution), or leads to forgoing participation in collegiate activities and behaviors linked to persistence behaviors, there are negative implications for first-generation student persistence (Pascarella \& Terenzini, 2005).

St. John et al. (2000) also review another integrative approach to student persistence, the college choice-persistence nexus model (St. John, Paulsen, \& Starkey, 1996). Economic and financial concerns, according to this model, serve as a nexus between the constructs of college choice and student persistence. Persistence according to the college choice-persistence nexus model is shaped through a three-stage process. First, the student's socioeconomic situation impacts her predisposition to pursue postsecondary education as well as her perception of her financial situation. Next, the student estimates the costs and benefits of selecting a particular institution. This perception of educational costs and benefit, in turn, induces commitment to the institution. Finally, once the student is enrolled, institutional characteristics (e.g., type of 
control, size), collegiate experiences, and academic performance reinforce the student's initial commitment.

Like other economic models of student persistence, students, the college choicepersistence nexus model (St. John et al., 1996) has implications for first-generation students pursuing postsecondary education. As noted previously, first-generation students are more likely to hail from lower socioeconomic segments relative to continuing-generation students (Engle \& Tinto, 2008). This economic reality, coupled with students' perceptions of their financial situation, can have negative consequences on first-generation students' decisions to pursue higher education according to the college choice-persistence nexus model. Beyond access, finances also play a role in students' estimates of the costs and benefits of pursuing postsecondary education, with a positive cost-benefit ratio critical to shaping student commitment to completing a credential. Researchers explore how different student segments perceive the economic utility of persisting to degree completion, with male students more likely to drop out or stop out as the result of being more adverse to taking on personal debt to finance higher education and more likely to assume future financial success without a postsecondary credential (Dwyer, Hodson, \& McCloud, 2012). If parental education, like gender, influences student perception of the costs and benefits of higher education, and if first-generation students as a group do not perceive the same economic value of higher education relative to students who parents have attended college, then negative implications for persistence are more likely to follow. Indeed, first-generation students report being more price sensitive than their continuing-generation counterparts (Nunez \& Cuccarco-Aalamin, 1998; Saenz et al., 2007) and more averse to taking on student loan debt (Somers, 
Woodhouse, \& Cofer, 2004). These realities suggest that first-generation students'

experiences of the costs and benefits of postsecondary education are distinctive and their desires and/or ability to persist to degree completion are influenced.

Economic theories of student persistence hinge on student perception. How students think about economic issues such as the cost of higher education, the expected return on investment in higher education, and the inherent risk under ambiguous circumstances has clear implications not only for whether students will make an initial investment in postsecondary education, but also for whether they will continue to invest their limited resources once enrolled. Indeed, research suggests that these economic perceptions are particularly salient for first-generation students. Clearly, closing the completion gap for first-generation students requires consideration of these economic assumptions as well as clear communication about the costs, benefits and risks of investing resources in postsecondary education.

\section{First-Generation Student Persistence \& Student Engagement}

One framework of postsecondary student success that blends the importance of student motivation and behavior, critical collegial experiences and institutional accountability is student engagement theory. Student engagement is the quantity and quality of time and effort that students invest in educational activities that foster successful outcomes, including learning, personal development, and degree completion (Nelson Laird, Chen, \& Kuh, 2008). As a construct, student engagement encompasses two components. First, student engagement includes the energy and resources that individual students invest in curricular and co-curricular activities that lead to collegiate success. In addition, student engagement encompasses the ways in which postsecondary 
institutions organize curriculum, pedagogy, programs and services to foster student activities that lead to collegiate success (Kinzie, Gonyea, Shoup, \& Kuh, 2008). "Engaging" collegiate activities include those characterized by frequent student-faculty interaction, team work, active learning, timely feedback, expectations of significant time on task and performance, and regard for disparate student abilities and learning modalities (Chickering \& Gamson, 1987).

Student engagement theory has evolved over time, starting with educational psychologist Ralph Tyler's investigations on the positive collegiate outcomes associated with increased time on task in the 1930s (Merwin, 1969). C. Robert Pace's work with the College Student Experiences Questionnaire in the 1970s demonstrates that students benefit when they invest significant time and effort in collegiate activities such as studying, talking with their peers and faculty about significant issues, and applying theory in practice (Pace, 1990). Writing at the same time, psychologist Alexander Astin's theory of student involvement bolsters the importance of student effort in successful student outcomes (Astin, 1984). Since Pace and Astin, other theories of student success emphasize both the importance of purposeful curricular and co-curricular activity as well as the institution's role in fostering this activity. The construct of "student engagement" as it is currently conceptualized was popularized with the development of the National Survey of Student Engagement, or NSSE. The widespread administration of the NSSE solidifies the notion that student behavior and educational practices can be effectively measured and utilized to improve collegiate outcomes like deep learning and persistence (Kuh, 2009).

Student engagement is tied to a number of positive collegiate outcomes, including 
deeper learning, greater tolerance for complexity, and heightened ability to work with diverse others (Kuh, 2009). These habits of mind (Kuh, 2003) increase students' capacity for lifelong learning and personal development. Student engagement is also linked to persistence, with measures of student engagement positively and statistically linked to degree completion behavior, even when controlling for student characteristics, other collegiate experiences, academic performance and financial aid (Kuh, Kinzie, Cruce, Shoup, \& Gonyea 2007). Among those institutions with better-than-expected persistence rates based on institutional characteristics (e.g., size, cost) and student body characteristics (e.g., academic preparation), high levels of student engagement are prevalent, namely high levels of academic challenge (i.e., the expectation of a significant amount of effort and higher-order thinking) and a heightened perception of a supportive campus environment (i.e., student perceptions of the quality of institutional relationships) (Nelson Laird, Chen, \& Kuh, 2008).

Researchers uncover critical differences in student engagement among diverse college student populations that have implications for persistence. In their review of 2007 NSSE data, Kinzie, et al. (2008) point to distinctions in voluntary engagement in learning opportunities like senior projects, internships, and study abroad among racial minority and majority students. An "engagement gap" between minority and majority students is most notably at predominately White institutions (Swail, Cabrera, Lee, \& Williams, 2005). Despite this gap, research indicates that participation in purposeful educational activities actually leads to larger collegiate gains among minority students than among majority students, with African-American students who participate in “engaging" activities more likely than White students to persist to their second year of 
college (Kuh et al., 2007).

Like racial minorities, first-generation students are distinctive in their pursuit of purposeful collegiate activities. In general, first-generation students are less likely to invest their energies in high impact academic activities (e.g., active and collaborative learning opportunities, significant interaction with faculty) and social activities (e.g., substantive conversations with peers) than their continuing-generation counterparts (Pike \& Kuh, 2005: Stebleton \& Soria, 2012). While citing distinct educational aspirations and living environments as the primary reasons why first-generation students are less engaged than continuing-generation students, Pike and Kuh (2005) also cite a knowledge gap tied to parental education. Specifically, Pike and Kuh theorize that first-generation students might be unfamiliar with the importance of active engagement, possessing less tacit knowledge about and experience with collegiate behavior and lacking role models for collegiate success. Furthermore, Pike and Kuh posit that the family members of firstgeneration students are often unable to provide assistance in the promotion of engagement, lacking the context for collegiate experiences that, in some cases, may appear odd or off-putting to those outside of the academy. To that end, Pike and Kuh place the obligation for fostering student engagement on postsecondary institutions: An institution of higher education cannot change the lineage of its students. But it can implement interventions that increase the odds that first-generation college students "get ready," "get in," and "get through" by changing the way those students view college and by altering what they do after they arrive. (p. 292) For researchers and practitioners examining postsecondary success through the lens of student engagement, closing the completion gap means closing the "engagement 
gap," or ensuring that colleges and universities create institutional conditions that encourage students to invest considerable energy and resources into their curricular and co-curricular pursuits. While it is clear that colleges and universities must widen their “engaging" offerings, it is also clear that different student populations - including firstgeneration students - approach engagement opportunities in distinct ways. In this way, closing both the engagement and the completion gap requires examining how firstgeneration students interpret opportunities to engage in the academic and social life of their institutions through their unique perspectives.

\section{First-Generation Student Persistence \& Critical Theories}

Viewed through a critical lens, the postsecondary completion gap between different student segments is the result of systemic societal pressures that limit opportunities for historically underrepresented and marginalized group, limiting their capacity to achieve success. From a critical perspective, student persistence is influenced by factors beyond individual colleges and universities, prompting postsecondary institutions to become microcosmic reflections of the life beyond the academy with implications for the degree completion of different student segments. These factors include societal oppression and neoliberalism.

\section{Societal Oppression \& First-Generation Student Persistence}

Societal oppression can be conceptualized as the systematic restriction of life options for one group and the maintenance of continued privilege for another (Frye, 1983). Often based on race (i.e., restricting the options of non-Whites), class (i.e., restricting the options of those of real or perceived lower socioeconomic and/or social standing) and gender (i.e., restricting the options of women), societal oppression fosters 
societal inequity, injustice and the marginalization of these groups. Often, societal oppression forces a duality for students from the non-dominant culture. Within educational environments dominated by the majority culture, an emphasis on values such as competition and independence coupled with a Eurocentric curriculum that stresses logic and absolutism means that some students, particularly racial and ethnic minorities, perceive little congruence between their educational lives and their home lives, where values such as cooperation, collaboration and contextual relevancy may be stressed (Hale-Benson, 1986; Delpit, 1996). In light of this forced duality, researchers maintain that some minority students respond in ways that are detrimental to their educational success. For example, under the pressure to conform to preconceived notions of minority student achievement, some minority students may succumb to stereotype threat, or unconscious physiological responses that produce intellectual performance that is significantly lower than the students' actual capabilities (Aronson \& Inzlicht, 2004).

Other minority students - most notably African-American students - appear to reject the values and norms of the educational environment, equating academic success to a process of "acting White" that is an affront to their cultural heritage (Fordham \& Ogbu, 1986). Indeed, racial and ethnic minority students attending predominately White institutions report more conflicts, more pressure to conform to stereotypes, less equitable treatment by faculty and staff, and less satisfaction with their institutions (Ancis, Sedlacek, \& Mohr, 2000).

The postsecondary persistence gap between first-generation and continuinggeneration students can be conceptualized as a logical response to the forces of societal oppression. Demographically, first-generation students are more likely to be members of 
societal groups who have historically been the targets of systemic oppression: non-White, lower socioeconomic status, and female (Terenzini, Springer, et al., 1996; Nunez \& Cuccarco-Alamin, 1998; Saenz et al., 2007; Engle \& Tinto, 2008). Based on these characteristics, lack of first-generation student success can be conceptualized as a response to systematic limitations on a population comprised of historically oppressed groups. Alternately, the education level of one's parents could be conceptualized as a proxy measure of one's social class. From this view, lagging access, persistence and degree completion becomes a response to oppression based on class.

\section{Neoliberalism \& First-Generation Student Persistence}

Careful consideration of the Unites States' push to improve postsecondary completion rates reveals the influence of a neoliberal ideology that works to promote continued international economic dominance, drive increased privatization and marketization, fuel the narrative of personal fulfillment through material consumption, and maintain an oppressive social and economic world order (Freire, 2000; Saunders, 2010). Left unchecked, these neoliberal forces have the potential to taint the completion agenda which, on its face, appears beneficial to first-generation college students.

The Obama administration has advanced an ambitious goal of ensuring that the U.S. leads the world in the number of college-educated citizens by the end of the decade (Kanter et al., 2011). To achieve the Administration's goal, the U.S. Department of Education has called for an increase in six-year college completion rates from 40 percent to 60 percent, including the addition of ten million associate's degree holders by 2020 (Kanter et al., 2011). On one hand, Obama's discourse on college completion highlights the transformative power of postsecondary education, linking postsecondary education to 
social mobility, democratic action and civil rights (Rodney \& Stephan, 2012). On the other hand, Obama's discourse on college completion reveals the creep of neoliberal ideology. Specifically, Obama's rhetorical linking of postsecondary to the knowledge economy carries a number of decidedly negative implications, including the narrowing of curriculum through a focus on STEM subjects; the expansion of the school choice movement and the proliferation of charter schools that restrict minority student participation; and the promotion of efficiency practices that leave teachers divided and disillusioned (Rodney \& Stephan, 2012). Aligned with the Obama administration's completion rhetoric, the U.S. Department of Education continues to couch the benefits of improved college completion as largely economic, all but guaranteeing increased lifetime earnings for those who complete a postsecondary credential and asserting that degree holders will be well-trained for the jobs that will drive future national economic growth (Kanter et al., 2011).

The neoliberal flavor of the national college completion agenda can have devastating consequences for historically under-served and under-performing populations like first-generation students. In his review of the influence of neoliberalism in higher education, Saunders (2010) characterizes neoliberalism as the confluence of three core beliefs: the application of market-based principles to all aspects of public and private life; the limitation of government in regulation of the economy; and, most critically, the reduction of individuals to "rational economic actors" (p. 45) who apply cost-benefit analysis to all decisions and interactions. Saunders asserts that over the course of the last four decades, postsecondary students have shifted their focus from the intrinsic benefits of higher education like finding a life of meaning and value to material values like 
financial success. As a result, these learners-turned-rational-economic-actors are less concerned with learning and exploring new knowledge and more concerned with gaining a credential that that will bring them financial success in the future.

Freire (2000) conceptualizes this "materialistic concept of existence" (p. 58) as one of the characteristics of an oppressive world order. Paralleling the tenants of neoliberalism, Freire's oppressive world order is a material-obsessed system in which money and material possessions, largely concentrated in the hands of the few, are the sole source of happiness and "the measure of all things" (p. 58). In this world order, education is beneficial to those who mean to perpetuate this system, whom Freire characterizes as oppressors, only when it drives private financial growth and reifies their dominant position in an unbalanced economic system. Absent critical examination that can prompt substantive change to this system, education is beneficial to students-turnedrational actors, whom Freire characterizes as the oppressed, only in its ability to increase the likelihood of achieving greater financial success. Viewed through a Freirean lens, the national college completion agenda reinforces a view of education grounded in neoliberal ideology. By couching the benefits of an increase in college completion largely in economic terms, the U.S. Department of Education speaking on behalf of the Obama administration (Kanter, et al., 2011) minimizes the non-monetary benefits associated with higher education, namely education as preparation for democratic citizenship and a life of meaning and value. Furthermore, by touting the increase to personal income that generally accompanies increased education, the Department of Education reinforces the neoliberal ideal of happiness through consumerism. Ultimately, by characterizing postsecondary education as job training, the Department of Education suggests a hidden 
motive in the college completion agenda: ensuring that degree holders are well-prepared for jobs that service the economy and create additional wealth for existing capital holders. While no student segment is immune, research suggests that first-generation students are particularly vulnerable to the trappings of neoliberalism. For a host of reasons ranging from financial hardship to family obligations, first- generation students tend to have lower educational aspirations than continuing-generation students (Terenzini, Springer, et al., 1996; Choy, 2001), to be over-represented at two-year institutions, (Nunez, Cucarro-Alamin, 1998; Choy, 2001) and, if they are first-generation as well as low-income, to be less likely to transfer to a four-year institution and complete a bachelor's degree after six years (Engle \& Tinto, 2008). The relatively modest educational aspirations of first-generation students coupled with their proclivity for twoyear institutions have the potential to limit this population's future social mobility, regulating them to a lower social and economic standing. Paradoxically, research suggests that first-generation students are more likely than their continuing-generation counterparts to emphasize the increased earning potential associated with earing a postsecondary credential while marginalizing the power of education to promote a life of meaning and value and active democratic citizenship (Saenz et al., 2007). Firstgeneration students' tendencies to focus on the material benefits of higher education reinforces the neoliberal ideal of consumerism while stifling critical examination of the forces that limit this segment's ability to realize their potential.

Critical examination of the postsecondary completion gap reveals the influence of pervasive societal forces that limit the life opportunities of first-generation students and maintain an exploitive, material-focused world order. In this vein, any attempt at closing 
the first-generation completion gap must acknowledge - and challenge - the standing of first-generation students within an oppressive neoliberal system. More significantly, postsecondary researchers and leaders must acknowledge that this inequitable system is reflected in the institutional life of colleges and universities and appreciate how individual first-generation students experience this system. Recognizing - and ultimately addressing - the inequities within postsecondary institutions requires a richer framework of understanding than is offered by the interactionalist model of student persistence (Tinto, 1993).

\section{Organizational Culture \& Postsecondary Education}

Characterized as "near paradigmatic" (Braxton \& Hirschy, 2005; p. 61) by postsecondary researchers, Tinto's (1993) interactionalist model of student persistence provides a useful heuristic for thinking about how constructs like student characteristics and institutional characteristics influence each student's desire and ability to persist to degree completion. Absent within the interactionalist model, however, is a nuanced explanation of how constructs like student entry characteristics (e.g., parental education), the external environment (e.g., family support for postsecondary education) and the internal environment interact at the discrete student level to influence academic and social integration. Indeed, a host of contemporary researchers critique the interactionalist model's explanatory power in general (see Braxton, 2000) and its application to firstgeneration students in particular (see Longwell-Grice \& Longwell-Grice, 2008). To that end, organizational culture is a promising framework for exploring how three of Tinto's critical constructs (e.g., student entry characteristics, students' external environments, and institutional environments) function at the individual student level to influence each first- 
generation student's desire and ability to persist to degree completion and colleges' and universities' ability to retain students through graduation.

\section{Definitions of Organizational Culture}

Tierney (1988) draws a distinction between functional and interpretive conceptions of organizational culture. Those who conceptualize organizational culture from a functional standpoint are rationalists who perceive culture as a real entity or product composed of finite elements. According to this view, culture is the adhesive that binds the organization and its members together. Rhoades and Tierney's (1992) functional conception of culture characterizes culture as "the informal codes and shared assumptions of individuals participating in the organization," with institutional norms, values and beliefs serving as "organizing concepts" (p. 4). An influential theorist within organizational culture and leadership, Edgar Schein's (2010) functional definition of organizational culture illustrates the utility of the construct:

The culture of a group can be defined as a pattern of shared basic assumptions learned by a group as it solved its problems of external adaption and internal integration, which has worked well enough to be considered valid and, therefore, to be taught to new members as the correct way to perceive, think, and feel in relation to those problems. (p. 18)

Similarly, Kuh and Whitt's (1988) functional definition of organizational culture is widely recognized as applicable to postsecondary institutions:

Culture in higher education is defined as the collective, mutually shaping patterns of norms, values, practices, beliefs, and assumptions that guide the behavior of individuals and groups in an institute of higher education and provide a frame of 
reference within which to interpret the meaning of events and actions on and off campus. (p. 12-13)

In contrast to functional culture, Tierney (1988) points to an understanding of organizational culture from an interpretive standpoint. To conceive of culture from the interpretive standpoint is to view an organization as a social construction where organization members continuously interpret and re-create their organizational reality. Unlike those who examine culture from a functional standpoint and conceive of culture as a set of finite elements that can be objectively studied, those examining culture from an interpretive standpoint focus on how members make meaning of the organization for themselves and for others. For those who conceive of culture from an interpretive standpoint, "organizational reality" (Tierney, 1988; p. 9) is a product of prior organizational history, organization member perception, and the present organizational context. Context is critical to an interpretative view of culture, with no assumption that what is true within one organization is true within a similar organization. In contrast to the adhesive of functional culture, interpretative culture is the "root" of the organization (Smircich, 1983). Geertz' (1973) interpretive conception defines culture as a web of significance, or "a pattern of meanings embodied in symbols" (p. 89). Similarly, Pettigrew (1979) defines culture as "an amalgam of beliefs, ideology, language, ritual and myth" (p. 572).

\section{The Properties of Organizational Culture}

Schein's (2010) review of the "observable events and underlying forces" (p. 14) of organizational culture found in the literature provides a useful framework for thinking about the complex nature of this construct. Among these cultural events and forces, 
Schein cites group behaviors and norms; espoused organizational values and philosophies; implicit rules for survival within the organization; organizational climate; embedded skills, language and habits of mind; collective meanings; and common symbols, metaphors and rituals. For Schein, four overarching properties comprise the nature of organizational culture. First, organizational culture is linked to structural stability, an organizing property that implies shared group identity as well as the means by which that identify remains stable over time as organizational members move in and out of the organization. In addition, organizational culture is linked to breadth and depth of organizational impact. In terms of breadth, culture is a pervasive construct that influences all group functions, including how the organization conceives of its core task, how it manages its internal processes, and how it interacts in relation to the external environment. In terms of depth, culture is largely experienced tacitly among organizational members, mostly at an unconscious level. Finally, organizational culture implies a process of patterning or integration, or the forming of all of the elements of the organizational experience into a comprehensible whole. For Schein, these properties of organizational culture comprise a functional view of organizational culture (Tierney, 1988) in which organizational culture can be objectively examined and serves as an organizing construct for organizational members.

Peterson and Spencer's (1990) distinction between organizational culture and organizational climate also highlights the properties of organizational culture. In contrast to organizational climate, which relates to members' shared attitudes and feelings about an organization, organizational culture encompasses the deeply shared values, assumptions, beliefs and ideologies of organizational members. While organizational 
climate is rooted is cognitive and social psychology and focuses on widespread thought and behavior patterns related to specific organizational situations, organizational culture is rooted in anthropology and sociology and is an organizing mechanism that permeates every facet of organizational life. And while organizational climate is a malleable snapshot of member attitudes at a specific point in time that influences member motivation, organizational culture comprises enduring patterns of beliefs that shapes meaning-making and member adaptation. Using the metaphor of weather, Peterson and Spencer characterize organizational climate as the daily weather pattern (e.g., cloudy, clear) and organizational culture as the meteorological zone in which one lives (e.g., tropics, desert).

Kuh and Whitt (1988) characterize the organizational culture of postsecondary institutions as postmodern constructs that are complex, multifaceted, and holistic. Similarly, Kuh and Whitt point to the paradoxical nature of organizational culture, describing the culture of colleges and universities as both "substance and form," "process and product," and "independent and dependent" (p. 41). Finally, although Kuh and Whitt's conception of organizational culture is more functional than interpretive (Tierney, 1988), they do acknowledge the constructivist nature of organizational culture within postsecondary institutions, asserting that because each individual constructs her own reality, "multiple realities exist, subjectivity is valid, and the illusion of a single objective reality that permeates conventional models or organizing is eschewed" (p. 95). Relative to the student experience, Kuh and Whitt further assert that new students are not passive receptacles of the culture. Instead, students actively shape their institutions, a process that Tierney (1997) describes as not simply "discovery of culture" but rather a 
"re-creation" of culture (p. 16). Finally the existence of subcultures (i.e., subgroupings of organizational members who share a common set of norms and values that may differ from the larger organizational culture) can lead to a postmodern fragmented experience of the college or university (Kuh \& Whitt, 1988).

In describing the strength of individual organizational cultures within postsecondary institutions, Kuh and Whitt (1988) reference a concept that they coin an institution's potency, or the degree to which campus norms, values, practices, and beliefs are uniform and exert normative pressure on faculty, staff and students. According to Kuh and Whitt, the organizational cultures of larger postsecondary institutions are less potent than the cultures of smaller institutions, where "singularity of purpose is easier to attain and is reflected by a relatively uncomplicated administrative structure" (p. 71). Similarly, Clark (1970) characterizes the sense of community which pervades the interaction between organizational members at smaller institutions:

[A small institution] allows informal as well as formal links across the specializations and internal divisions inherent in formal organizations. An aggregate of strangers brought together to pursue a common purpose within a small organization is more likely to develop a community than is an aggregation set to multiple purposes in a large system and encourage convergent rather than divergent personal experiences leading toward a sense of oneness. (p. 257)

The potency of organizational culture within smaller institutions coupled with the sense of community explains why many investigations of this phenomenon focus on small, liberal arts institutions (e.g., Clark, 1970; Newcomb, Koenig, Flacks, \& Warwick, 1967). Taken together, the properties of organizational culture are useful constructs for 
conceptualizing the complexity of postsecondary institutions.

\section{The Origin of Organizational Culture in Postsecondary Institutions}

In their review of the literature on organizational culture in postsecondary institutions, Kuh and Whitt (1988) trace the origins of the notion of culture from two distinct disciplinary orientations. First, anthropological culture encompasses two traditions: the sociocultural tradition and the ideational tradition. The sociocultural tradition of culture is based on the view the social systems result from and are sustained by member interactions that foster shared expectations and shared meanings. The sociocultural tradition is predicated on the assumption that the culture of an organization exists "out there" for objective study and "does something to" the members of the organization. Diverging from the sociocultural tradition, anthropological culture from the ideational tradition is based on the view that individual meaning-making systems are shaped not through persistent social interaction, but through the use of language and symbols. Championed by theorists like Geertz (1973) and Smirich (1983), ideational culture is predicated on the assumption that the culture of an organization exists "in here," within the minds of individual organizational members and "is something for" the members of an organization. A number of researchers have applied an anthropological view of culture to the study of postsecondary institutions, most notably Clark (1970; 1972); Masland (1985) and Peterson and Spencer (1990).

In contrast to the anthropological origin of organizational culture, Kuh and White (1988) also cite a sociological origin in the conceptualization of culture. Based on the sociological tradition of examining social structures, organizational culture from a sociological orientation is based on four elements. First, organizational culture based in 
sociology emphasizes the institutional structures and environmental conditions that organize members into subgroupings. These elements of culture include the tangible internal structures (e.g., mission statement, curriculum, characteristics of the student body) and observable external contexts (e.g., government funding levels, social discourse relating to postsecondary education, competition for students among institutions) that influence organizational behavior. However, these elements also include more tacit institutional characteristics (e.g., sagas, ethos, and artifacts that reflect deeply held values and beliefs) and external factors (e.g., politicized college completion agendas, public perception of the value of postsecondary education, family support for college-going) that can have a powerful influence on the behavior of organizational members.

From institutional structures and environmental contexts, a second element of organizational culture from the sociological tradition emerges: subcultures (Kuh \& Whitt, 1988; Schein, 2010). Broadly conceived, a subculture is a subgrouping of organizational members who, through persistent interaction, share a common set of norms and values (some of which are distinctive from the dominant organizational culture) and exert some control over organizational members in an attempt to guarantee conformity to those norms and values (Bolton \& Kammeyer, 1972). Kuh and Whitt conceptualize subcultures as enhancing (i.e., a subgroup adhering to dominant organizational values more fervently than other organizational members), orthogonal (i.e., a subgroup embodying parallel values that neither strengthen nor weaken dominant organizational values) or countercultures (i.e., a subgroup embodying alternate values that threaten dominant organizational values).

In addition to organizational structures, environments and subcultures, a 
sociological view of culture requires an examination of the process through which new members are socialized within the organization (Kuh and Whitt, 1988). Induction to the culture of an institution is not a one-way street. Analyzing the process of socialization within academic institutions from a postmodern perspective, Tierney (1997) asserts that new members (e.g., new faculty and staff or first-year students) join an organization, they engage in more than simply a "discovery of culture" (p. 16). Instead, new organization members engage in a "re-creation" (p. 16) of the institution's culture, shaping "norms, values, practices and assumptions" (Kuh \& Whitt, 1988, p. 13) as they acclimate to the organization.

Most critically, a sociological view of organizational culture includes an emphasis on what Kuh and Whitt (1988) characterize as enactment, or how members make meaning of the organization through a process of social construction (Weick, 1988). Because students filter the meaning of the organization though a distinctive life context and unique life experiences, the notion of a single organizational reality is supplanted with the notion of multiple organizational realities, with one construction of the organization no more "real" than another. A number of researchers have applied a sociological lens to the study of culture within postsecondary institutions, most notably Clark and Trow (1966); Bolton and Kammeyer (1967); Feldman and Newcomb (1969); and Kuh and Whitt (1988). These organizing principles of organizational culture in the sociological tradition (i.e., institutional structures and conditions; subcultures; socialization processes; enactment processes) offer a useful lens through which to examine postsecondary institutions. 


\section{The Elements of Organizational Culture in Postsecondary Institutions}

Cultural researchers and theorists identify the components of organizational culture within postsecondary institutions in an effort to understand its nature and to investigate its impact on those inside and outside of the academy. A seminal researcher in the area of organizational culture, Edgar Schein (2010) reviews the literature on the cultural events, forces and structures related to organizational behaviors and norms, including: espoused organizational values and philosophies; implicit rules for survival within the organization; organizational climate; embedded skills, language and habits of mind; collective meanings; and common symbols, metaphors and rituals. Schein characterizes organizational culture according to three levels. The first level of organizational culture is comprised of physical artifacts, or the overt structures, processes and behaviors of the organization that are easily observed. The second level of organizational culture is comprised of the espoused beliefs and values cited by those working within the organization. The third - and most profound - level of organizational culture is comprised of the tacit assumptions inherent within physical artifacts and espoused values and beliefs. Schein asserts that although institutional artifacts can be examined with relative ease, deriving their meaning is more complex. Similarly, although the espoused beliefs and values of organizational members are easy to attain, they may be little more than organizational actors' rationalizations or ambitions. In order to truly understand organizational culture, the researcher must unearth the tacit assumptions and shared meanings that permeate the organization at the unconscious level.

Like Schein (2010), Peterson and Spencer (1990) advance a conceptual model of 
organizational culture that includes both explicit and implicit elements. The most explicit elements of organizational culture are the institution's geospatial features, including the architecture and characteristics of the physical plant. Other explicit elements of organizational culture include institutional artifacts; the purposeful use of tradition, myth and symbolism; and the espoused values and beliefs of members. Echoing Schein (2010), Peterson and Spencer (1990) maintain that these explicit elements of culture (i.e., geospatial features, artifacts, tradition, myth, symbolism, espoused values) provide an "idealized view of the institution, highlighting values and beliefs that are avowed but not necessarily practiced" (p. 11). In order to understand the true nature of organizational culture, one must examine the behavioral patterns of members and uncover the embedded values and beliefs.

Like Schein (2010) and Peterson and Spencer (1990), Chaffee and Tierney (1988) identify three basic elements of organizational culture. The first element, organizational structure, encompasses the formal and informal roles and relationships between members as well as the manner in which these members organize and execute their work activities. The cultural view of structure for which Chaffee and Tierney advocate emphasizes not only formal organizational charts and operational procedures, but the manner in which individual members make meaning of their roles and relationships as well as the informal ways they execute their work. In addition to the structural element of organizational culture, Chaffee and Tierney cite the institutional environment, or "the people, events, demands, and constraints in which an institution finds itself" (p. 15). Central to Chaffee and Tierney's understanding of the environment is the manner in which members understand the nature and boundaries of their institutional context, or the enacted 
environment. In the enacted environment, multiple organizational realities exist, and objects and relationships in the environment that do not capture the attention of members are excluded from consideration. Lastly, Chaffee and Tierney cite values, or shared beliefs, behavioral norms and priorities that permeate the institutional, as a final element of organizational culture. Specifically, the values expressed in institutional mission and in institutional leadership are central to understanding organizational culture. Tierney (1988) explicates the underpinnings of organizational culture in postsecondary institutions by outlining its manifestations in the physical environment; the organizational mission; the processes by which new members are socialized within the organization; the processes by which members share information within the organization; the strategies that organizational members employ in the execution of its mission; and the behavior of institutional leaders. In order for organizational culture to function productively, organizational structures, environments and values must be congruent.

Masland (1985) identifies abstract "windows" of organizational culture: sagas, heroes, symbols, metaphors, and rituals. The first cultural window, the organizational saga, is a narrative of important accomplishment in institutions' histories that continue to shape member values and behavior in the present. Clark's (1970) describes organizational saga as an exaggerated understanding of an organization's history that provides organizational members with a link to the institution's past and present and a desire to advance the institutional mission into the future. For Clark, the most important function of the organizational saga within postsecondary institutions is the "capturing of allegiance" (p. 235) that breeds an emotional investment in the institution that is similar to religious zeal. This development of this allegiance is a five step process. Initially, 
institutional "believers" (p. 246) emerge among the faculty and garner enough influence to protect their values and vision of the institution. Eventually, these values and vision are manifested in the curriculum, garnering enough strength to influence day-to-day behavior. Third, a base of "believers" outside of the institution provides added resources and begins attracting like-minded students to the institution. As these students move through the institution, they develop strong subcultures that encompass the core values and beliefs of the institution. Ultimately, "the saga itself- as ideology, self-image, and public image - has forceful momentum" (p. 246), shaping how the institution views itself and its role in the external environment as well as how organizational outsiders understand the institution.

Masland's (1985) second window of organizational culture, organizational heroes, consists of important people from the past - frequently the founders of institutions - that continue to serve as models of organizational ideals and values. Organizational heroes frequently take on exaggerated, myth-like qualities, their stories passed down to new members as examples of organizational ideals and behaviors. In the same way that heroes exemplify organizational values, symbols, are material manifestations of organizational values that are recognizable to those inside and outside of the organization. Often, symbols are expressed in the language of organizational members in the form of metaphors that personify organizational values. Finally, organizational rituals are repeated actions or ceremonies that represent cultural values in action. Organizational rituals provide continuity with an institution's past and serve as a way of expressing cultural values to new organization members.

Kuh and Whitt (1988) present seven elements of organizational culture inherent 
within postsecondary institutions. First, the culture of an organization is shaped by its historical root. The story of a college or university's founding can take on a mythical quality of a saga (Clark, 1970), with its founder achieving the idealized status of a hero (Masland, 1985). Next, the organizational culture of a postsecondary institution is maintained both by its academic program as well as by the personnel core, or group of influential faculty members (Kuh \& Whitt, 1988). Once established by a strong academic program and personnel core, organizational culture is strengthened by the social environment and dominant student subculture of the organization. While the academic program and the faculty serve as "donors" of organizational culture, students are far from passive receptacles organizational values. Rather, students actively shape the cultural values and beliefs of the organization as they move through their colleges and universities. Once embodied by the academic program, the faculty and the students, organizational values are reflected in the institutional artifacts, including institutional architecture, ceremonies, rites, and rituals. The physical plant of the institution "reflects distinctive values and aspirations of how [faculty, staff and students] live and work in college" (p. 65), while ceremonies, rites and rituals of the institution "give form to communal life" and "enrich the campus ethos and allow interpretations and meanings to be made of special events" (p. 67). Fully realized, organizational culture emerges as the institution's distinctive themes, or core values and beliefs transmitted via organizational ethos, norms, and saga. Most critically, these themes are reflected in individual actors, or the faculty, staff and students.

As a collective, individual actors form institutional subcultures that share the common values of the institution while simultaneously maintaining distinctive values. 
Kuh and Whitt (1988) review the literature on three broad institutional subcultures evident in academia: faculty subculture (which can be further reduced to the subculture of the academic profession and to several disciplinary subcultures), administrative subculture and student subculture. Student subcultures, or "shared perspectives on the relative importance of matters such as academic performance, extracurricular activities, social life, and work" (Kuh \& Whitt, 1988; p. 47), can be conceptualized as national (i.e., the perspective shared by students across institutions), institutional (i.e., the perspective shared by students at a single institution) or subcultural (i.e., the perspective shared by a distinct subgroup within a single institution). According to Kuh and Whitt, the formation of student subculture is influenced by precollege characteristics, including geographical origin; educational background; socioeconomic status; political and religious beliefs; and educational goals. Once formed, student subcultures are maintained by formal and informal ceremonies and rituals; student body size and homogeneity; the degree to which students support one another; institutional ethos; and the degree to which students participate in institutional governance. In their attempt to characterize student subcultures, Clark and Trow (1966) advance a typology of postsecondary student subcultures, including the collegiate (i.e., loyalty to the institution and a de-emphasis on intellectualism); vocational (i.e., a view of higher education as training for the professions and a de-emphasis on intellectualism); academic (i.e., commitment to intellectualism and value of high grades); and nonconformist (i.e., detachment from faculty and administrative cultures and off-campus points of reference). Similarly, Katchadourian and Boli (1985) advance a typology of student subculture that mirrors that of Clark and Trow (1966), describing students as careerists, intellectuals, strivers and 
unconnected. As a whole, the elements of organizational culture as outlined by Kuh and Whitt (1988) offer a critical framework for examining organizational life within colleges and universities.

\section{The Function of Organizational Culture in Postsecondary Institutions}

Organizational scholars and researchers who approach culture from a functional standpoint (Tierney, 1988) advance a number of propositions related to the utility of the construct in promoting organizational effectiveness. For example, Schein (2010) posits that organizational culture is the mechanism through which organizational members address the challenges presented by external adaptation (i.e., operating and surviving within an organizational field and external environment ) as well as internal integration (i.e., orientating internal stakeholders toward a common approach to organizational survival and growth). In this way, Schein's functional view of organizational culture is a process characterized by patterning and integration, or the way that those inside and outside of the organization derive order and meaning from organizational life. In addition, Schein asserts that organizational culture and organizational leadership are two sides of the coin, one unable to exist without the other. Peterson and Spencer (1990) reinforce the utility of organizational culture in fostering organizational effectiveness; attracting, selecting and socializing new members; providing members with a sense of purpose in their work; providing members with a sense of identity; fostering an image of legitimacy among those outside of the organization; and providing the framework for which to understand those aspects of organizational life not specified in formal operating procedures and quantifiable measures of success. Fugazzotto (2012) describes how two common organizational forms - mission statement and physical space - serve as 
manifestations of abstract culture with ties to organizational strategy. While institutional mission statements represent both social structure and underlying cultural assumptions, the physical space provides the arena in which those structures and assumptions are enacted on a day-to-day basis. Mission and physical space are linked by institutional strategy, or the way in which institutions enact their policies - including the execution of institutional mission and the use of physical space - in pursuit of their missions. The effectiveness of an organization, then, hinges both on the strength of its organizational forms (i.e., mission and space) as well as the way in which those forms are leveraged in practice (i.e., strategy).

Higher education scholars outline the utility of organizational culture within colleges and universities. For Bergquist (1992), organizational culture provides meaning, context, purpose and continuity not only for students, faculty, and staff, but also for those outside of the academy. In addition, the organizational culture of a college or university defines institutional reality for internal stakeholders and "provides lenses through which its members interpret and assign value to the various events and products of this world" (p. 2). Most critically, the organizational culture of a postsecondary institution is grounded in its most prized value: the institution's educational purpose: The culture of academic organization must thus be understood within the context of the educational purposes of collegiate institutions. The ceremonies, symbols, assumptions, and modes of leadership in a college or university are always directed toward the institution's purposes and derive from its cultural base. (Bergquist, 1992; p. 3)

Chaffee and Tierney (1988) expand on the benefits derived from attending to organizational culture on a college or university campus. These benefits include the 
ability to understand conflict between organizational members; the ability to frame organizational decision-making and organizational action within a broader context and to appreciate the symbolic power of both; the ability to discern structural and operational irregularities that breed tension, inefficiency and ineffectiveness; and the ability to understand why alternate groups perceive institutional performance differently. Masland (1985) cites additional functionality of attending to organizational culture within postsecondary institutions, including the ability to explain prior institutional decisions and actions and the ability to influence current institutional power within a professional bureaucracy (Mintzeberg, 1979) where explicit and implicit control mechanisms are generally weak.

Effective management of postsecondary institutions is linked to the management of organizational culture. Dill (1982) characterizes the academic management of faculty and staff as the management of meaning (i.e., symbolic events that emphasize core values) and social interaction (i.e., structural elements that foster the transfer of institutional values among academic staff). Similarly, Rhoades and Tierney (1992) assert that organizational problems are best addressed when administrators attend to the "values, beliefs, traditions, and histories that organizational members hold" (p. 4). Rhoades and Tierney describe "cultural leadership" of postsecondary institutions as recognizing unique cultural elements of colleges and universities, acknowledging the need to shift values and beliefs in order to evoke organizational change, and employing culturally-based strategies in strategic and tactical management. The management of organizational culture is tied to a host of change efforts within the academy, including conflict management (Tierney, 1988); general education reform (Awbrey, 2005); 
organizational governance (Tierney \& Minor, 2004); faculty identify and institutiondiscipline tensions (Silver, 2003; Considine, 2006); and the relationship between academic staff and senior administrators (Kuo, 2009). Less frequently, the management of organizational culture has been tied to the student experience. Gallant \& Drinan (2006) examine academic dishonesty from an organizational culture perspective, advocating that academic leaders use this framework to invoke real change in student behavior. In addition, Thorton \& Jaeger (2006, 2007) detail how organizational culture can impact the development of student civic responsibility. Utilizing McNay’s (1995) typology of organizational culture, van der Velden (2012) investigates how the dominant organizational form of postsecondary institutions (i.e., the institution as collegium, bureaucracy, corporation, and enterprise) influences student voice, or students' levels of engagement with the institution. González (2002) uncovers how social, physical and epistemological elements of campus life foster marginalization and alienation from the “dominant White culture" among first-generation Chicano students. More can be learned about how students' experience of organizational culture influences their persistence to degree completion.

In summary, organizational culture is a useful framework for explicating how Tinto's (1993) constructs of entry characteristics, external environments and internal environments intersect at the individual student level to influence postsecondary outcomes. Kuh and Whitt's (1988) sociological definition of the organizational culture of colleges and universities, while functional on its face, acknowledges the individualized, interpretive experience of the construct:

Culture in higher education is defined as the collective, mutually shaping patterns 
of norms, values, practices, beliefs, and assumptions that guide the behavior of individuals and groups in an institute of higher education and provide a frame of reference within which to interpret the meaning of events and actions on and off campus. (p. 12-13).

Organizational culture is characterized as a force that is as stabilizing, unconscious and integrating (Schein, 2010) as well as complex, multifaceted, holistic and constructivist (Kuh \& Whitt, 1988). While there is little consensus among scholars about the elements that comprise organizational culture, Schein's (2010) three levels of culture (physical artifacts, espoused beliefs and values, and tacit assumptions) provides a theoretical umbrella for categorizing the many manifestations of organizational culture.

The constructs of organizational culture have been applied extensively to the management of academic staff (e.g., Dill, 1992), institutional leadership (e.g., Rhoades \& Tierney, 1992) and institutional change (e.g. Chaffee \& Tierney, 1988). Although collegiate student subcultures have been studied at length (e.g., Clark \& Trow, 1966), the influence of organizational culture on student outcomes such as degree completion has received less attention. This study applied a functional, constructivist view of organizational culture from the sociological tradition (Kuh \& Whitt, 1988) to firstgeneration college students, exploring how this population created meaning from institutional contexts with which they had limited prior exposure. In addition, this study explored how first-generation students' experiences of the organizational culture of their colleges and universities was shaped by their prior cultural contexts (Kuh \& Love, 2000). Most critically, this study examined how first-generation students' experiences of organizational culture influenced their desire and ability to persist to degree completion 
while highlighting what these students' experiences of organizational culture meant for postsecondary institutions' ability to retain this population through graduation.

\section{Conceptual Framework for the Current Study}

This study filtered the constructs of Tinto's (1993) interactionalist theory of student persistence (i.e., student entry characteristics; educational goals and commitments; internal and external environmental characteristics; academic and social integration) through the lens of organizational culture grounded in the sociological tradition. According to Kuh and Whitt (1988), organizational culture from the sociological tradition is based on four elements. First, organizational culture based in sociology emphasizes the tangible and intangible institutional structures and environmental conditions that organize members into subgroupings. In this vein, this study examined first-generation students' experience of both the tangible elements (e.g., institutional artifacts, explicit value statements) and tacit elements (e.g., heroes, rituals, sagas, symbols, implicit values) of their institutions. In addition, the study explored firstgeneration students' experiences of overt and covert forces external to their institutions that influenced degree completion behavior.

From institutional structures and environmental conditions, subcultures emerge (Schein, 2010; Kuh \& Whitt, 1988). Broadly conceived, a subculture is a subgrouping of organizational members who, through persistent interaction, share a common set of norms and values (some of which are distinctive from the dominant organizational culture) and exert some control over organizational members in an attempt to guarantee conformity to those norms and values (Bolton \& Kammeyer, 1972). This study examined first-generation students' experience of student, faculty and staff subculture. 
In addition to organizational structures, environments and subcultures, a sociological view of culture requires an examination of the process through which new members are socialized within the organization (Kuh \& Whitt, 1988). This study did not consider the ways in which first-generation students acclimate to their colleges and universities. Instead, in keeping with constructivist nature of organizational culture as conceived by Kuh and Whitt, the study considered the ways in which first-generation students participate in the "re-creation" of the culture of their institutions (Tierney, 1997).

Most critically, Kuh and Whitt (1988) maintain that a sociological view of organizational culture includes an emphasis on enactment, or how members make meaning of the organization through a process of social construction (Weick, 1988). Kuh and Love (2000) describe how students" "meaning-making systems" are shaped by their cultures of origin, comprised of family influences, prior educational experiences, and community forces. These cultures of origin mediate the importance that students attach to various values, beliefs and behavior that they encounter, including the importance of participating in postsecondary education and persisting to degree completion. As a result, knowledge of students' cultures of immersion - the overarching values and beliefs of academic institutions - coupled with knowledge of their cultures of origin is necessary for true understanding of students' ability to integrate within their institutions (Kuh \& Love, 2000). When the values and beliefs inherent in students' cultures of origin are incongruent with those inherent in their cultures of immersion, or when students lack access to or experience utilizing cultural capital on a college or university campus, they are forced to bridge cultural distance, ultimately finding success by acclimating to their institution's dominant culture or by joining cultural enclaves (Kuh \& Love, 2000). This 
experience of cultural distance may lead some students to experience what Kuh and Love coin cultural stress, which may have implications for postsecondary outcomes like degree completion. This study applied Kuh and Whitt's (1988) description of cultural enactment within postsecondary institutions and Kuh and Love's (2000) constructs of cultures of origin and cultures of immersion to the examination of first-generation degree completion behavior. Specifically, the study explored how family influences, prior experiences, and community forces (i.e., students' cultures of origin) shaped the "meaning-making systems" through which first-generation students enacted the structural elements and environments of their colleges and universities (i.e., students' cultures of immersion), including whether the values and beliefs relating to their cultures of origin were congruent with values and beliefs of their cultures of immersion. In addition, the study explored the cultural distance that first-generation students experienced between their cultures of origin and their cultures of immersion, including the level at which this cultural distance related to experiences of cultural stress as well as the degree to which first-generation students sought out cultural enclaves as a means to alleviating this stress. 


\section{CHAPTER III \\ REVIEW OF METHODS}

This chapter provides a summary of methodology for the current study. The current study's purpose, research questions, philosophical and methodological framework, and sample selection are reviewed. This chapter also includes an overview of the case study institution and reviews methods for data collection, coding, and analysis. The chapter concludes with a review of procedures for ensuring trustworthiness and credibility of the data collected as well as ethical safeguards.

\section{Study Purpose \& Research Questions}

The purpose of the current study was to explore how first-generation students experience their postsecondary institution and what this experience means for degree completion. As the postsecondary completion agenda gains momentum, closing the completion gap for all student segments is of critical importance. As a segment historically underrepresented and underserved within higher education, first-generation students are those who are the first in their immediate families to pursue education beyond the secondary level (Choy, 2001; Chen, 2005). As a whole, first-generation students are less likely than their continuing-generation counterparts to persist to degree completion (Ishitani, 2006; Saenz et al., 2007; Cataldi et al., 2011). This completion gap between first-generation and continuing-generation students persists even when

controlling for other demographic characteristics and pre-enrollment experiences (Nunez 
\& Cuccarco-Alamin, 1998; Ishitani, 2003). In addition, first-generation students appear to experience the postsecondary environment differently that continuing-generation students, with first-generation students less likely to succeed at private institutions (Pascarella \& Terenzini, 2005) and smaller institutions (Lohfink \& Paulsen, 2005) where continuing-generation students flourish. In order to explore first-generation students' unique experiences within small, private institutions and to investigate what these experiences means for degree completion, the current study addressed the following research questions:

1. How do external forces influence first-generation students' experiences of a small, privately-controlled institution?

2. How do first-generation students interpret the functional aspects of their institution's culture?

3. What do these interpretations mean for first-generation students' ability to navigate the functional aspects of their institution's culture?

The current study filtered the constructs of Tinto's (1993) interactionalist theory of student persistence through the lens of organizational culture. Although the framework of organizational culture has frequently been applied to the study of postsecondary education (Chaffee \& Tierney, 1988; Tierney \& Minor, 2004; Bergquist \& Pawlak, 2008), this framework has been applied less frequently to the study of postsecondary student outcomes such as degree completion. Answering the research questions generated practical considerations for fostering college and university cultures that promote first-generation student success. More critically, answering the research questions addressed gaps in the scholarship on first-generation student persistence, 
namely the distinct way that first-generation students experience their institutions and how these experiences influence degree completion.

\section{Philosophical \& Methodological Frameworks}

The current study was grounded in a constructivist view of knowledge and knowledge claims. The constructivist views reality as the interaction between the individual and the social spaces she occupies (Merriam, 2009). As such, what the constructivist values as knowledge of a phenomenon hinges on what that phenomenon means to others. For the constructivist researcher, the understanding of meaning is not achieved through asocial, detached methods of data collection. Rather, constructivist understanding is achieved through examination of the individual's experience as she interprets the social world in which she lives (Crotty, 1998). In this way, the current study took a constructivist view of first-generation degree completion by focusing on this segment's interpretations of the collegiate environment and exploring what these interpretations meant for degree completion.

The current study's focus on the first-generation student experience also lent itself to a phenomenological perspective and the research designs and methods that are consistent with it. Phenomenology is the study of the essential structure of human experience (Merriam, 2009). Through the phenomenological interview, the researcher captures how individuals experience their world and create meaning from what they encounter (Patton, 2002). Similarly, the study of culture hinges on the examination of the meaning that individuals attach to their external world (Kuh \& Whitt, 1988). In this way, the current study incorporated a phenomenological approach to examine how firstgeneration students experience their institutions and what this experience means for 
degree completion.

With their emphasis on what first-generation students' interpretations of their institutional environments mean for degree completion, the current study's research questions suggested a qualitative research design. Merriam (2009) defines qualitative research as a methodology centered on uncovering how individuals interpret their experiences, exploring how individuals attach meaning to those experiences, and understanding how individuals construct their social world. Specifically, this study utilized a qualitative case study research strategy. Qualitative case study research is distinctive from other qualitative methods through its focus on a "bounded system" (Creswell, 2013), or a discrete unit or units of analysis around which boundaries can be drawn and for which there are finite sources of data. Put another way, case study methodology involves examination of a research phenomenon (e.g., first-generation students' degree completion) within its natural context (e.g., a college or university) (Yin, 2003). Merriam (2009) characterizes case study research as particularistic (i.e., focusing on a single research phenomenon within a bounded context), descriptive (i.e., providing "thick" descriptions of the research phenomenon), and heuristic (i.e., generating new understanding of the research phenomenon). Through a qualitative case study research strategy, this study aimed to provide rich description of discrete units of analysis (i.e., small, private postsecondary institutions) with the goal of generating new understanding of how first-generation students experience these environments and what this experience means for degree completion.

A qualitative case study research was an appropriate design for the current study for a number of reasons. Case study research is appropriate when true understanding of 
the research phenomenon requires examination within context and when the boundaries between the research phenomenon and its context are fluid (Yin, 2003). Given that firstgeneration students' experiences of organizational culture of postsecondary institutions are nearly impossible to separate from the institutions themselves, a case study research strategy was applicable. In addition, with its focus on understanding-in-context, case study research is a particularly useful framework for constructivist-minded researchers who conceptualize knowledge claims as social constructions (Brown, 2008). Because the current study focused on socially-derived phenomena open to individual interpretation (i.e., the student experience of the environment of colleges and universities), a constructivist methodology like case study research was necessary to address the research question effectively. Finally, case study research has been utilized extensively to examine one of the current study's central phenomena: the organizational culture of postsecondary institutions (Chaffee \& Tierney, 1988; Bergquist \& Pawlak, 2008). Utilizing case study research to examine the first-generation student experience of organizational culture expands the knowledge base on the importance of this construct to college and university leaders while addressing a gap in the scholarship on how firstgeneration students' interpretations of small, private institutions influence their desire and ability to complete a postsecondary degree.

\section{Selection of the Case Study Institution}

Cultural scholars suggest that the organizational culture of colleges and universities is best discerned at smaller residential institutions, where common norms, values, practice and beliefs are more rigidly enforced across campus (Kuh \& Whitt, 1988) and where a sense of community among organizational members is more easily 
established (Clark, 1970). In addition, within case study research, a case is most useful when it encompasses ample sources of evidence relating to the research questions (Stake, 2005). Most critically, previous empirical investigations demonstrate that institutional size and control (i.e., public vs. private) have a distinctive relationship to first-generation student persistence, with first-generation students attending small, private institutions less likely to persist to degree completion than first-generation students who attend larger, public institutions (Pascarella \& Terenzini, 2005; Lohfink \& Paulsen, 2005). Keeping proportion of first-generation students (i.e., at least ten percent of the student body), institutional size (i.e., less than 5,000 students) and institutional control (private) in mind, eight colleges and universities within driving distance of Indianapolis, Indiana (the researcher's home) were considered as case study institutions. Ultimately, I selected "Performance University," a small, privately-controlled university with a healthy proportion of first-generation students.

Founded in the early twentieth century as one of the nation's first comprehensive institutions to "embrace the 'practical' side of learning along with the 'literary and classical," Performance University is a traditional, privately-controlled, residentiallybased institution located in the working-class Midwestern town of "Davis" (PU History, 2015). Although affiliated with the Presbyterian Church at its inception, Performance has remained a non-sectarian, non-profit institution open to all qualified students (PU History, 2015). Classified as a "Baccalaureate College - Diverse Fields" by Carnegie, Performance University offers a traditional liberal arts education coupled with professionally-focused programs (Performance University, 2015). Performance's academic programs are organized into three colleges (Arts \& Sciences, Fine Arts, and 
Professional Studies) and one professional school (School of Business).

Throughout its history, Performance has remained a traditional undergraduate institution. Although offering graduate programs with the School of Business and the College of Professional Studies, Performance's graduate student population is small, accounting for less than four percent of the student body (Integrated Postsecondary Education Data System, 2016). While Performance's overarching mission is "to deliver on the promise of education," a more detailed expression of its missions is what Performance community members refer to as the "Three Prepares." Specifically, Performance purports to prepare its students for "professional success, democratic citizenship in a global environment, and a personal life of meaning and value" (Mission and Values, 2015).

With over 2,000 undergraduates during the fall of 2014, Performance University serves a healthy proportion of first-generation students. Of the undergraduates entering the institution for the first time during Fall 2014, $29 \%$ indicated on the Free Application for Federal Student Aid (FAFSA) that neither parent had attended college. This is consistent with Performance's five-year average of 29.2\% (Office of Institutional Research, 2016). Like many of its counterparts serving an increasingly diverse student body, Performance faces challenges in retaining students from matriculation to graduation. The first-year retention rate (i.e., the number of first-year students who return to the same institution for their second year) for undergraduates entering Performance as first-time, full-time students during Fall 2014 was only 73\% (Integrated Postsecondary Education Data System, 2016). In addition, the six-year graduation rate for full-time undergraduates entering Performance during Fall 2006 was 55\% (Integrated 
Postsecondary Education Data System, 2016), a full ten percentage points less the sixyear completion rate for private institutions nationally (Kena et al., 2016). Salient to the current study, the first-year retention and completion rates for first-generation students at Performance are somewhat lower than the general population. The first-year retention rate for first-generation students entering Performance during Fall 2014 was 71\%, compared to $73 \%$ for the general populations (Office of Institutional Research, 2016). Moreover, less than half of the first-generation students (49\%) entering Performance during Fall 2006 completed a degree in six years, compared to a plurality (55\%) of the general population in the Fall 2006 cohort (Office of Institutional Research, 2016).

Given its traditional nature (i.e., small, privately-controlled, residentially-based, academic offerings programs steeped in the liberal arts) coupled with its critical mass of first-generation students who under-perform in relation to their continuing-generation peers, Performance was ideal for examining how this contemporary population experiences the forms of a conventional institution.

\section{Selection of Participants}

In order to pinpoint potential research participants, I partnered with Performance University's Dean of Student Development. Utilizing the university's student information system, the Dean identified Performance's self-reported first-generation student population: those students who indicated on the Free Application for Federal Student Aid (FAFSA) that they were the first in their families to attend college. The Dean emailed an invitation to this generation population (see Appendix A) with a link to the Survey Monkey screening survey instrument (see Appendix B). The final question of the screening survey inquired whether recipients were interested in a follow-up 
conversation about their collegiate experience. All totaled, 123 Performance students completed the screening survey. Of these 123 students, 53 indicated an interest in a follow-up conversation and were sent a second email from me inviting their participation in an in-person interview (see Appendix C). Of these 53 students, eighteen - fourteen women and four men - responded to the second email and completed an interview to comprise the research participants of the current study. The participants represented a diverse sample of the Performance student body, studying within all four of the university's major academic divisions, hailing from urban, rural and suburban areas, and residing on- and off-campus. Although age, marital status, race, ethnicity, and socioeconomic status were not primary considerations within this investigation, participants revealed variations across each of these dimensions.

\section{Brief Description of Participants}

“Asia” was a second-year Information System systems major within Performance's School of Business. Asia transferred to Performance from a nearby regional public university. A quiet young woman, Asia appeared hesitant to reveal herself.

"Beth" was a second-year English Education major. She identified as "lowermiddle class" and frankly discussed her ADHD diagnosis. Confident and gregarious, Beth described herself as academically talented and self-disciplined. She was actively involved in residential life at Performance, living in a residence hall as a First-Year Experience Mentor and holding a work-study job.

"Brian" was a third-year Information Systems major within the School of Business. Originally drawn to Performance for its vocal education program, Brian 
remained actively involved in the music community on campus. He described himself as shy and lived on campus.

“Cassie" was a fourth-year student preparing to graduate from Performance. Although starting at Performance in the Nursing program, Cassie switched into the Theatre program during her second year. Cassie stopped out for a semester early in her college career to battle cancer but later returned to complete her degree. Although she had lived on campus in the past, Cassie lived off-campus for her final year at Performance.

“Clarissa” was a fourth-year Accounting major hailing from a small, rural community about three hours from Performance. An academically-talented honors student, Clarissa described herself as a challenge-seeker. She was active in residential life on campus, working for the Office of Residence Life. Her residential experience prompted Clarissa to explore the possibility of entering a graduate program in college student affairs upon graduation.

"Chloe” was a third-year Entrepreneurship major. A self-described loner, Chloe reported pushing herself to achieve her goals. Chloe was a Performance-area native who lived off-campus after a brief stint living in a residence hall during her first semester on campus.

“George" was a second-year Business major. Originally drawn to Performance for its men's basketball program, George reported loving to learn new things and working a significant number of hours at an off-campus job. A Performance-area native, George lived at home in order to save money.

"Judy" was a non-traditionally aged student returning to college to complete an 
Accounting degree through Performance's accelerated degree program for adult learners.

Describing herself as determined, Judy worked a full-time job at a local bank in the Davis area, where she and her husband and children resided.

"Jordan" was a third-year History major from a suburban area. Describing herself as quiet and studious, Jordan lived on Performance's campus and was actively involved in a multicultural sorority.

"Justin" was a third-year Business major hailing from a major metropolitan area. Justin was a second-generation Polish-American who was open about growing up economically challenged. A transfer student who also took a gap year between high school and college, Justin had always lived off-campus and reported being passionate about self-discovery.

"Janelle" was a second-year Nursing major from a major metropolitan area. Janelle described herself as shy with a passion for helping people. She lived on campus. "Kathleen” was a second-year Nursing major. Financially independent from her parents, Kathleen lived with her boyfriend about thirty miles from Performance and commuted every day while also working a significant number of hours off-campus. She described herself as shy but ambitious.

"Karen" was a third-year Art Education major from a small town. Describing herself as outgoing, independent and achievement-oriented, Karen had always lived on campus.

"Nan” was a third-year International Business major from a major metropolitan area. Describing herself as introverted and hardworking, Nan was the third of her siblings to attend Performance. While she had initially lived in a residence hall, Nan 
resided in her sorority house.

"Saki" was a fourth-year Human Services major. Formally emancipated from her father (her only surviving parent), Saki lived on campus year-round. She described herself as introverted and sheltered and was open about her diagnoses of depression, anxiety and Post-Traumatic Stress Disorder.

"Susan" was a fourth-year International Business major. She transferred to Performance from a nearby regional public university. A Performance-area native, Susan lived with her grandparents and commuted to campus. She described herself as organized and a hard worker.

"Sara" was a fourth-year Studio Art major. Hailing from a small rural community, Sara described herself as shy and "small town." Sara lived on-campus and worked as a First-Year Experience Mentor.

"Tom" was a third-year Management major. A member of the Football team, Tom described himself as persistent and lived on campus.

Table 1

Summary of Participants

\begin{tabular}{ccccc}
\hline Name & $\begin{array}{c}\text { Year in } \\
\text { College }\end{array}$ & Academic Major & $\begin{array}{c}\text { On- or Off- } \\
\text { Campus }\end{array}$ & $\begin{array}{c}\text { Hometown } \\
\text { Characteristic }\end{array}$ \\
\hline "Asia" & 2nd & Information Technology & Off-Campus & Local \\
"Beth" & 2nd & English Education & On-Campus & Suburban \\
"Brian" & 3rd & Information Technology & On-Campus & Suburban
\end{tabular}

(Table Continues) 


\begin{tabular}{|c|c|c|c|c|}
\hline Name & $\begin{array}{l}\text { Year in } \\
\text { College }\end{array}$ & Academic Major & $\begin{array}{l}\text { On- or Off- } \\
\text { Campus }\end{array}$ & $\begin{array}{c}\text { Hometown } \\
\text { Characteristic }\end{array}$ \\
\hline "Cassie" & 4th & Theatre & Off-Campus & Suburban \\
\hline "Clarissa" & 4th & Accounting & On-Campus & Rural \\
\hline "Chloe" & $3 \mathrm{rd}$ & Entrepreneurship & Off-Campus & Local \\
\hline "George" & 2nd & Business General & Off-Campus & Local \\
\hline "Judy" & 2nd & Accounting & Off-Campus & Local \\
\hline "Jordan" & $3 r d$ & History & On-Campus & Suburban \\
\hline "Justin" & $3 \mathrm{rd}$ & Business General & Off-Campus & Urban \\
\hline "Janelle" & 2nd & Nursing & On-Campus & Urban \\
\hline "Kathleen" & 2nd & Nursing & Off-Campus & Local \\
\hline "Karen" & $3 r d$ & Art Education & On-Campus & Rural \\
\hline "Nan" & $3 r d$ & International Business & Off-Campus & Urban \\
\hline "Saki" & 4 th & Human Services & On-Campus & Suburban \\
\hline "Susan" & 4 th & International Business & Off-Campus & Local \\
\hline "Sara" & 4 th & Studio Art & On-Campus & Rural \\
\hline "Tom" & $3 r d$ & Management & On-Campus & Suburban \\
\hline
\end{tabular}

\section{Collection of Evidence}

Case study research is not linked to one particular method of data collection, with most case research strategies incorporating multiple forms of evidence collection (Merriam, 2009). 
A web-based survey was utilized as a screening and participant recruitment tool (see Appendix B). In addition to general demographic information (i.e., year in school, self-identified first-generation status, native/transfer student status), the open-ended survey gleaned responses related participants' pre-college influences (e.g., family, early educational experiences), their impressions of the tangible and intangible elements of Performance's culture, and their desire and ability to navigate the institutional environment.

Because the current study centered on the first-generation student experience, the phenomenological interview was the primary method of collecting evidence. In addition to being an effective method of exploring the human experience, phenomenological interviews are the preferred method for uncovering members' experiences of organizational culture within postsecondary institutions. Citing Gorden's (1975) assertion that interviewing is the most effective methodology for uncovering the implicit nature of organizational culture, Masland (1985) provides insight for uncovering the underlying nature of this construct within postsecondary institutions:

But because culture is implicit, interview questions cannot ask about culture directly. Instead the researcher should probe the four cultural windows [saga, symbols/metaphors, heroes and rituals]. Asking respondents what make their college distinct or unique, or what makes it stand apart from similar schools a prospective applicant might consider, uncovers organizational saga. Similar questions focus on the school's educational philosophy and what is unique about its academic mission. Respondents draw upon their understanding of the institution's saga when answering questions. They disclose what college means to 
them. They also refer to the symbols and rituals that represent this meaning in a more tangible form. Thus listening carefully to responses in an interview is an excellent means of uncovering manifestations of organizational culture. (p. 148149, emphasis added)

In the current study, interview probes centered on research participants' precollege influences, their experience of the Performance culture, and their ability to navigate the institutional environment (see Appendix D). Consistent with robust interviewing strategies that shed light on the research questions, the formal interview protocol included experience/behavior questions, opinion/value questions, and feeling questions (Patton, 2002). Further, follow-up probes included reflexive statements through which participants were asked to clarify responses that were not clear and to elaborate on preceding statements (Dana, Kelsay, Thomas \& Tippins, 1992).

Interview sessions for the current study were conducted during late Fall 2014 (November-December) and early Spring 2015 (January-February). Interview sessions were audio recorded, and for each audio recording a verbatim transcript was produced for use in data analysis. In addition to audio recording, detailed field notes were drafted during interview sessions with field annotations added after each interview as was practical. These field notes included not only the main ideas and phrases that participants revealed, but also the researcher's reflexive comments pertaining to the interview session. Ultimately, interview transcripts and field notes became the crux of the case documentation that is critical to a case study research strategy (Yin, 2003).

The current study also utilized document analysis, or the exploration of the written, visual, digital and physical material pertaining to the research questions 
(Merriam, 2009). Through examination of select artifacts such as institutional websites, print and online promotional material, and public policy documents, I uncovered the explicit and implicit "norms, values, practices, beliefs and assumptions" (Kuh \& Whitt, 1988; p. 12) that undergird the institution.

Finally, the current study incorporated naturalistic observation of organizational life at Performance (Patton, 2002). During preliminary site visits, I determined public campus locations that are ideal for making observations relating to student behavior and organizational culture. Consistent with robust observational research, I took stock of the physical setting, the actors who occupied the space, the activities and interactions among the actors, public conversation, and nonverbal communication (Patton, 2002). Public campus locations ideal for observing student life within the case study institution included the student union, the dining center, the hallways of academic buildings, and the entrances to administrative and service areas. In addition to observing human behavior, I observed the architecture and physical plant of Performance, inferring how the form and function of physical space and the condition of the facilities might relate to institutional values that are the essence of organizational culture.

\section{Analysis of Evidence}

Data analysis within the current study involved thorough within- and betweenparticipant analysis of survey responses and interview transcripts in addition to reviewing observational field notes. This analysis incorporated a constant comparative approach in which I interpreted survey, interview and observation data as it was collected, revisited data over time, and re-imagined what data meant as new concepts and relationships emerged (Glaser \& Strauss, 1967). 
Data analysis in the current study began with the open coding of survey responses, interview transcripts and observational field notes. During opening coding, I distilled, examined, compared and conceptualized the raw data in order to develop an initial impression of the evidence (Corbin \& Strauss, 2007). Through careful review of survey results, interview transcripts and observational field notes, I generated conceptual labels to characterize the data. As conceptual labels emerged, I moved to axial coding, in which labels were grouped into related categories (Corbin \& Strauss, 2007). In the current study, data labels generated during open coding were compared, and similar labels were grouped into working categories. As categories emerged, I sought linkages between the constructs (Merriam, 2009). Ultimately, categories were linked in a conceptual model that addressed the research questions and offered an explanation for how first-generation students' experience of organizational culture influenced their degree completion within their institutional context.

\section{Ensuring Trustworthiness of Evidence}

Threats to trustworthiness are inherent within all forms of research. One such threat, researcher bias, involves a researcher approaching the study with a predisposition for what he or she will find. As an administrator in Performance University's Office of Student Success for over seven years (a tenure that concluded three years prior to data collection), I was acutely cognizant of my potential for researcher bias. During my years at Performance, I forged distinctive impressions of the culture and developed suppositions about how this culture might be perceived by students. Furthermore, I encountered many first-generation students, forming beliefs and feelings about their precollege experiences and their post-matriculations trials and triumphs. In order to mitigate 
researcher bias, I employed reflexivity, consciously reflecting on my biased view of Performance and bracketing these biases before approaching formal study (Johnson, 1997). Specifically, I isolated my preconceived notions relating to the university's culture and values, focusing instead on the participants' account of their pre- and postmatriculation experiences and their interpretations of Performance University.

Another threat to trustworthiness includes threat to interpretive validity, or the accuracy with which the researcher portrays the meaning of the participant (Johnson, 1997). To curtail threats to interpretative validity in the current study, I sought participant feedback after each interview session through the process of member checking (Merriam, 2009). That is, I sought clarification of meaning from the participants after the interview sessions, employing reflective statements to check understanding of participant responses (Dana et al., 1992).

A third threat to trustworthiness includes threats to internal validity, or how closely the research findings match the reality of the research context (Johnson, 1997). In order to limit threats to internal validity, the current study employed data triangulation by examining multiple types of evidence (i.e., comparing observations gleaned from interview and survey responses with those gleaned from document analysis and naturalistic observation).

External validity refers to the degree to which the findings of one study can be applied to another situation (Merriam, 2009). Although the goal of case study research is understanding-in-context and not transferability per se, the current study employed what Geertz (1973) coins "thick," or highly descriptive, accounts of research findings. This focus on internal validity increases confidence in my interpretations of the evidence and 
allows the reader to draw plausible conclusions about the experience of others within similar contexts.

In addition to threats to validity, all research strategies include threats to reliability, or the degree to which research findings can be replicated (Merriam, 2009). Since the current study employed a case study research strategy that examined the firstgeneration student experience within a specific institutional context, replication of findings is neither easily obtained nor highly desirable. Instead of focusing on reliability, the study focused on credibility, or the degree that the study's conclusions were consistent with the evidence (Merriam, 2009). In order to attend to credibility, the current study utilized a detailed audit trail of interview memos, field notes, methods, procedures and decisions throughout the research period (Merriam, 2009).

\section{Ethical Safeguards}

The current study's research protocol was submitted to the Institutional Review Board at Illinois State University as well as the IRB board of the case study institution. Survey and interview probes were assessed for potential risks to participants, with an emphasis on crafting questions that did not intentionally elicit strong negative reactions. Prior to their interview session, participants read and signed an informed consent form which detailed - without deception - the purpose of the research, their role within the research, and their right to terminate participation at any time before, during, or after interview sessions (see Appendix E). In addition, all participants were assigned a pseudonym to be utilized in the write-up of results. All participants were assured that their responses were kept confidential, and extra care was exercised to keep audio recordings, field notes and interview transcripts secured for the duration of the data 
collection and analysis periods.

\section{Summary}

This chapter provided an overview of the methodology of the dissertation study. Specifically, this chapter addressed the study's purpose and research questions; case selection and sampling strategies; collection and analysis of evidence; and issues relating to trustworthiness, credibility and ethical safeguarding. What follows are the results of inquiry within the study's research questions relating to participants' pre-college contexts; participants' interpretations of the case institution; and what these interpretations meant for participants' ability to navigate the case institution in pursuit of a degree. 


\section{CHAPTER IV}

\section{FINDINGS}

Closing the first-generation degree completion gap is critical to maintaining economic prosperity and democratic action at the national level; to promoting material success and purposeful living at the individual level; and to ensuring equity and relevance at the institutional level. As colleges and universities seek strategies for retaining firstgeneration students through graduation, a number of theories of student persistence have been offered and examined, including Tinto's (1993) sociological interactionalist theory of student persistence. Though long a dominant model of persistence, many scholars are critical of the interactionalist theory and its application to non-majority populations like first-generation students. Indeed, the interactionalist model lacks explanatory power for first-generations students enrolled at small, private institutions where their continuinggeneration counterparts flourish (Pascarella \& Terenzini, 2005; Lohfink \& Paulsen, 2005). Exploring this paradox, the purpose of this study was to examine first-generation students' experiences of a small, privately-controlled postsecondary environment viewed through unique lenses shaped by external contexts and prior experiences. The study filtered the constructs of Tinto's (1993) interactionalist model (e.g., student entry characteristics; postsecondary goals and commitments; internal and external collegiate environments; and academic and social integration) through the lens of organizational 
culture in the sociological tradition (Kuh \& Whitt, 1988). Specifically, this study addressed three research questions:

1. How do external forces influence first-generation students' experiences of a small, privately controlled institution?

2. How do first-generation students interpret the functional aspects of their institution's culture?

3. What do these interpretations mean for first-generation students' ability to navigate the functional aspects of their institution's culture?

Related to the constructs of student entry characteristics, postsecondary goals and commitments within the interactionalist theory (Tinto, 1993), Research Question \#1 examined how pre-matriculation external forces (e.g., family influences) influenced participants' experiences of "Performance University," a small, privately-controlled, residentially-based university located in the Midwestern town of "Davis" (Performance University, 2015). Research Question \#1 interview questions centered on the critical people and incidents that shaped participants' pre-college lives, while survey questions relating to Research Question \#1 centered on prior educational experiences and family involvement in postsecondary education. Inquiry within Research Question \#1 revealed that the first-generation participants entered college with many of the same externallyderived assets as continuing-generation students, including strong primary and secondary educational experiences and a belief that a postsecondary degree is necessary for success later in life. Similarly, first-generation participants described pre-matriculation challenges common to many college students, including stress derived from a disposition to shyness and immersion within a new environment. While participants cited common 
sources of persistence strength, they also described pre-matriculation assets unique to those who are the first in their families to attend college, including a strong work ethic derived from family members who want more for their children; parental life experiences which served as a foil against which to work; and the support of extended family members. Similarly, participants described challenges unique to first-generation students, including a lack of information about the collegiate experience; hometown peers who worked against persistence; and family members whose lack of familiarity with the collegiate environment meant that they could not translate their support into actionable advocacy.

Related to the construct of the institutional environment within the interactionalist theory (Tinto, 1993), Research Question \#2 explored participants' interpretation of the functional aspects of the Performance culture. Specifically, Research Question \#2 addressed how participants enacted, or made meaning of, their collegiate environment through a process of social construction (Weick, 1988). Survey questions relating to Research Question \#2 consisted of queries about participants' perception of Performance University's physical appearance and their understanding of Performance's explicit cultural values, while interview questions relating to Research Question \#2 centered on participants' interpretation of tangible cultural incidents (e.g., connection to institutional history, participation in ceremonies and traditions) and cultural representations (e.g., connection to the physical campus, symbols, institutional actors). In addition to their experiences of the tangible aspects of Performance's institutional culture, survey and interview questions revealed participants' interpretations of the institution's tacit cultural values and norms. On the whole, participants described largely positive experiences of 
Performance University as the result of the values and norms that they perceived to be emphasized at the institution. Specifically, participants' interpretations of Performance's institutional culture suggested that these first-generation students experienced a sense of care through an emphasis on the value of community; a sense of inclusion through an emphasis on the value of individuality; and a sense of achievement through an emphasis on the value of challenge.

Related to the constructs of academic and social integration within the interactionalist theory (Tinto, 1993), Research Question \#3 explored what participants' interpretations of the Performance culture meant for their desire and ability to navigate their collegiate environment. Survey questions related to Research Question \#3 centered on participants' perception of institutional fit; their view of institutional support; and their intention to persist to degree completion at Performance. Interview probes related to Research Question \#3 centered on participants' socialization within the academic and social communities of Performance; the trials they faced navigating their collegiate experience; and the circumstances and people pivotal to the resolution of their collegiate challenges. Through their experiences of Performance University, participants described being able to accomplish a number of tasks critical to degree persistence, including adjusting to an unfamiliar environment; overcoming social isolation and academic challenge; and finding deeper purpose in collegiate pursuits.

What follows are common themes that emerged as the result of inquiry within the study's research questions. Organized by research question, this chapter presents emergent themes in participants' pre-matriculation influences, cultural interpretations and institutional navigation. The chapter concludes with common themes synthesized into a 
theoretical model of first-generation student persistence at Performance University.

\section{Research Question \#1: External Influences}

Research Question \#1 (i.e., How do external forces influence first-generation students' experiences of a small, privately-controlled institution?) centered on precollege, extra-institutional factors in degree completion. Inquiry within Research Question \#1 revealed that first-generation participants' pre-matriculation influences and extra-institutional contexts (e.g., the entry characteristics, pre-college goals and commitments of the interactionalist theory) contained many of the same strengths and challenges relating to persistence as continuing-generation students' influences and contexts. However, participants' accounts of their pre-matriculation influences and extrainstitutional contexts also contained unique sources of college-going strength, a notion that runs counter to cultural deficit thinking that dominates the discourse on non-majority students. (Valencia, 2010). In addition, participants described pre-matriculation challenges unique to their experiences as the first in their families to attend college. Traditional colleges and universities must acknowledge these unique challenges in order to promote the degree completion of contemporary student populations.

\section{Sources of Strength Common to All Students}

The pre-matriculation influences and extra-institutional contexts described by first-generation participants contained many of the same strengths relating to persistence as those described by continuing-generation students. Indeed, multiple participants cited two sources of college-going strength common to all college students: primary and secondary educational experiences supportive of collegiate attendance and a stronglyheld belief that completing a college degree is necessary for success in the future. 
Positive primary and secondary educational experiences. Pre-college educational experiences are a critical component of student entry characteristics that orient students to future college attendance and achievement (Tinto, 1993). On the whole, participants reported primary and secondary educational environments that promoted the value of collegiate attendance and, in general, prepared students for postsecondary success. Reflecting on their primary school years (i.e., grades K-8), multiple participants described an experience that served as a foundation for later college attendance and success, regardless of whether or not those experiences were in small, rural schools or within large urban or suburban schools. Indeed, more than one participant described the impact of being identified as college-bound by a primary or middle-school teacher. While accounts about the level of college preparation received at the secondary level were more varied across participants, multiple participants described how initiatives like selective enrollment high schools, dual-enrollment courses, and advanced placement courses served them well on their journey to college. Indeed, multiple participants described college preparation as the primary mission of their high school educations. Most critically, nearly all participants described at least one high school teacher or guidance counselor who encouraged them to attend college and provided actionable advocacy in making their collegiate aspirations a reality. From help in discerning a major to assistance with writing entrance essays, participants described personal influences within their secondary educational experiences that were supportive of future college attendance.

Belief in the necessity of a postsecondary degree. In addition to primary and secondary educational influences that strengthened postsecondary goals and 
commitments, first-generation participants described a belief in the necessity of a postsecondary degree that is common among all students. Participants' conception of "the good life" centered on a professional-class job with higher earning potential, and without exception, participants perceived a college degree as their primary chance at "the good life." This belief in the necessity of a college degree was emphasized in the home, with more than one participant describing pursuing a postsecondary credential as something that was not framed as a choice by parents and extended family. Moreover, multiple participants who were perceived as "smart" early in their educational careers reported feeling the inevitability of college attendance more poignantly, even when the thought of attending a college or university felt daunting. In their strong advocacy for attending college, family members of participants often employed the economic argument that attending college is necessary for economic stability in a rapidly changing, technology-driven world.

As a whole, first-generation participants described multiple external sources of support for degree persistence that mirrored the pre-matriculation, extra-institutional influences of other student segments. As is common across all student segments, participants described pre-matriculation educational experiences that were largely supportive of college-going as well as home environments in which a postsecondary degree was framed as the key to a better future. As a result of these influences, participants' postsecondary goals and commitment were bolstered.

\section{Sources of Strength Unique to First-Generation Participants}

Overall, the first-generation participants revealed unique sources of strength inherent within their entry characteristics and their postsecondary goals and commitments 
(Tinto, 1993). These strengths included pride at being the first in their family to attend college; a strong work ethic gleaned from parents who wanted better for their children; parental and sibling experiences that served as foils against which to work; and the support of extended family members who were intimately involved in participants' postsecondary pursuits.

First-generation status as a source of pride. Far from embarrassed at being the first in their families to attend college, several participants cited their first-generation status as a source of motivation to persist. For example, Saki related with pride her decision to earn a degree as a way to fulfill the unrealized dreams of her parents: [My father] didn't get a chance to even finish high school; he had to drop out in order to go to work. He worked at the Daily News. My dad worked there for 30 years; he basically went straight there when he got out of high school. He was telling me about his experience; he dropped out and went to go work there. He always told me he wished he had finished school and gone to college. He even went so far as to say he felt less intelligent because of that, and I always felt really sad about that ... I understand why he did it [didn't finish high school], and I kind of wish that I could make him feel better. I said, I'm going to do this [college] for you, I'm going to do this for me, I'm going to do this for my mom - she died before all of this had happened. I wanted to be the person who came through and actually did things in my family ... I want to be the person that does this and gets through and makes a path for myself.

Similarly, Greg described how being a first-generation student motivated him to continue his studies even though he already knew what he wanted to do when he 
graduated:

A lot of times I want to push school to the backburner, because I know more of where I want to go and what I want to do. But at the same time, I want to get the degree. It's something my parents didn't get to do, and something I've always wanted to say that I've done.

As a group, participants described postsecondary goals and commitments that were shaped by their pride in the being the first in their families to attend college and by their desire to honor the wishes of their family. This pride and desire were critical antecedents to persistence behavior, providing motivation for participants to engage in the academic and social activities that were necessary for collegiate success within their institutional environment.

Strong work ethic. While each participant was raised within a distinctive family context, a common theme emerged across multiple participants: a strong work ethic. The value of hard work was particularly salient among those participants whose parents emigrated to the U.S. and started their own businesses. For example, Justin described how observing his Polish-born mother's work ethic shaped his childhood:

[Mom] worked very hard. She's not from this country. She came [to the U.S., from Poland] when she was 16. Now, we're at this point where I see her working day in and day out. She owns a small cleaning company in [large metropolitan city], and to go from one place to another, no college degree, that kind of thing, was very large and impactful.

A family context dominated by the value of hard work had consequences for participants' ability to confront the challenges of completing a postsecondary degree. 
Indeed, Clarissa explicitly stated how being raised with a strong work ethic prepared her for the realities of college:

[I feel prepared for collegiate challenges] because my parents both have great work ethics, and I was raised to have realistic expectations of the world.

The strong work ethic instilled in these first-generation students by their parents was a valuable resource in overcoming the inevitable trials of completing a college degree. Moreover, the realization that the back-breaking efforts of their parents might be avoided by obtaining a degree served as a powerful motivator to persist.

Parental experiences as a foil. Related to their observation of the extraordinary amount of work required of those without a college degree, participants described utilizing the life experiences of their parents and older siblings as a foil against which to work and as a catalyst for deciding to attend college. Indeed, the desire to avoid the fate of their parents was a powerful factor in many participants' decision to pursue a degree. For some participants, the desire to avoid the struggles of their parents by attending college was gleaned by personal observation coupled with indirect edicts and unspoken understanding between them and their family members. Nan recalled how observing her father work and hearing him lament about his lack of education prompted her to want a different life for herself:

[My father] works so hard, like 24/7. I hardly even see him. Kind of growing up, he always emphasized how much an education would have done for him, how much work he could have - not skipped over, but it would have been a different type of work, not so physical and draining.

Likewise, Beth described observing her parents' struggles and absorbing her parents' 
advice about pursing a college degree:

I've seen them [parents] going through their own job struggles with the economy and whatnot, and with other restrictions on employment. I would see it first hand, but my dad would just remind me, you're going to go to college, you're going to get a degree, you're smart, this is what you're going to do.

Other participants reported blunt warnings from their parents to avoid their mistakes and pursue a college degree. Asia recalled:

[My mom] pretty much said, you don't want to have a life like me, so you need to go to college.

Likewise, Karen described explicit statements from her parents about wanting a better life for her than they endured:

My parents always said that they want more for me, and that they know I can achieve more than they did, so they really wanted me to go to school, and they believed in me that much.

Plainly, some participants framed their decision to attend college as a reaction to their parents' lack of postsecondary education, either through direct observation of parental working conditions, consistent reminders about how lack of a college degree impacted their parents' lives, or explicit pleas from parents who wanted something better for their children than they experienced. In this way, first-generation status for these participants was an asset in fostering degree completion.

Supportive extended family. Similar to the influence of parents on postsecondary goals and commitments, the first-generation participants described the positive influence of non-parental family members, namely siblings and grandparents. 
When speaking of older siblings who also attended college, participants described models - and in some cases, foils - for persistence. For example, Clarissas' older sister provided early exposure to college life while serving as a foil for what not to do with regard to selection of an institution and an area of study:

Most of the time I relied on [college] advice from teachers or my older sister. I learned quite a bit from her experiences, as she attended a four-year university (engineering program) through her sophomore year before deciding to transfer into a nursing school and live at home. She liked her undergrad, but the decision ultimately came down to not liking her major.

Similarly, Sara described how her sister's selection of a university provided her with an example of the type of institution that is not for her:

I didn't learn a whole lot about college until my sister went a year before I did, and all I knew were there were small hallways and lots of rooms and one bathroom to share among everybody on the floor. Big Box University [where older sister attends] is so big, and I just knew that I didn't want to go, because I'm ... small town. Not really into the whole super large campus, not really knowing a lot of people, large class sizes.

In addition to siblings, multiple participants spoke of grandparents who provided significant support for collegiate attendance. Susan described a strong grandfather who served as a model for professional success and who preached the necessity of attending college in today's economy:

[My grandfather] is very strict, and he [made it known that], you are going to college, you don't have a choice. He worked at Blue Cow Dairy for 35 years in 
sales and marketing, so it was a big thing to watch him growing up. Don't tell him this, but I was like, I'll follow in his footsteps. I ended up loving it. His big thing [about insisting she attend college] is, that's the way the world is going. Back in his day, you could just go in [to a job] and they would take you on your honor and merit, stuff like that. But nowadays, if you don't have a degree, you can't even get your foot in the door ... I was six years old and my grandfather told me I was going to be a lawyer and make him lots of money and build him a house [laughs]. That's still kind of the theory he has, [that] I'm going to build him a house.

Similarly, Janelle described a grandfather who, after a lifetime of wanting his granddaughter to attend college, was able to make this desire a reality in his passing: [Attending college] was always in the back of my mind, it's just financially I wasn't sure it could happen. But it was a for sure thing after my grandpa passed, because I knew that's what he would have wanted, and he would have wanted whatever I would have wanted too. His mentality was, no pain no gain. You either try, and if you try your hardest, and if it's not going so well, you still try until you can't try anymore. So, I was going to try to figure out any way to go to college, and so was my mom, and then [grandpa] also offered me some money. And I wanted to do it because I wanted to make myself proud and my family, especially my grandpa, even after he passed.

In summary, participants described siblings and grandparents who served as positive non-parental influences for college persistence. On one hand, siblings' collegiate experiences served as foils for participants, modeling collegiate "mistakes" that 
participants were resigned not to make. On the other hand, grandparents served as cheerleaders, providing strong motivation to attend college while, in some cases, providing the financial means to make attendance a reality.

\section{Areas of Challenge Common to All Students}

Much like externally-based sources of strength common to many student segments, the first-generation participants related elements and experiences within their pre-matriculation environments that have the potential to hinder all students' success. These elements included a dispositional orientation to shyness; inconsistent college preparation at the primary and secondary level; and "culture shock" as the result of attending college in a new geographical environment.

Shyness. Dispositional influences are an importance component of student entry characteristics within the interactionalist model (Tinto, 1993). A number of participants described themselves as shy, some to the point of social paralysis. For these participants, their initial days on campus, where they were forced to interact with a barrage of new people and situations, were particularly difficult. Most often, these participants cited participation in Performance's highly structured, highly social "First Week" programming as their key to overcoming their shyness and fully embracing their collegiate experience.

Inconsistent college preparation. Like dispositional influences, prior educational experiences are critical parts of student entry characteristics within the interactionalist model (Tinto, 1993). Like other student segments, the first-generation participants' perception of college readiness efforts within their high school was varied. While some participants described secondary educational experiences that prepared them 
for postsecondary success, others reported a lack of preparation in core subjects like writing composition, mathematics and the sciences. Others spoke of lack of preparation within areas that would ultimately become their academic majors, like fine arts. Most critically, some participants described educational experiences that neither exposed them to collegiate challenge nor groomed them in the study habits necessary for collegiate success. This lack of consistency in pre-college preparation presents challenges to all students and to institutions like Performance concerned about degree completion.

Geographical challenges. Like pre-college educational contexts, geographical contexts (i.e., the physical and social characteristics of one's home town) are important characteristics that can influence degree completion (Tinto, 1993). As with other student populations, the geographical contexts from which the first-generation participants hailed framed their Performance experience in ways that challenged degree completion. For participants from rural areas, life at Performance provided exposure to people whom they perceived to be well-traveled and highly cultured. More critically, life at Performance for rural participants provided exposure to diverse populations like non-White and LGBT students with whom they had limited previous exposure. For participants from urban areas, life at Performance provided a provincial setting that emphasized personal relationships within small groups, a notion that may seemed both foreign and daunting to those hailing from bustling metropolitan areas. And for participants hailing from the Performance University area, life at Performance was lived within the safety and tranquility of the "PerformaBubble" that seemed wholly separate from the grittier, more dangerous hometown with which they are familiar. Regardless of the geographic context from which they hailed, adjusting to life on the Performance campus presented new 
challenges which first-generation students, like all students, were forced to overcome.

As a group, first-generation participants described multiple external challenges to degree persistence that mirror the challenges of other student segments. As is common among many new college students, multiple participants described a predisposition to shyness that made their initial days at Performance particularly difficult. Furthermore, some participants related secondary educational experience that did not prepare them well for the realities of college. Finally, participants described challenges originating from their need to adjust to a university environment that differed from the geographic area from which they had hailed. These commonly cited elements of the external environment present challenges to the broad swath of students who share them and to colleges and universities like Performance that seek improvement in their completion rates.

\section{Areas of Challenge Unique to First-Generation Participants}

Even as participants cited pre-college obstacles that cut across all student segments, they revealed collegiate challenges in their pre-college contexts that were unique to their first-generation status. Specifically, being the first in their families to attend college led participants to possess incomplete or inaccurate information relating to college; to experience changing relationships with hometown peers who were unsupportive of collegiate goals; and to describe parents whose unfamiliarity with the collegiate context meant that they were unable to translate their support for completing a degree into actionable advocacy.

Incomplete/inaccurate college information. According to the interactionalist model of student persistence (Tinto, 1993), students' pre-enrollment beliefs about the 
collegiate experience serve as critical precursors to postsecondary goals and

commitments and to academic and social behaviors that can promote or hinder collegiate success. As a group, participants described pre-enrollment beliefs about college that suggested incomplete or inaccurate information about the collegiate experience, thereby problematizing first-generation status within the interactionalist model. Furthermore, in addition to expressing general uncertainty relating to college, participants described inaccurate beliefs about college affordability as the result of being the first in their families to pursue postsecondary education. Absent exemplars within their home cultures, participants drew from media-fueled stereotypes of the college experience. As a whole, participants admitted to knowing little about college life before enrolling at Performance University as the result of being the first in their family to attend college. Even participants like Chloe, who had an older sibling who attended college and who reported high quality secondary education experiences, cited a collegiate knowledge gap as the result of her first-generation status:

I knew a little. My sister went to college for about a year and a half, but she dropped out. So I had been on a college campus before and kind of seen it. And I took dual-credit classes in high school, so I sort of knew what the workload was going to be going in. So I guess I was semi-prepared just based on that. But I didn't really know a lot about the campus life and things like that.

In addition to feeling unprepared with regard to what to expect from their college experience, a number of participants reported a pre-enrollment belief that attending college was a costly endeavor. This belief was exacerbated for this population by lack of credible information about college affordability. For example, Janelle cited a belief in the 
long-term financial burden of college based not on intimate knowledge of the process, but on casual perception of her high school teachers:

I knew that [college] is expensive, and based on my teachers in high school, some of them were still paying their debt off, and they were like 40, 50, some of them. I knew that would be tough on me. I knew that scholarships were out there, but that they're also really tough to find and get unless you're really motivated and dedicated to finding them, and even then [it is] still hard because there's a lot of competition.

In addition to believing that college was expensive, some participants reported a pre-enrollment belief that the college experience was dominated by fun and socializing. This pre-matriculation belief in "college as a party" was based largely on stereotypes presented in the media, a critical source of postsecondary information for first-generation students who received limited instruction on the college experience in the home. For example, Karen reported a belief in the dominance of fraternities and sororities on campus that was fueled by college-themed movies:

I heard a lot about Greek life, and that sounded fun. I also knew a lot about movies and stuff like that, so anything you could see in a stereotypical college movie, I knew.

Likewise, Susan revealed a belief in "college as a party" dominated by media stereotypes, and it was her desire to avoid this atmosphere that drew her to a small institution like Performance:

The only thing I heard was through TV, like partying all the time, which I was like, that's not me. So, maybe I'll try a smaller school or something like that. 
Pre-enrollment beliefs about college were important precursors to participants' collegiate experience. As the first members of their families to attend college, participants reported unique challenges related to incomplete and inaccurate information about the postsecondary experience. Specifically, participants' pre-matriculation perceptions of college life as a mysterious and costly party cast their looming collegiate years in an uncertain and inaccurate light, with potentially negative implications for future persistence behavior.

Strain in relationships with hometown peers. The influence of hometown peers is an aspect of student entry characteristics that may influence degree completion (Tinto, 1993). In contrast to the supportive influence of family members, the firstgeneration participants described hometown peers that were less than supportive of their collegiate endeavors. For example, multiple participants related the differences that became apparent as they immersed themselves in their college experience and left their hometown friends behind. As Nan engaged with new peers and new activities at Performance, she discovered that she and her friends back home no longer shared the same values:

[Home town] friends, I feel like I just really didn’t have similar values. We're just very different. I've had to explain my interests, like my international interests. I really like volunteering, and they don't. They're like, why would you want to volunteer? Here [at Performance], my best friends encourage me to do things like that, encourage me to travel. I feel like I have a lot more in common with them.

Similarly, Susan described coming to realize how different her hometown friends' socio- 
economic situations really were from her own situation after spending time at Performance:

I feel like my back home friends didn't have as hard of a life. I went to a private school, and stereotypically you just don't have that hard knocks life. They were more just like normal people ... Carina [an on-campus friend] and I are on the same level, so I connect with [on-campus friends] in very different ways. Multiple participants articulated a desire to isolate themselves from their hometown and hometown peers who did not pursue postsecondary education. Saki explicitly stated that separating herself from the friends she made in high school felt necessary, even though it was difficult:

Most of my friends in high school, I don't talk to any of them anymore because I've distanced myself for far from my home town ... I guess it's kind of heartbreaking, because we were friends for so many years. But it's part of growing up, sadly.

Like Saki, Beth saw separating herself from hometown friends as a necessary part of personal growth during college years, citing the maturity level of her hometown peers as the reason she chose to separate:

Maintaining home friends, that's been difficult. Everyone makes their own friends at college, so I kind of left all that behind because a lot of them were immature. I felt like I didn't need that anymore, and I wanted to grow and become my own person. So I kind of took advantage of this opportunity - maybe a little too much - and kind of abandoned what I left behind. You just figure out who your real friends are. They always say you'll come back and be with them 
again, but I don't think so, because I've matured in different ways. So, I don't really miss the people back home, even though I was so infatuated with friends back in high school. But now it's just like, I'm my own person now, I'm an individual, and it's great. I love it where I'm at right now.

Indeed, Karen described selecting Performance in part as a way to separate herself from her hometown peers:

I chose a school that no one from [her high school] had gone to in the last ten years because I didn't want to see any of them for a long time ... some distance. In addition to the tension with hometown friends who did not share their collegiate aspirations, a number of participants described hometown peers who held negative perceptions of "Davis," the town in which Performance was located. For example, Clarissa recalled hometown friends who were incredulous of her decision to attend Performance and live in Davis:

I was excited to get here, but then there was also the Davis thing. If I said [that I was going to] Performance, [home town people] would say, but what about Davis?

Negative impressions of Davis were even evident among the hometown peers of participants who hailed from the Davis area. Susan's hometown friends (who were Davis residents themselves) offered two common, yet competing, negative characterizations of life in Davis: unsafe and unexciting:

[My friends] are like, don't you worry about getting shot? [laughs]. It's not a very good neighborhood. My [family/friends] are all like, why are you staying in town? Why are you going to Performance, it's so boring, nothing ever happens, 
it's such a small little school. Not very good things I guess ... A lot of people worry about Performance just because of Davis. Davis doesn't have the best stats or record. People just talk it down, talk it down.

Finally, some participants described hometown peers who held a negative view of Performance as an artsy environment with a strange, quirky vibe. Clarissa described her hometown friends' view of Performance as focused on the interest of fine arts students, an experience that, as a Business major, she did not share:

Anytime I've ever had family or anybody visit campus, I feel like they've only ever really noticed the Theatre students. A lot of times when they're describing it, they'll call it artsy or something, which is weird because I'm a Business student, and that doesn't describe my experience at all.

In contrast to the overall supportive influence of family members, participants described the chilling effect of hometown peers on persistence behavior. As the result of separation from hometown friends and immersion within a new environment, participants spoke of discovering differences between themselves and their hometown friends. This, coupled with these friends' generally negative perceptions of Performance, lead some participants to seek separation from their hometown peers. Some participants even reported hometown friends who, upon engagement with Performance, held perceptions of the university as strange or held perceptions that were inconsistent with the participants' experience of the institution. In these ways, the sum result of hometown peers' influence on these participants' institutional experiences was detrimental to persistence.

Lack of actionable advocacy from supportive parents. Parental involvement in the educational life of traditionally-aged students is a critical component of 
matriculating students' pre-college entry characteristics (Tinto, 1993). While the parents of the first-generation participants voiced ubiquitous support for postsecondary attendance, their lack of familiarity with the collegiate context prevented them from translating this support into actionable advocacy. For example, in their accounts of their decision to attend Performance University, participants described a choice made largely on their own and parents who, lacking exposure to the postsecondary landscape and, in some cases, the means contribute financially, were left to trust in their children's instincts. Tom described his solitary decision to attend Performance:

My family let me decide where I went to college, mainly because it was my education and I would be paying for it. They supported me in whatever college I looked at and are very happy with my choice.

The majority of participants spoke of parents who were supportive of their children's decision to attend Performance. In large part, this support for participants' choice of institution stemmed from their parents' view of Performance as an educational environment with which they were familiar. In particular, participants who attended small high schools reported strong parental support of Performance because it seemed like high school. Asked how his parents would characterize Performance, George described a view of the university as a context with which his father was personally familiar:

[Parents would characterize Performance as] small, tight-knit, small community. I also went to a small [high] school with like 300 kids. My dad went to the same school when he was younger. It's something we're both familiar with.

Much like the decision to attend Performance, the bulk of participants described 
parents who, although supportive of their children's desire to complete a postsecondary degree, were unfamiliar with the college experience and, as a result, were unsure how to assist. For example, Cassie pointed to parents who pushed for continued higher education without an understanding of the challenges of being a college student: My family is pushing for me to continue my education in some form, whether that's in [graduate] school or getting a minor, but they don't know a whole lot about how I spend my current time as a student. I'm burnt out by the idea of papers and tests and taking notes. They want me to do more education, but they don't really know how exhausted I am by the idea of more school.

Similarly, Clarissa described parents whose assistance was largely emotional as opposed to functional and whose understanding of her experiences was limited:

They are supportive, but never really involved in the academic side of anything. I have taken on much of the responsibilities myself as far as figuring out my class schedule, housing, and really all of the little details that I notice some of my peers get help from their parents on, but that's not really a huge deal for me. More than anything, my parents and family have provided me with emotional support throughout my academic career. Whenever I am facing difficulties, they help talk me though it and remind me that I just need to do what makes me happy. Even though they don't understand all of my decisions (I'm graduating with an accounting degree but applying to grad schools for Student Affairs), they trust that I'm making decisions that will lead me to the right place.

Tom specifically acknowledged how his parents' lack of postsecondary influence limited their ability to provide more than emotional support: 
My family doesn't really play a role in my education, besides making sure everything is going ok. They have never sent a kid to college before so I don't believe they really know how to handle this situation other than just to make sure I have everything I need and am doing everything I need to be doing to graduate. As a group, participants related an interesting paradox: full-throated parental support for the decision to earn a degree at Performance University (an institution whose small size evoked the feel of high school environment with which they were familiar) minus the ability to provide substantive assistance in this effort. It was in this space where the participants' first-generation status was most poignant, with parents who strongly supported their children's collegiate effort but, due to their own lack of experience with the collegiate context, did not know the best way to leverage this support into specific and actionable advocacy.

\section{Summary}

Interview and survey questions relating to Research Question \#1 centered on the pre-college, extra-institutional forces (e.g., family and hometown contexts, prior educational experiences) of the study's first-generation participants. Inquiry within Research Question \#1 revealed that while participants' external influences contained some of the same sources of strength as other student segments, including high quality primary and secondary experiences and a strongly held belief in the necessity of a postsecondary degree, they also contained strength unique to the first-generation population that run counter to the cultural deficit discourse that surrounds these students' home cultures (Valencia, 2010; Tierney, 1999). Specifically, the participants cited their status as a first-generation as a source of pride, a strong work ethic instilled by parents 
who wanted more for their children and whose experiences served as a foil against which to work, and involved extended family members as sources of support for college-going.

While the first-generation participants cited a plethora of external assets in their journey to complete a college degree, they also cited a number of challenges external to their Performance experience. Although challenges such as a predisposition to shyness; inconsistent college preparation in high school; and adjustment to a new geographical setting were common to all students, some challenges were unique to a first-generation population, including incomplete and/or inaccurate college information; strained relationships with hometown peers; and a lack of actionable advocacy from parents who were unfamiliar with the postsecondary landscape. Clearly, college and universities concerned with the success of their first-generation students must leverage the assets inherent in these students' external influences while addressing the unique trials of those who are the first in their families to attend college.

\section{Research Question \#2: Interpretations of Institutional Culture}

Related to the construct of the institutional environment within Tinto's (1993) interactionalist theory of student persistence, inquiry within Research Question \#2 (i.e., How do first-generation students interpret the functional aspects of their institution's culture?) centered on how the first-generation participants - shaped by the assets and obstacles in their pre-college contexts described above - experienced the institutional culture of Performance University. On the whole, participants' interpretations of the cultural forms, institutional subcultures and shared values of Performance suggested that the first-generation participants experienced a sense of care through an emphasis on the value of community; a sense of inclusion through an emphasis on the value of 
individuality; and a sense of achievement through an emphasis on the value of challenge.

\section{Care through the Value of Community}

The bulk of participants described the importance of community and communitybuilding that they perceived to permeate Performance University. On the whole, participants gleaned the importance of community and community-building through their observations during their initial campus visit; through their participation in Performance's traditions and ceremonies; through their interpretations of institutional symbols; and through their perception of Performance faculty and staff. As a result of this discernment of the value of community, participants experienced a sense of care for their well-being at Performance.

Value of community within campus visit. Participants interpreted an emphasis on the value of community almost immediately during their initial campus visit. While referencing the beauty of the physical campus, most participants cited the importance of the human element of their campus visit, most saliently their experiences of a community of care. Invoking the metaphor of home, Saki described how the type of people that she encountered during her tour of Performance's main administrative and class building made her feel like she was coming home:

I knew I wanted to attend Performance when I was touring Sawyer Hall ... So many people were coming up to me, talking to me, making me feel welcome, trying to direct me toward programs, telling me about the university and just being so open about their experiences here. Everyone was so kind, and I come from a place where that isn't as common, so I was really floored. I knew that his was going to be my home. I just felt welcome. 
Value of community within traditions and ceremonies. In describing their experiences of Performance traditions and ceremonies, participants invoked an institutional emphasis on community through their observation of mass participation and community-building efforts within these events. For example, Tom described his perception of the "Beer Games", an unsanctioned Performance event that drew not only a large number of current and former Performance students but also students from neighboring institutions:

People from other schools come here, they will come here and visit [for the Beer Games]. It's weird that people like that would come here to Performance when they go to a Division I school. But that's just something every year that happens that most people on campus come to unless you're like in Greek Life or some sports events.

In addition, the Candlelight Ceremony during First Week orientation represented the value of community-in-action for multiple participants. Janelle described the community-building focus of this ceremony:

As we walked, there were candles on the sides and we could hear singing ... All you see are all the candles from [the fine arts center] all the way to the quad, and then when you get to the quad, there are the upperclassmen with candles. You'll see some people who help that are faculty. They were singing a song that basically makes you feel welcomed, and it was very touching and uplifting and welcoming ... It felt like the moment that the school made it known that you're a Performance student, you're welcome here.

Similarly, the Candlelight Ceremony fostered a sense of connection to the Performance 
community for Jordan:

You felt like everybody was connected, like it was something intangible that connected PU. It was, I'd say, the most beautiful thing I've ever experienced. Clearly, participants discerned an institution-wide emphasis on community and community-building through their participation in Performance's traditions and ceremonies.

Value of community within institutional symbols. In addition to discerning institutional values relating to community within Performance traditions and ceremonies, participants also perceived the values of community and care for community members within common university symbols. For example, the Performance Homestead, a picturesque plot of land and Victorian-style home adjacent to the central campus, was representative of the value of community to Justin:

[The Performance Homestead] is not just the Homestead, but it's what it means if you maybe look at it a little deeper. It's this preserved plot of land. You look at the architecture, and the feel you get from the place, it's obviously very old. That's what you get from Performance: this is a stable community that has been here for a while, and there's this close-knit feeling that I know personally you don't see a lot in the city.

Similarly, the "Green Roll," Performance's ambiguous athletic mascot, represented the value of community to Beth:

To me, Green Roll is the community that I'm in. It's the spirit, the love of Performance.

Coupled with their experience of institutional traditions and ceremonies, 
institutional symbols like the Performance Homestead and the Green Roll mascot personified the tacit values of community and care for community members among the participants.

Value of community within faculty and staff. While discernment of cultural values within activities and artifacts was consistent across participants, the most commonly cited examples of the values of community and community-building at Performance University were faculty and staff. As a group, participants reported that Performance faculty demonstrated care for their students both inside and outside of the classroom. Jordan characterized this sense of community as a bond:

I feel a close bond with all my professors when I ask them for assistance in something to with class.

Similarly, Susan described the caring relationships that she built with faculty and staff in the School of Business:

I have formed great relationships with the dean and my professors. They have made sure that I will be ready to take on the world when I graduate.

Most clearly, participants articulated their view of the importance of community and community-building at Performance in their descriptions of the person most representative of the university. For example, multiple participants cited the Director of the Center for Inclusion \& Engagement as the ideal representative of Performance. To Beth, it is the value that the director placed on fostering a sense of community that made her a shining example of Performance:

I appreciate it so much that this woman has taken the time to get to know every single student on campus. She has attempted to learn every name, to discover 
who they are as people, where they come from.

Experiencing care through community. Ultimately, participants' perceptions of the value of community and care for community members in institutional experiences like the campus visit, in institutional forms like traditions and ceremonies, and in institutional members like faculty and staff facilitated an overall experience of care. Often, participants articulated their experiences of care at Performance by utilizing the metaphors of "home" or "family" to describe the institution. Beth incorporated both of these metaphors within her description of the Performance community:

The Performance community has an unbreakable bond - we are a family from the first day of orientation all the way past graduation ... Performance is my home and always will be.

For Janelle, the parallel between her Performance experience and the experience of being in a family extended not just to the positive aspects, but also to more difficult family dynamics:

[Performance is] like a family, and with that I mean exactly like a family.

Sometimes you may get upset, but the professors do try their best to help you.

Likewise, Saki's view of the Performance culture as a family included a sense of family loyalty even as she perceived the university's imperfections:

I love Performance. There are obviously problems, like there are going to be at any institution. But it's my home.

To articulate her experience of care at Performance, Beth invoked a term utilized across many of the participants: the "PerformaBubble":

Performance is a place of love and community. The staff and faculty are some of 
the most caring people ... This is the PerformaBubble: it's a heartwarming sensation you get when you talk to faculty who care about you.

Ensconced within the confines of the "PeformaBubble" - where the values of community and community-building permeated institutional experiences, artifacts and members participants discerned a sensation of care.

\section{Inclusion through the Value of Individuality}

In addition to community and community-building, participants described an emphasis on the value of individuality at Performance. Specifically, participants discerned the institutional value of individuality through their immersion in the student subculture and through their interpretation of institutional symbols. As the result of this discernment of the institutional value of individuality, participants experienced a sense of inclusion within the Performance community.

Value of individuality in student subculture. On the whole, participants perceived a student body that was proudly heterogeneous. For Beth, this individuality was rooted in representation from a host of demographic groups:

Performance represents uniqueness and diversity. Almost every culture, ethnicity, gender, sexual orientation, etc. is represented here at Performance. Ironically, the population is tiny. However, everyone gets to experience one another on a daily basis.

Janelle expanded the notion of individuality in the Performance student body to include distinctiveness in personal passions:

Everyone on campus is different. To be honest, there are some [Performance students] really passionate about what they want to do or believe in, and then 
there are some still trying to figure themselves out. Also, there are some who are not stressed about becoming something or someone but going through the college experience and trying things out to find their way. Everyone is different personality-wise, with some similarities.

Indeed, for Karen, a rejection of conformity and a commitment to individuality was the very definition of what it meant to be a Performance student:

I think the definition of a Performance student is one person who doesn't have a group; they fit in anywhere and everywhere. I think that type of person is a genuine Performance student because one person at this school can branch out to all of the different departments and have friends everyone. There's no stereotype. It's like, the more different you are, the more Performance you are. It's kind of backwards. It's important to stand out here.

Clearly, participants perceived rejecting conformity and embracing individual differences to be dominant values within the Performance student body.

Value of individuality within institutional symbols. Multiple participants cited qualities of institutional symbols that suggested that the value of individuality extended beyond the student body to the broader Performance community. For example, Susan described her view of the unique nature of two Performance symbols: a stone "P" statue situated outside of the main administrative building and her favorite faculty member and administrator:

[Stone "P" statue] represents Performance to me because it's always there and it's unique - you don't see a giant stone "P" anywhere. The other symbols are [business professor] and [dean of School of Business]. They are very 
professional. They do their jobs, but they also have something quirky about them. [The dean] has a tattoo and [the faculty member] has purple hair. They're just something quirky about them that makes them unique.

In addition, Jordan evoked the unique nature of Performance's athletic mascot, the Green Roll:

We don't have your traditional mascot like an animal or a person. But I think what makes Performance unique is, it's a color... I think it just makes us unique, and it's funny.

This discernment of individuality within institutional symbols indicated that participants perceived the significance of this value within the Performance culture.

Experiencing inclusion through individuality. Ultimately, participants' perceptions of the value of individuality within the student subculture and within institutional symbols fostered an experience of inclusion within the Performance community. Justin characterized his own journey to inclusivity as moving beyond awareness of individual differences to being open to the possibilities that individual differences present:

People [at Performance] are definitely conscious of other's opinions, feelings, thoughts, and overall presence in the classroom and on campus ... There are people from every walk of life possible, and it just kind of opens you up in that respect. For me personally, it was letting go of this need not to have people agree, but [to] have people understand one another.

For participants, this journey from awareness of difference to the experience of inclusion was the result of their experiences of a Performance culture that they perceived to value 
being true to one's self.

\section{Achievement through the Value of Challenge}

Finally, in addition to the values of community and individuality, participants described an overarching emphasis on challenge and personal accountability that dominated their academic experience at Performance University. Participant discerned the value of challenge in their interactions with faculty and, more saliently, in their interactions with the Performance curriculum. For participants, the result of this perception of challenge was an experience of achievement, with implications for continued success at the university.

Value of challenge in faculty interaction. As a group, participants perceived a Performance faculty body that held their students to high standards and expected them to take responsibility for their learning. Chloe perceived Performance faculty members' anticipation of excellence to be challenging yet attainable:

Their standards and expectations are so high and yet so achievable. It's amazing. Similarly, Janelle described the careful balance between challenge and support that she perceived in Performance faculty members:

[Faculty] can be understanding, but at the same time you're becoming more independent and need to take responsibility and ask for help when you need it. I have learned some very valuable life lesson in some of my classes.

Plainly, challenging students with high expectations and supporting their efforts to meet them were central to participants' view of Performance faculty members.

Value of challenge in Performance curriculum. When speaking about curriculum, multiple participants referenced "performance learning" by name. The 
espoused core of a Performance University education and a central feature of its marketing efforts, performance learning is the university's distinctive brand of experiential education (Performance Learning, 2015). For the participants, performance learning was an educational philosophy defined by an emphasis on vocational training; out-of-class, competition-centered learning; and trust in students' ability to meet lofty expectations.

Multiple participants characterized performance learning at Performance as an education that prepared them for the technical aspects of a specific career. Saki cited this vocational focus beginning in the first year of college as one of the reasons she decided to attend Performance:

Performance starts right off with submerging students into the field, which is what drew me to the University in the first place. It makes sure you are preparing yourself for career right off the bat, allowing you to declare a major before you even hit the front door and getting hands on experience even as early as your freshman year.

Likewise, Susan described performance learning as career-specific preparation: Performance offers a hard curriculum and backs it up with real world experiences. Performance learning is a big thing at Performance, and they strive to create an atmosphere that will truly prepare students for their future careers.

Participants characterized performance learning as education that took place largely outside of the traditional classroom setting. Nan described what she perceived to be a unique approach at Performance:

Performance University represents performance learning, which is something that 
not all colleges can provide. Performance also represents the importance of learning outside of the classroom and engaging with your industry prior to graduation.

In addition, participants described performance learning as an experientiallybased education in which learning occurred in the context of action. Chloe described two learning-by-doing activities that she encountered during her time at Performance:

In six months I will have started and run my own business and have the opportunity to continue to do so in the future, as well as intern with a company that could set me up with a job when I graduate.

Moreover, Karen described how the experiential element of performance learning at Performance was particularly beneficial for a first-generation student who, lacking in prior exposure to more academic knowledge, preferred learning through doing at the collegiate level:

Performance learning is my Performance standpoint, I guess. I love that [performance learning], because being first-generation, I'm more hands on. I don't like to sit behind a desk all the time. I like to work with my hands, do what I'm going to be doing, and learn from experience rather than do the desk work. It's just the type of intelligence that I have. Coming in without that school background, it really means a lot to me.

Another distinctive feature of performance learning among participants was education through competitive experiences. This competition-based learning was particularly salient for participants in the School of Business. For example, Nan described a business plan completion during her first year at Performance: 
In the spring [of first college year] we were working on a business plan competition with freshmen. My team won in our class, and we just found out we were going to compete against the other classes and present and everything. We ended up placing second, which wasn't the goal, but I was really happy with that. Like Nan, School of Business student Tom described competition as part of his own major coursework:

One of my classes this semester - Performance Management - we're dealing with a school district to develop a project or plan to help them. We're in two different teams. The winning team, the school's actually going to use [the plan].

For participants, learning at Performance was not simply about performing. Rather, learning was about producing at an exemplary, near-professional level. Brian alluded to this expectation of excellence in a marketing class project based, interestingly, on the promotion of performance learning:

Last semester I took a marketing class and we did a presentation on performance learning. Before taking that class, I wouldn't even know what it was. After taking that class and researching as much as I did, it kind of goes along with the professors wanting you to excel ... The professors want you to excel beyond what you thought you could, I guess that aspect of achieving greater heights.

Even more critical than participants' experiences of high expectations in performance learning was the feeling that Performance faculty trusted in their students' ability to succeed. Tom described this feeling of trust he experienced moving through a performance learning-based curriculum:

Most of my classes last semester and this semester, they put in you in a spot 
where they know you can succeed and they push you ... We are being thrown into situations, and [the faculty] trust you that you're going to put your best into it, that it's going to be the quality that they expect.

As a whole, participants characterized "performance learning" as an experiential philosophy of education marked by a focus on career training, out-of-class learning, competition, and the belief that all students were capable of achieving excellence. Equal parts challenge and support, performance learning bolstered participants' confidence and was appealing to a first-generation population that reported uneven college preparation in their secondary education.

Experiencing achievement through challenge. Ultimately, the emphasis on challenge and personal accountability that participants discerned from their faculty members and from a curriculum grounded in performance learning facilitated an experience of achievement. Specifically, the confidence that Performance faculty demonstrated in participants' abilities and the high quality outcomes that participants produced within near-professional setting fostered a sense of accomplishment. For Chloe, this achievement fueled by challenge was central to her perception of the Performance experience:

That's what I feel like Performance runs on: their faith in students to get things done ... They just throw you in and know you're going to succeed, even if you fail and learn something from it and it translates into something else later on. Plainly, participants' ability to overcome challenge and find achievement had positive implications for their desire and perceived ability to persist at Performance. 


\section{Summary}

Interview and survey questions relating to Research Question \#2 centered on the first-generation participants' interpretations of Performance's institutional culture. The institutional values that participants gleaned through their collective impressions of the campus environment; their shared interpretations of tangible artifacts and events; and their common descriptions of institutional actors and subcultures had significant implications for their success at Performance. Specifically, participants' collective enactment of Performance's institutional culture suggested that these first-generation students experienced a sense of care through an emphasis on the value of community; a sense of inclusion through an emphasis on the value of individuality; and a sense of achievement through an emphasis on the value of challenge.

As a collective, participants articulated a sense of being cared for at Performance through their experience of the values of community and care for community members at the institution. For example, participants cited community and community-building among Performance's institutional values as the result of experiences like a welcoming campus visit, well-attended ceremonies and traditions, meaning-rich institutional symbols, and interaction with warm faculty and staff. The impact of these experiences was embodied in participants" use of "home" and "family" metaphors and in institutional representatives like the Director of the Center for Inclusion and Engagement. This perception of care at Performance had positive implications for degree persistence, creating an environment in which students felt comfortable not only in seeking membership in the academic and social communities of the campus but also in seeking help from institutional members eager to provide assistance. 
Overall, participants expressed feeling as if they were included at Performance as the result of institutional experiences that promoted positive regard for individuality and being true to one's self. This sense of inclusion was bolstered by participants' experiences of a student body that rejected conformity and unique institutional symbols like the Green Roll. The result was a collegiate environment in which students were likely to feel at ease with difference (both their own and their fellow Performance community members') and to feel included in the academic and social life of the campus.

Finally, participants described a sense of achievement as the result of a Performance culture that stressed challenge. For participants, achieving personal excellence at Performance was largely the result of their experiences of faculty members who held them to high standards as well as the challenge-rich elements of a curriculum rooted in performance learning. Cleary, an environment in which students achieved excellence as the result of being challenged to do their best work within a framework of support was an environment in which students were more likely to thrive.

\section{Research Question \#3: Navigation of Institutional Culture}

Related to the constructs of academic and social integration within Tinto's (1993) interactionalist theory of student persistence, inquiry within Research Question \#3 (i.e., What do these interpretations mean for first-generation students' ability to navigate the functional aspects of their institution's culture?) centered on what the first-generation participants' experiences of the Performance culture meant for their desire and ability to navigate the institutional environment. Through their experiences of the Performance culture, participants overcame navigational obstacles critical to degree completion, including adjusting to an unfamiliar environment; overcoming social isolation and 
academic challenge; and finding deeper purpose in their college career.

\section{Adjusting to an Unfamiliar Environment}

On the whole, the first-generation participants described elements of their orientation experience at Performance that helped them adjust to a university context with which they had limited prior exposure. From a sociologically-based organizational culture perspective, understanding how first-generation students navigate their collegiate environments involves examining how they are socialized within their college or university (Kuh \& Whitt, 1988). Individually, participants described disparate orientation experiences that varied in timing, length and content. All native participants were involved in Performance's traditional "First Week" programming, while transfer participants (Asia, Justin, Susan) experienced a shorter, less programmed transfer student orientation. In addition, some participants (Chloe, Janelle) were involved in an extended orientation through Performance's Edge program for academically-underprepared students, while others arrived on campus early as participants in a scholarship program for historically under-represented students (Sara) and the University Honors program (Clarissa). Regardless of the specific context and duration of the orientation program, participants described an orientation experience that was highly structured and focused on acclimation.

Structured time and activity. Collectively, participants described an orientation experience in which their time and activity were planned for them in advance. Some participants like Beth discerned the design behind a highly structured orientation:

They had all these activities for us, introductions, just to keep our minds off the fact that Mommy and Daddy were gone, and that was great. I think the 
psychological aspect of it is very clever, to have something like that, such a strong presence, so that we aren't just sitting in our rooms all emotional and crying, because that's what students do, and it's hard not to do that. During First Week they had us doing all these activities, and we got to know people, and it was just great.

Likewise, Cassie described how keeping busy during First Week kept her from being homesick:

I think the thing I liked about First Week was that it didn't give you a lot of opportunity to be homesick, because everything was on the go, going from this place to that place, always activities. In the moment I liked it.

Not all of the participants had an appreciation for Performance's highly structured orientation schedule. Indeed, some first-generation participants experienced frustration at being forced to participate in strange activities that prevented them from attending to outside obligations. Chloe described a frustrating orientation experience that kept her from what she perceived to be more important tasks:

I came in doing Edge and First Week, and I hated it because I had to take off work, and I'm a workaholic, and we were busy from like 8:00 in the morning until midnight. They wouldn't let us go back to our rooms and sleep. And other people didn't have to be up early, but I was in Edge, so I had to go to class. So that was frustrating.

Moreover, Saki recalled an orientation experience during First Week that was downright stressful:

First Week was pretty stressful here. They basically kind of force you to go 
places with your [First-Year Experience Mentor], and you can't opt out, you have to go ... I don't remember exactly what we did, but I remember there was talking and pairing people up, and trying to get people to talk. At one point I actually got in trouble because I got up and left because I had stuff I needed to do and they were forcing me to sit there with them until like 11:00pm when I had other things I needed to accomplish. I was pretty frustrated that they weren't accommodating at all.

Structured interaction. Similar to the way in which time and activity were structured, participants also perceived their Performance orientation as a period of structured interaction with other new students. For Brian, this required interaction was positive:

[Orientation] was probably a good thing for me, because I was really in my shell and shy at that point.

Janelle had a similar positive view of the structured interaction of Performance's orientation:

The Edge program helps you socialize with people, but I'm very shy. It helped me break out of my shell ... It made me less shy, more independent, and more to the point where my mom would be like, I haven't heard from you.

Other participants, unfamiliar with the collegiality and living-learning focus of a traditional, residentially-based university, found the structured interactions inherent in Performance's orientation programming to be less than positive. Both George and Tom characterized the icebreakers that were a staple of Performance's First Week to be "awkward." For Saki, being forced to interact with new people during orientation was 
distressing given her personal mental health background:

I remember there was talking and pairing people up, and trying to get people to talk. I was very frustrated during First Week, because I was forced to be very introverted in my childhood because of my family situation, so I don't really know how to interact with people very much in crowds. [Crowds] make me very nervous, because I have PTSD, and I get very nervous when I'm in an enclosed space with a crowd of people. I feel like I have to be in a corner looking at everyone. It was very overwhelming. There was a lot of upset during First Week, me breaking down to my First-Year Experience Mentor.

Still, as a whole, participants reported achieving a critical goal of any orientation program: a sense of comfort and belonging on Performance's campus. Jordan described the acclimating effect of First Week:

I loved all of the performances that they took us to at night. I think those helped us get comfortable around the other freshmen and the environment of the school. For Janelle, the orientation to college that she received through her participation in the Edge program was critical to adapting to an academic and social environment that was unsettling to a first-generation student with limited prior exposure:

The Edge program is to help people learn how to adapt to college life and work ... I feel like it's what you need to adapt to college.

Regardless of the specific program, participants as a whole described an orientation process at Performance that provided a solid foundation for future academic and social integration. Though some participants found the structured nature of Performance's orientation activities to be awkward or even frustrating, others found them 
helpful in acclimating new students to a collegiate context with which they have had limited exposure.

\section{Overcoming Social Isolation}

As a group, first-generation participants described initial feelings of isolation that inhibited their social integration within the institution (Tinto, 1993). For Beth, this sense of isolation was a new sensation:

In high school, I was loud, I was very popular. I had lots of friends from different social groups. It was my thing; I didn't belong to one group. I was the class clown and whatnot. I had really peaked in high school ... I got to college and I was quiet, and for the first time, that was something I hadn't experienced ... I just felt so excluded, like I couldn't be myself. And that was something I struggled with: just accepting the fact that I'm starting over here. It's like kindergarten all over again.

On the whole, participants related two strategies for overcoming initial social isolation: focusing on relationship-building and seeking cultural enclaves on campus.

Building relationships. Multiple participants described a concerted effort at relationship-building as central to overcoming social isolation. For example, Sara recalled forming close friendships as the anecdote to her early sense of loneliness: When my parents left that first time, I bawled my eyes out. It's that whole, I'm used to having them around and stuff, and then it's like, oh my god, they're leaving! That lasted awhile, at least all of freshman year. [To overcome it], I developed some of the best friends I could ever ask for.

For Beth, overcoming isolation through peer relationships did not occur until her second 
year, when she was finally open to the notion:

Freshman year, I did not feel like I fit in at all. I was alone, sad and depressed. But, it was my fault because I did not put myself out there. My sophomore year, I came into contact with so many different people and found myself represented in a little piece of everybody.

For participants living on-campus, the focus on relationship-building within their residence halls helped them overcome early social isolation. A self-described shy student, Janelle recounted a transformative residential experience in which the value placed on relationships was clearly intentional:

Everyone on that floor was friendly. I mean, they would have us do constant icebreakers, because [Performance staff] were like, you guys need to know who lives on this floor, and you guys need to feel comfortable talking to each other in the halls ...

The activities we did [were] always fun. It made us cry on certain levels that we didn't even know we could relate on, especially since we're all from different places. My experience living in that building: I loved it ... We didn't have suitestyle [residence hall rooms], so we had the bathroom where all the stalls are next to each other, and all the showers are in that area. It basically forced us to talk to each other in the hallways, say hi, how are you doing? At some point, you ended up knowing everyone on that floor and then you'd know some people on the other floors too.

For Tom, the relationships he forged in his residence hall continued beyond his first year: [My residential experience] was probably one of the best experiences so far at 
Performance. You live around twenty-some people, and you're there 24/7, and you just really get to know people. My whole floor that still goes here, we're still friends. It's a good experience for sure.

Moreover, Nan's positive residential experience during her first year prompted her to seek other relationship-centered experiences at Performance:

Having that close relationship with fifteen or so people was really great. I had a really positive experience, and it also led me to become interested in Greek life and gaining more close relationships.

For some participants, the personal relationships that they forged were central to their decision to persist to degree completion at Performance. When queried as to why she chose to graduate from Performance, Susan cited the benefits she received from her relationships with faculty and administrators in the School of Business:

I have formed great relationships with the dean and my professors. They have made sure I will be ready to take on the world when I graduate. .

Similarly, Tom credited the relationships he developed at Performance as the primary reason he remained on track to graduate:

I am on track to graduate on time, and plan on staying because I have made lots of good relationships with people I care about.

Clearly, building strong relationships with other Performance students and with faculty and staff was critical to overcoming feelings of initial isolation for the participants.

Finding cultural enclaves. Some participants described seeking membership within campus-based student groups as finding cultural enclaves, or student subcultures that embraced values, attitudes and beliefs similar to their own (Kuh \& Love, 2000). For 
example, the cultural enclaves that Tom found were based on shared interests:

I am a part of the Performance football team, and in the business school, which both have a family atmosphere. I get along with both groups of people, and also there are people just like me.

Cassie described how participation in the Unity student group allowed her to connect with students with uncommon, similar beliefs:

I had to go through a sort of interview process and talk about some issues that I would be interested in looking into. It was my first chance to really come out as a Wiccan. Up until then, it was something I was really scared about. This is something that's been a part of my life since I was a little girl ... If this [Unity group] was something I was going to get into, I needed to bare it all and let people know who I am. As scared as I was, people were so cool with it. I remember when we got separated into groups we were supposed to interview each other. The person I was interviewing, it was going great for a while, and I was thinking I wouldn't have to come out with this yet. And then he was like, oh by the way, what's your religious affiliation? And I was like, ok, I'm Wiccan. And he was like, get out, I used to be pagan, shut up! They are kind of different but they have a lot in common. Then I eventually started coming out to the rest of the applicants. Even though not all of them knew about it - the questions devil worship, stuff like that - they were very open to getting the real information and what I had to say about it.

Jordan related how her multicultural sorority became a second family in which she felt she could remain true to her racial and ethnic heritage: 
I finally found an organization where I could fit in with and call my home away from home. That was something I was terrified of: not finding a group or organization that I could join that I could feel was a fit for me. With my sorority, we're not a sorority, we're a sisterhood. We're a very small sorority; we're a multicultural sorority. We're not a cookie cutter sorority, we're very unique and different. That really hit home for me, because I myself am mixed [racially], and didn't feel like I fit in with the better known sororities on campus. I felt, I don't want to be like that! I'm White, Black and Puerto Rican, and I grew up in a very unique environment. To be able to stay true to my culture and who I was, it was very gratifying.

In sum, participants overcame initial feelings of isolation by focusing on relationships with students, faculty and staff at Performance. While relationships forged with the context of residence hall floors and classrooms were beneficial, relationships emerging within the context of cultural enclaves with others who shared interests, beliefs, values and cultural heritage were particularly powerful in helping those who were the first in their families to attend college.

\section{Overcoming Academic Challenges}

In addition to social isolation, participants described the challenges of navigating a new academic environment. While many of these challenges appeared common to all college students on their face, closer examination revealed subtle differences for the firstgeneration participants. For example, multiple participants spoke of problems with time management. While some participants did echo the commonly-cited collegiate challenge of balancing studies with extra-curricular activities, they were more likely to cite 
balancing studies with off-campus obligations relating to work and family. George described the challenges of keeping up with his studies and off-campus responsibilities like work:

[A significant academic challenge is] trying to run and grow my own business while going to school and balancing that. A lot of times I want to push school to the backburner, because I know more of what where I want to go and what I want to do.

Similarly, Kathleen struggled to find breathing room given her school and work demands:

When I'm not here, I'm at work, and when I'm home I'm sleeping. I try to work out my work schedule, and most of the time I have Monday, Wednesday and Friday off, but then I'm also studying. It's really hard to find time to yourself. In addition to challenges relating to time management, participants described entering a world of new customs and a new set of academic expectations. Indeed, multiple participants recalled their initial days and weeks at Performance as a time in which they encountered new academic practices. These practices felt particularly foreign to first-generation participants who had limited prior exposure to the postsecondary environment. For example, Cassie described feeling surprised that Performance classes did not meet every day as they had in high school:

It surprised me that classes were only offered on certain days. At first I was like, I've got these two classes that conflict, and other people were like, no it doesn't, these two classes are on Monday/Wednesday and these two on Tuesday/Thursday. I was like, what? 
Kathleen described being unfamiliar with new writing formats in which she was provided little direction:

Like with formatting, professors want APA, and I grew up with MLA. They are just like, go to this website. I don't know how may points I've missed because I had no idea how to format it.

Sara described her experience with an entirely new educational vernacular:

I didn't know what a syllabus was, and older students in my classes were like, oh syllabus day, and I was like, I don't know what this is!

Unlike the early challenge of social isolation, academic difficulties emerged over time across participants. For example, George maintained that academic difficulties did not emerge until his second year at Performance:

I went through high school and didn't really have to try or study. The same thing for freshman year here; I just showed up for class, paid attention, and I could do it all. Sophomore year, a couple of weeks in, I got smacked in the face. It was almost like it was like, welcome to college, here it is. There was tons of homework ... And not just class; my work outside of class had picked up in terms of school work. It was definitely a big wake up call. I was like, you're in college now.

Similarly, Kathleen described an increasing level of academic challenge after what seemed like an easy start at Performance:

The first few weeks of classes are easy, to be honest, because they're just starting you out. But the last few weeks hit you hard. I guess since it was really easy in the beginning it was what I expected. But, I didn't expect to have two days to 
write a five page paper. I just wasn't used to that at all. In high school to write a five page paper I had three weeks.

Janelle described the trials of a new type of learning required at the college level:

This year, my problem is, sometimes when learning things ... you're used to learning in a certain way and memorizing in a certain way. But this year made me realize that doesn't work for every class.

Similarly, Brian related the pitfalls of group work that was emphasized in the Performance classroom:

We all do group work here in [School of Business]. Although last semester was great for groups for me, freshman year was not so much. I had a four-person group where two people did work, and I was one of them. Trying to get them to actually try, they don't always understand that.

In order to overcome these academic challenges, participants described employing a number of strategies, including honing their critical thinking skills; modeling the disposition and habits of resilient peers; and seeking assistance in the face of difficulty.

Developing critical thinking skills. One strategy for overcoming academic obstacles described by participants was a focused effort on developing critical thinking skills. At Performance, this focus on critical thinking was built into the first-year curriculum. All first-time, first-year students enrolled in two linked courses during the fall semester: University Seminar (a first-year seminar focused around ethical decisionmaking and college orientation topics) and Critical Writing, Reading and Research, or CWRR. For first-year students, University Seminar and CWRR formed a first-semester learning community, allowing them to take two first-year classes together as a cohort. As 
a group, participants described a Seminar-CWRR experience that instilled the basics of critical thinking and introduced students to the challenges of the college classroom. For example, Janelle described how her University Seminar centered on Christianity opened her mind to exploring issues in a scholarly manner and helped her develop critical thinking skills:

My Seminar was on religion. I have nothing against it, but I was just like, religion? What are we going to talk about? I thought that maybe he [Seminar instructor] might try and force a religion on us or something. But it was completely not like that. When we went in there, he let us have our opinion on [religion]. We went through the whole Bible and talked about how it's been translated over years, and how it could have possibly changed it in a way. People were allowed to have their opinions ...I liked [Seminar], because it got me to start thinking in different ways and consider things I didn't consider before. He [instructor] also said that he was raised in a really religious family, and that it was ok at certain times to question it, because sometimes certain events make you question it, but at the end of the day what matters is your personal relationship [with a higher being] and how you feel about it ... [Seminar instructor] also brought up something I didn't really think of: what does "religious" mean to you? Does it mean you go to church every day, does that make you religious? Or is it bigger than that?

Similarly, Tom recalled the academic rigor he encountered in his section of CWRR: My CWRR teacher was a little tougher than some of the ones I've heard of, extensive papers, stuff like that. But, it wasn't too bad. I enjoyed it. 
Karen summarized how courses like CWRR and Seminar, while sometimes unpopular with students, instructed them on the challenging realities of college-level academics: [CWRR and Seminar], they turn people off to Performance a little bit, because we're like, why do we have to do this? But I think it does teach people - the professors who do it right - it teaches the workload [students] are going to be facing their freshman year.

In addition to strengthening their critical thinking skills through the first-year curriculum, multiple participants cited instructors who fostered their critical thinking abilities. For Susan, this took the form of her favorite instructor giving life to her potential:

I just love learning from her. She takes the things I have in my brain that I don't know are there and just brings them out and brings them to life. It's so interesting to watch the way she teaches. Every day when I go to class, I just learn something that's going to be so useful.

George described a favorite instructor who employed a baseball metaphor to prompt his students to think about problems in new ways:

On the first day of class he talks about seeing the baseball diamond, because he wants us to see the picture. He always went back to the baseball diamond: you have to go to first [base] before you go to second [base] kind of deal. Which was relatable to me, so I enjoyed it. It's enjoyable even though you're still learning and thinking about things differently.

Indeed, the critical thinking skills that Janelle's favorite instructor instilled in her left an impression that extended beyond class time: 
He opened your mind to thinking in many different ways. What I liked most was he made you think and literally every single way you could possibly think, to the point where you'd probably be sitting in his class thinking the whole class period, trying to process what you have just talked about. Even after class, you'd be talking about it with your friends and your roommates.

Whether through first-year curriculum centered on innovative ways of approaching issues or through innovative Performance instructors who challenged their students to think critically and creatively, participants described the development of critical thinking skills as central to overcoming academic challenges.

Modeling resilient peers. In addition to sharpening their critical thinking skills through challenging curriculum and innovative instructors, some participants also described utilizing their Performance peers to overcome academic challenges. Specifically, the first-generation participants recalled on-campus peers who served as models for academic success and persistence. For example, multiple participants described Performance friends who exuded a sense of confidence. Cassie admired this self-assurance in her closest on-campus friend:

She's got this level of confidence that's so unique ... You just see that confidence, her personality, the way she just owns a room, her laugh. Similarly, Janelle admired the forthright nature of her closest Performance friend in academic matters, believing this to be a mature quality to which to aspire:

If she does not agree with her grade she will talk about it. Some people would see that as wrong, but she's just doing what she's supposed to do. As an adult, you're supposed to go out and if you have a problem with something, you need to make 
it known and handle it and get it done.

In addition to being confident, multiple participants described Performance friends who exhibited perseverance in the face of difficulty. Cassie describes her closest on-campus friend as someone who overcame obstacles:

She's one of those people who was born with so many cards against her, and she just pushes through them to the point that you don't even see those things about her.

Janelle viewed her best upperclassmen friends as wise role models:

This semester has been really rough on me, and they've been there for motivation, pushing me forward. Something they tell me is, if you mess up, mess up with confidence. They're like role models as well [as friends].

Clearly, these confident, resilient peers provided the first-generation participants with exemplars of how to navigate academic difficulties at Performance, a critical tool for a population that lacked these exemplars within their home cultures.

Seeking help during difficulty. Nearly all participants related a willingness to seek help during times of academic difficulty as a key to overcoming academic challenges. For example, Janelle emphasized how Performance's Edge program for academically under-prepared first-year students helped her develop both academic and social skills:

The [Edge] program, it helps you socialize with people, but I'm a very shy person. It helped me break out of my shell. The [Edge] program, it's from morning to night, and that especially gets you used to life in general. After the program was done, I knew how to study better, and get my work done better, and 
manage time better.

Similarly, Susan described how Performance's curricular focus on group work was instrumental to overcoming social isolation:

I think a lot of group projects - even though I hate them - Performance has so many of them, at the end you have to be friends, you don't have a choice. I think the classes themselves helped me out of the I'm-not-going-to-have-any-friends [mindset].

Indeed, Karen perceived a team approach that permeated the whole of the Performance culture when students were in need of assistance:

I know that when any student starts to fall behind, Performance has a team employed to help [him or her] get back on [his or her] feet.

Overall, participants described a team of "go-to" faculty and staff members that they regularly sought out for assistance. These Performance "go-to" people possessed similar qualities of warmth, motivation and wisdom. For example, participants described seeking help from Performance faculty and staff members who exuded comfort and care in their interactions with students. Multiple participants perceived this quality in the Director of the Center for Inclusion and Engagement, with Beth describing her as "easy to talk to" and Karen describing her as "emotionally open and super-friendly." In addition, Saki cited a warm quality in her faculty advisor that she had never experienced before:

She's one of the only people who has straight up looked me in the eye and said, I respect you and I think you've got it going for you and I think you can do this. In addition to warmth, multiple participants described their "go-to" people at 
Performance as providers of motivation during difficult times. For Justin, the motivation he received from the dean in the School of Business took the form of focus and structure:

She pretty much kept me on task, on the road to success as opposed to letting myself tumble around.

More than other qualities, participants cited wisdom as the resource they sought from their "go-to" people on campus. For Susan, this wisdom was the organizational assistance she received from her favorite Performance faculty member:

I'm very organized ... I always go to her like, I have sixteen different ways I can do this, how do you want me to do it? She helps me a lot with that.

Similarly, Clarissa cited a sense of objectivity in decision-making that she received from her campus job supervisor, the Director of Residence Life:

More than anything I can get an objective point of view, because with friends have a lot more emotion in it when you come to them and something is bothering you. My boss has always just been like, this is clearly a bad idea, or, what do you want? He can pose that question and just has more of that experience that can help me make a better decision.

Plainly, participants' willingness to take advantage of institutional programs and services and to seek the help of Performance "go-to" people was a critical resource in navigating academic difficulty. The consistent warmth that participants experienced from these individuals set them at ease when navigating unchartered territory. The motivation that participants received from their "go-to" people encouraged them to carry on in difficult times. And the wisdom that participants sought provided guidance that rendered seemingly insurmountable obstacles manageable. 
In summary, the first-generation participants described navigating academic challenges that arose from unfamiliar customs, high expectations, and new freedom. To overcome these challenges, participants related a conscious effort to develop new critical thinking skills and an openness to seeking institutional assistance. Often, this assistance took the form of seeking out Performance "go-to" people who served as a source of warmth, encouragement and wisdom to participants as they traversed uncharted academic waters.

\section{Discovering Deeper Purpose}

Ultimately, as the first-generation participants adjusted to a new institutional environment and overcame social and academic difficulties, they uncovered deeper purpose in their Performance experience. This deeper meaning was achieved through the resolution of distracting off-campus challenges; through interaction with inspiring Performance faculty and staff; and through participation in curricular and co-curricular activities.

Resolving off-campus challenges. Multiple participants characterized the moment that they "arrived" at Performance as the moment that they were able to resolve significant off-campus challenges that pulled their focus and prevented them from finding deeper meaning in their college experience. For Justin, finding purpose in his college experience occurred only after he dealt with the passing of his father and embraced his place and purpose at Performance:

Right before the spring semester of my first year, my father passed away. It was a big moment for me. I realized that I had arrived and was part of the campus that following fall. That spring semester I was really kind of just in it. Coming back, 
returning to the campus that fall, after that spring semester, I was like, here I am. I am here to do this and to finish and to feel good about my experience. I was happy not to get off course after what happened.

Similarly, Saki felt purpose within her college experience only when she was kicked out of her home and embraced by the Performance community:

It was over a year before I actually started to feel at home. Ironically, it was when I got kicked out of my house. I was worried about being homeless and disadvantaged and out there on my own. Performance gave me more financial aid to help me pay for housing on campus. Performance gave me a place to stay over the summer. Performance helped me find jobs. Performance was there for me the whole time. I was pretty shocked, because I didn't think that colleges had that kind of power, or that anyone cared enough to really want to help. I knew that Performance was kind, but I guess it never really set in how much this was my home until then. It's just been a big part of me ever since. Probably about the middle of sophomore year, second semester, is when it really hit.

Only when these participants addressed significant issues unrelated to their postsecondary pursuits were they able to focus on their Performance experience and discover richer meaning in their college career.

Interacting with inspiring faculty and staff. Uninhibited from the burden of off-campus challenges, participants described a sense of deeper purpose in their collegiate pursuits stirred by inspiring Performance faculty and staff. Indeed, when queried about their favorite instructors, participants often cited instructors who exuded passion and enthusiasm in the classroom. For example, Jordan described a history 
professor whose high-energy teaching style, while initially jarring, ignited interest within her:

He's very passionate about what he does. I was terrified my very first class with him because he gets in your face. He gets so into what he's talking about, and it could be a war or some political event, and he'll just be jumping around the room, and he'll get all sweaty. It's the greatest thing, because he keeps you captivated in his class. You're never wanting to doze off, and when he does find a student who dozes off in his class, he'll get up in their face and say, wake up! and stomp his foot, and he'll make the whole class jump. But it's so fun going to his class, especially knowing even though it might be an 8:00 a.m. class, you're going to have fun in that class and you're going to learn something new and he's going to make you love it at the end.

Nan, too, described an international business instructor whose passion for his discipline was infectious:

He's my favorite instructor because he teaches with so much excitement; he gets you into it. The other day he was talking about laws that you have to take into consideration in international business. When I first got to class, I was really tired and I wasn't really in the mood to listen to a lecture. But the way he described everything made everything so interesting. I definitely like his teaching style.

Moreover, the passion that Susan's favorite instructor conveyed for her discipline prompted her to change her major:

It's so interesting to watch the way she teaches ... I knew that I needed to be in Marketing because of the passion that she has brings out the passion in myself. 
Plainly, Performance instructors whose passion for their discipline was palpable sparked a similar passion among the first-generation participants.

Participating in curricular and co-curricular activities. In addition to uncovering passion through interaction with inspiring faculty, multiple participants reported finding a deeper sense of purpose in their Performance experience through their involvement on campus. After initially feeling disconnected as a commuter student, Chloe described the connection to her academic pursuits that she experienced after she traded off-campus employment for an on-campus job:

Because I commuted, I felt like, I go to class, I go to work, I'm done. But last semester, I only got a campus job ... I was really diving into my college experience and really getting into things related to my major. I felt like, ok, this is definitely where I want to be.

Beth's involvement as a First-Year Experience mentor provided a sense of purpose and importance at Performance that facilitated a sense of home within the institution:

Being a [First-Year Experience Mentor], you're in a fishbowl. Everybody knows who you are. So what you do, what you say, what you put out there, everyone knows ... I finally found that place where I can be myself, but I also need to be a paraprofessional representing the staff, the school and myself in an appropriate way. Once I started to meet the other Mentors and experience First Week with the students when they would just rely on my for everything, that's when I felt at home. I am such an important part of Performance ... Relying on someone and being relied on, that's something that's appreciated here at Performance. Clearly, engaging in activities that were connected to participants' academic pursuits and 
that were critical to the functioning of the institution facilitated a deep sense of purpose among the first-generation participants.

In summary, participants described navigational issues that related to discovering deeper purpose within their Performance experience. For participants, this purpose was unearthed through the resolution of off-campus challenges that pulled focus away from their Performance experience; through interaction with inspiring faculty and staff; and through participation in curricular and co-curricular activities.

\section{Summary}

Inquiry within Research Question \#3 centered on what first-generation participants' impressions of Performance University's culture meant for their ability to navigate the institutional environment and ultimately persist to degree completion. Through their descriptions of life on Performance's campus, participants revealed four broad navigational issues: adjusting to an unfamiliar collegiate environment; overcoming social isolation and academic challenges, and finding deeper purpose in their collegiate experience.

Acclimating to an unfamiliar environment with which they had limited prior experience was an obstacle that participants had to overcome in order to achieve their postsecondary goals. Participants revealed a number of adjustment strategies in this endeavor, including participating in Performance's structured orientation programming, taking advantage of institutional programs like Edge, and resolving common collegiate challenges like roommate issues that had the potential to derail even the most prepared students.

Another commonly cited navigation issue was overcoming an early sense of 
social isolation as the result of being away from home and immersed in a strange new environment. As a group, participants described overcoming this isolation through relationship-building and establishing cultural enclaves in which they surrounded themselves with other Performance students who shared their values, beliefs and customs.

In addition to social challenges, participants described navigating academic challenges that arose as the result of new expectations and customs. To overcome these academic challenges, participants described a focused effort on developing new critical thinking skills and a willingness to seek out help as needed. In addition, participants described on-campus peers who they perceived to be confident and resilient and who provided a model for success at Performance.

Finally, participants described navigational issues that related to discovering deeper purpose within their Performance experience. For participants, this purpose was unearthed through addressing distracting off-campus challenges, through interaction with inspiring Performance faculty, and through participation in curricular and co-curricular programing and campus employment.

\section{Conclusion}

Inquiry within the three research questions revealed a relationship between the first-generation participants' external influences, their experiences of the Performance culture, and their navigation of the institutional environment. To start, first-generation student persistence at Performance begins with external forces that serve as critical antecedents to the collegiate experience. First-generation-specific assets such as pride in being the first in one's family to attend college and a strong work ethic instilled by 
supportive family members intersect with common assets like positive primary and secondary education experiences and a belief in the necessity of a college degree to prepare first-generation students for success at Performance. In addition, firstgeneration-specific obstacles such as incomplete college information and lack of actionable advocacy from family members intersect with common pre-college challenges like shyness and inconsistent college preparation to challenge first-generation student persistence at Performance. In this way, forces external to Performance provide a framework for the first-generation experience that is formulated prior to matriculation.

Shaped by pre-college external influences, first-generation students' interpretation of the Performance culture upon matriculation is marked by their discernment of dominant institutional values. For example, first-generation Performance students experience a sense of care through their perception of the value of community. "Community" is evident in a number of institutional forms at Performance, from wellattended ceremonies to a caring faculty body. In addition, first-generation students at Performance experience a sense of inclusion within the institutional environment through their perception of the value of individuality. This emphasis on being distinctive and remaining true to one's self is embodied by a student body that rejects conformity and by unique institutional symbols. Finally, first-generation students at Performance experience a sense of achievement through their discernment of an institutional value of challenge. Indeed, Performance students cannot escape being challenged to do their best work, either through interaction with faculty who hold them to high standards or through a "performance learning" curriculum that emphasizes near-professional results in competitive settings. 
Ultimately, first-generation students' experiences of care, inclusion and achievement hold implications for their ability to navigate the institutional milieu of Performance. Through experiences of care, first-generation students at Performance find adjusting to a strange and unfamiliar environment easier. Through experiences of inclusion, first-generation students at Performance are better equipped to overcome early feelings of isolation. And through experiences of success, first-generation students at Performance obtain the confidence to overcome academic challenges and seek out their unique collegiate purpose.

\section{Summary}

In an effort to shed new insight into first-generation degree completion at small, privately controlled institutions, this chapter summarized inquiry within the study's three research questions relating to the experiences of first-generation participants at Performance University. Inquiry within Research Question \#1centered on the forces within the first-generation participants' external environment that influenced their postsecondary goals and commitments as well as participants' perception of Performance. Inquiry within Research Question \#2 centered on the first-generation participants' experiences of the institutional culture of Performance. Inquiry within Research Question \#3 centered on the first-generation participants' desire and ability to navigate the institutional environment of Performance. 


\section{CHAPTER V}

\section{CONNECTING FINDINGS TO THE LITERATURE}

In an effort to shed light on the degree completion behavior of first-generation college students, the purpose of this study was to explore this population's experiences of a small, privately-controlled institution. Filtering the constructs of Tinto's (1993) interactionalist theory of student persistence through the lens of organizational culture grounded in the sociological tradition, this study centered on three research questions:

1. How do external forces (e.g., family, prior educational experiences) influence first generation students' experiences of a small, privately-controlled institution?

2. How do first-generation students interpret the functional aspects of their institution's culture?

3. What do these interpretations mean for first-generation students' ability to navigate the functional aspects of their institution's culture?

Inquiry within the three research questions revealed new insights into the firstgeneration student experience at private colleges and universities. Within Research Question \#1 (How do external forces influence first generation students' experiences of a small, privately-controlled institution?), inquiry revealed that the first-generation participants possessed unique assets that bolstered their collegiate success, including a sense of pride in their first-generation status; a strong work ethic gleaned from observing family members who toiled and sacrificed in order to get ahead; and supportive family 
members whose life experiences offered a foil against which to work. In addition to assets, participants described challenges unique to their first-generation status, including incomplete and inaccurate college information; strains in relations with hometown peers; and lack of actionable advocacy from supportive family members.

Within Research Question \#2 (How do first-generation students interpret the functional aspects of their institution's culture?), participants relayed a number of shared experiences through their discernment of the cultural values of "Performance University." Through their discernment of the value of community in cultural elements like ceremonies and the faculty subculture, participants described experiences of care. Through their discernment of the value of individuality in institutional symbols and in the student subculture, participants described experiences of inclusion. And through their discernment of the value of challenge in their interactions with faculty members and the Performance curriculum, participants described experiences of achievement.

Within Research Question \#3 (What do these interpretations mean for firstgeneration students' ability to navigate the functional aspects of their institution's culture?), inquiry revealed that participants' discernment of the cultural values of Performance University facilitated a number of critical navigational tasks. Through their experiences of the value of care, the first-generation participants adjusted to an unfamiliar institutional environment. Through their experiences of inclusion, participants overcame feelings of social isolation. And through their experiences of achievement, participants built confidence to overcome challenges and found deeper purpose in their pursuit of a postsecondary degree. 
Figure 1 synthesizes the relationship between the first-generation participants' external influences, their experiences of the institutional culture, and their navigation of the institutional environment into a conceptual model of first-generation degree persistence at Performance University: 
EXTERNAL INFLUENCES

\begin{tabular}{|l|}
\hline \multicolumn{1}{|c|}{ ASSETS: } \\
* Positive primary \\
and secondary \\
educational \\
experiences \\
* Belief in the \\
necessity of a \\
postsecondary \\
degree \\
* First-generation \\
status as a source of \\
pride \\
* Strong work ethic \\
* Parental \\
experiences as foils \\
* Supportive \\
extended family \\
\end{tabular}

\begin{tabular}{|l|}
\hline \multicolumn{1}{|c|}{ OBSTACLES: } \\
* Shyness \\
* Uneven college \\
preparation \\
* Geographical \\
challenges \\
*Incomplete/ \\
inaccurate college \\
information \\
* Strain in \\
relationships with \\
hometown peers \\
* Lack of actionable \\
advocacy from \\
supportive parents \\
\end{tabular}

\section{INTERPRATION OF} CULTURE

CARE through the value of COMMUNITY:

* Campus visit

* Ceremonies and traditions

* Institutional symbols

* Faculty and staff

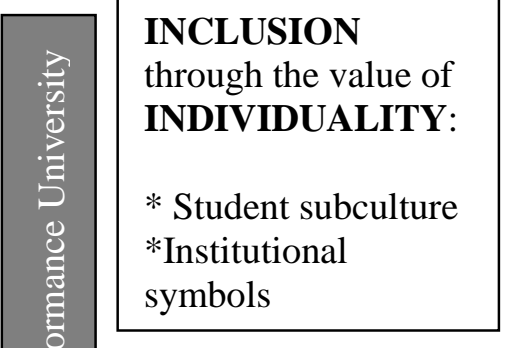

ACHIEVEMENT

through the value of

CHALLENGE:

* Faculty interaction

* "Performance learning" curriculum

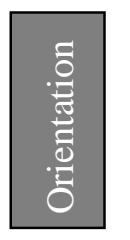

NAVIGATION OF CULTURE

ADJUSTMENT to institutional environment through:

* Structured time and activity

* Structured interaction

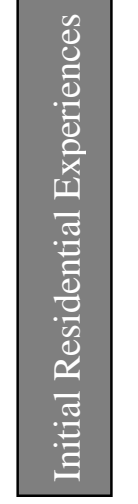

Overcoming

SOCIAL ISOLATION

through:

* Building relationships

* Finding cultural enclaves

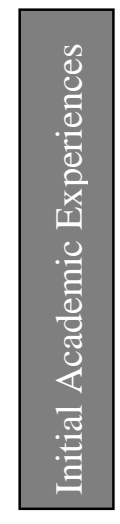

Overcoming

SOCIAL ISOLATION

through:

* Building relationships

* Finding cultural enclaves

Discovering

PURPOSE through:

* Resolving offcampus challenges

* Interacting with inspiring faculty

* Participating in curricular and cocurricular activities

Figure 1. Conceptual model of first-generation persistence at Performance University. 
The following sections link the four major components of the conceptual model (first-generation assets; first-generation obstacles; interpretations of institutional culture; navigation of institutional culture) to the theoretical and empirical literature on degree persistence and organizational culture.

\section{First-Generation-Specific Assets}

Related to student entry characteristics and the external environment within the interactionalist model of student persistence (Tinto, 1993), the college-going assets described by first-generation participants centered chiefly on the positive influence of family members. Consistent with the literature on the influence of family on firstgeneration postsecondary attendance (Saenz et al, 2007; Irlbeck et al., 2014), participants in the current study described family members who provided critical supports for attending college. Indeed, participants described encouragement for college-going that went beyond supportive parents and encompassed extended family members like siblings and grandparents. For their part, older siblings who attended college provided models for college-going and, in some cases, foils against which to work. In addition, grandparents served as forceful cheerleaders for postsecondary attendance and, in some cases, provided the financial means to make participants' collegiate dreams a reality. This support for educational endeavors from extended family members is consistent with the literature on the role of immediate and non-immediate family within non-majority cultures (Barnett, 2004; Ceja, 2006; Sanchez, Reyes, \& Singh, 2005; Herndon \& Hirt, 2004).

The most salient example of an asset that the first-generation participants gleaned 
from their home culture was the strong work ethic that they learned from observing their parents. This strong work ethic can be conceived as a form of cultural capital called nondominant cultural capital (Winkle-Wagner, 2010). Tied to Bourdieu's (1979/1984) notion of field, non-dominant cultural capital includes the skills and norms that are distinctively valuable within non-dominant communities. Within a first-generation household, hard work is particularly valuable, as achieving even modest material success within an economy in which postsecondary education is increasingly essential requires the exertion of additional effort. In turn, this normalization of hard work within firstgeneration households has positive implications for persistence, as the exertion of time and effort in the pursuit of a self-improvement has already been ingrained for students hailing from these environments.

Recognition of the unique assets inherent within non-dominant cultures like firstgeneration households requires respect for these cultures, a notion that Tierney (1999) coins cultural integrity. Reverence for the cultural integrity of first-generation students' home cultures requires acknowledging the considerable strength for collegiate achievement within these cultures (e.g., support for college attendance among extended family members, a strong work ethic gleaned from hardworking parents) as well as a commitment to building cultural capital for collegiate success within these contexts. In sum, the family-centered assets described by the participants in the current study relate to the literature on cultural influences within first-generation families. Consistent with empirical investigations on the role of family support for college-going within first-generation households (Saenz et al, 2007; Irlbeck et al., 2014), participants 
described family relationships that bolster collegiate attendance, including support from extended family members like siblings and grandparents. In addition, participants' account of the strong work ethic that they gleaned from observation of family members can be conceptualized as a form of non-dominant cultural capital (Winkle-Wagner, 2010). Indeed, the very act of recognizing the assets inherent within first-generation students' home cultures is central to respect for the cultural integrity of non-dominant cultures (Tierney, 1999).

\section{First-Generation-Specific Obstacles}

Like assets, first-generation-specific obstacles relate to student entry characteristics and the external environment within the interactionalist model of persistence (Tinto, 1993). In the current study, one persistence obstacle unique to the first-generation participants was incomplete and/or inaccurate knowledge relating to the collegiate experience within their pre-college contexts. Beyond basic academic preparation at the secondary level, this incomplete/inaccurate information related to navigational skills required for collegiate success, including managing management, finances, institutional bureaucracy, and the physical and temporal spaces of the university (Richardson \& Skinner, 1992). Further, the lack of accurate information regarding the collegiate experiences within the first-generation participants' families translated to a lack of models for curricular and co-curricular engagement prior to their enrollment at Performance (Pike \& Kuh, 2005). Ultimately, the first-generation participants' experiences of challenge presented by their lack of understanding of the collegiate environment and by their family's inability to provide guidance in collegiate expectations 
is consistent with the other empirical investigations (Barry, Hudly, Cho \& Kelly, 2008).

Taken together, obstacles relating to the under-developed knowledge of the collegiate environment inherent within the first-generation participants' households can be linked to notions of cultural capital, social capital, field, and social reproduction (Bourdieu, 1979/1984). Bourdieu conceptualizes cultural capital as the skills, abilities, tastes, preferences and norms that serve as cultural currency within a given field, while social capital is the networks and connections through which cultural currency is exchanged. When the skills, abilities, tastes and preferences that one possess (i.e., cultural capital) are not valued within a given field (i.e., a postsecondary institution), or when one lacks social connections (i.e., social capital) within the field, then a social structure is reinforced (i.e., social reproduction) that maintains the dominance of those possessing the "right" cultural resources while marginalizing those lacking those resources. In the current study, the incomplete/inaccurate college information and lack of actionable advocacy from supportive parents that participants described can be conceptualized as under-developed cultural and social resources, which threatened their success within the field of Performance University.

In addition to under-developed information about college, the first-generation participants described emerging tensions in their relationships with hometown peers as the result of opting to attend college at Performance. This emerging tension with hometown peers relates to the marginalization of the role of "college student" by a reference group who was important to participants in the recent past (Richardson \& Skinner, 1992). Participants' descriptions of their relationship with hometown peers 
post-matriculation suggested that these peers perceived little value in college in general and in participants' decision to attend Performance specifically. This marginalization of the "college student" identify by significant others can have implications for firstgeneration students' desire and ability to complete a degree (Richardson \& Skinner, 1992).

In sum, the collegiate obstacles described by participants connect to the sociological and psychological literature on first-generation students. The incomplete and/or inaccurate information about the collegiate experience described by participants is consistent with other investigations of this phenomenon (Pike \& Kuh, 2005; Barry et al., 2008). This lack of credible information about college can be conceptualized as underdeveloped cultural capital, with implications for success within the Performance environment (Bourdieu, 1979/1984). Finally, the emerging tension with hometown peers described by the first-generation participants can be conceptualized as the rejection of their "college student" identify by a critical reference group (Richardson \& Skinner, 1992).

\section{First-Generation Participants’ Interpretations of Institutional Culture}

Related to students' experiences of the internal environment within the interactionalist model of student persistence (Tinto, 1993), the first-generation participants' interpretations of the elements of "Performance University's" institutional culture is marked by their discernment of dominant cultural values. These interpretations included participants' experiences of Kuh and Whitt's (1988) tangible elements of culture: institutional structures, environmental conditions, institutional subcultures and 
socialization processes. In addition, these interpretations included participants' experiences of Masland's (1985) tacit “windows" of culture: symbols, metaphors and rituals. More critical than the objective properties of the elements of the Performance culture, however, was the first-generation participants' enactment of those elements, or the act of creating meaning of the institution through a process of social construction (Weick, 1988). In their enactment of Performance University, the tangible and intangible elements of the university's culture were filtered through participants' internalized "meaning-making systems" that were shaped by family influences, prior educational experiences and other forces eternal to the institution (Kuh \& Love, 2000). It was through this enactment of the Performance culture that participants discerned and articulated the dominant cultural values of the institution.

The dominant cultural values of Performance University discerned by the firstgeneration participants have links to the persistence literature. Specifically, participants' experiences of care through the value of community, inclusion through the value of individuality, and achievement through the value of challenge have positive implications for their desire and ability to complete at degree at Performance. As a group, the firstgeneration participants in the current study described experiences of being cared for as the result of their discernment of the value of community. According to Kuh (20012000), when "community" is among a college or university's perceived institutional values, a compelling "cultural pull" is created among institutional members, with positive implications for student success. In the current study, participants most clearly experienced care through community in their interactions with warm Performance faculty 
members. This experience of care among a group of first-generation students who articulated their desire to persist undergirds the critical nature of perceived faculty support among this student segment (Longwell-Grice \& Longwell-Grice, 2008).

In addition to care through community, participants in the current study articulated experiences of inclusion at Performance. These experiences were the result of their perception of the embrace of individual differences among the Performance student body and within the value placed on uniqueness within prominent institutional symbols. This feeling of inclusion among a group of first-generation students who voiced their desire to graduate from Performance is reflective of the literature on the importance of this population's satisfaction with their academic and social experiences to degree persistence (Forbus, Newbold \& Mehta, 2011; Mehta, Newbold \& O’Rourke, 2011). Finally, participants related experiences of achievement at Performance as the result of their discernment of the value placed on challenge. These experiences of accomplishment and personal growth resulting from the exertion of effort relate to the classic student development theory of challenge and support (Sanford \& Adelson, 1962). In addition, these experience of achievement relate to the development of self-efficacy, or one's perception of her ability to find success in a variety of facets of life (Bandura, 1997). Specifically, as participants met the high expectations established by Performance faculty and progressed through the performance learning curriculum, they gained confidence in their ability to meet collegiate challenges, with positive implications for degree persistence. Participants' experiences of achievement in the face of challenge undergird the literature on the importance of self-efficacy to the first-generation student 
population (Wang \& Castañeda-Sound, 2008).

As a whole, participants' interpretations of the Performance culture and discernment of dominant Performance values relate to the literature on organizational culture as well as sociological and psychological influences within the first-generation context. Through their enactment (Weick, 1988) of the tangible and intangible elements of the Performance culture, participants gleaned the importance of the values of community, individuality and challenge. The feelings of being cared for that participants experienced as a result of the value placed on community reinforce previous investigations relating to the importance on the perception of care among first-generation students (Longwell-Grice \& Longwell-Grice, 2008). In addition, the feelings of being included at Performance that the first-generation participants experienced through the value placed on individuality relate to other investigations relating to the importance of this population's satisfaction with their academic and social experiences (Forbus, Newbold \& Mehta, 2011; Mehta, Newbold \& O’Rourke, 2011). Finally, the feelings of achievement that the participants experienced as the result of the value placed on overcoming challenges among the Performance faculty and in the curriculum relate to literature on the importance of building self-efficacy among first-generation students (Wang \& Castañeda-Sound, 2008).

\section{First-Generation Participants' Navigation of Institutional Culture}

Related to academic and social integration in the interactionalist model of persistence (Tinto, 1993), the first-generation participants' navigation of Performance was marked by overcoming obstacles critical to degree completion. Indeed, the 
participants' accounts of adjusting to the institutional environment, overcoming social and academic challenges, and discovering deeper purpose in their collegiate endeavors are linked to the literature on first-generation student persistence and organizational culture.

\section{Adjusting to the Institutional Environment}

Facilitated by their overarching experiences of care within the Performance community, the first-generation participants described their adjustment to an unfamiliar collegiate environment. Most saliently, participants described adjusting to the Performance environment through their participation in structured orientation programming. Specifically, participants recalled how their experiences of an orientation program marked by structured time and structured interaction with faculty, staff and fellow students facilitated their adjustment to an unfamiliar environment. These affirming accounts of their orientation experiences support the empirical literature on the importance of orientation programming for this population (Terenzini, Springer, et al., 1996; Pascarella \& Terenzini, 2005). Moreover, the critical nature of orientation programming described by the first-generation participants undergirds Tierney's (1997) assertions around the importance of socialization processes for new organizational members who create and re-create culture as they move through the organization.

\section{Overcoming Social Isolation}

Bolstered by their experiences of inclusion at Performance, the first-generation participants described overcoming feelings of social isolation. In large part, participants related overcoming social isolation by participating in curricular and co-curricular 
activities at Performance. This participation in the life of the institution by a group of persisting students supports Astin's (1984) classic student involvement theory, which explicates how students demonstrate their collegiate commitment by focusing their energy on curricular and co-curricular pursuits. This participation also bolsters empirical investigations that highlight the importance of involvement to first-generation student success (Nunez \& Cuccaro-Alamin, 1998; Stebleton \& Soria, 2012).

The first-generation participants' curricular and co-curricular involvement at Performance also relates to student engagement theory, or the quality and quantity of time that college students invest in educational opportunities inside and outside of the classroom that foster outcomes like deep learning, personal development and degree completion (Nelson Laird et al., 2008). The "engagement" behaviors described by the participants - from significant involvement in student organizations to profound out-ofclass conversations with Performance faculty - undergird the literature on the importance of this construct to first-generation student success and reinforce the need for postsecondary institutions to foster conditions for engagement among all populations (Pike \& Kuh, 2005).

The most significant involvement and/or engagement described by participants involved joining cultural enclaves, or student subcultures who shared similar backgrounds, interests, values and/or behavioral expectations (Kuh \& Love, 2000). By joining cultural enclaves, the participants re-framed the Performance environment in familiar ways and successfully navigated the institution. The critical role that cultural enclaves played in participants' Performance experiences bolster the literature on the 
importance of physical and cultural spaces to non-majority student persistence (Davis, 2010).

\section{Overcoming Academic Challenges}

Bolstered by experiences of academic achievement at Performance, the firstgeneration participants in the current study described overcoming a host of obstacles related to adjusting to the demands of the college classroom. One such demand was time management, or the often-cited struggle among college students to balance academic responsibilities with other responsibilities. Consistent with other investigations on the characteristics of first-generation students (Saenz et al., 2007; Engle \& Tinto, 2008), the first-generation participants in the current study were more likely to cite the challenge of balancing, extra-institutional responsibilities like off-campus work with the demands of their studies.

In addition to struggling with time management, some first-generation participants characterized their matriculation at Performance as entering a foreign world with strange vernacular (e.g., "syllabus"), customs (e.g., classes that don't meet every day) and expectations (e.g., APA writing format). This perception of the postsecondary environment as a foreign land is consistent with the literature on first-generation students' unfamiliarity with the knowledge and navigational skills that are critical to collegiate success (Richardson \& Skinner, 1992).

In order to overcome academic obstacles, participants in the current study employed a number of strategies that are consistent with the literature on first-generation student success. For example, participants described their experiences of a first-year 
Performance curriculum that emphasized critical thinking skills coupled with a personal commitment to incorporating these skills in their collegiate efforts. This focus on developing critical thinking skills both by the institution and by the participants undergirds empirical investigations relating to the importance of these skills for firstgeneration students (Terenzini, Springer, et al., 1996; Pascarella et al., 2004).

In addition to a concerted effort at developing critical thinking skills, participants described overcoming academic obstacles through modeling resilient peers who exhibited confidence and perseverance and who served as models for academic success and persistence. The positive influence of peers on participants' collegiate efforts mirrors the literature on the role that on-campus mentors can play in retention efforts (Stuber, 2011; Wang, 2012).

Finally, the first-generation participants cited their willingness to take advantage of institutional programs and services and seek assistance from "go-to" people as critical to their ability to overcome academic challenges. This willingness to seek and accept help from the institution is consistent with the literature that highlights the importance of this characteristic for a population that is less likely to receive navigational assistance from those at home (Stebleton \& Soria, 2012).

\section{Discovering Deeper Collegiate Purpose}

Ultimately, the first-generation participants' experiences of achievement inside and outside of the classroom led them to discover deeper purpose in their collegiate pursuits. However, before this discernment could occur, the first-generation students were compelled to confront off-campus challenges that pulled their focus away from their 
Performance experiences. These challenges dealt primarily with issues related to family strife, off-campus employment, and/or financial stress. Moreover, the challenges described by participants reflect empirical investigations that find first-generation students more likely to work significant hours off-campus (Saenz et al., 2007), more likely to have significant family obligations like dependent care (Engle \& Tinto, 2008), and more likely to be of lower socioeconomic status (Choy, 2001).

Once free to focus on their collegiate pursuits, the first-generation participants reported finding deeper purpose through interaction with inspiring Performance faculty members. This inspiration took the form of faculty piquing participants' interests through the passion and enthusiasm that they exhibited for their discipline. Moreover, the credit that these first-generation students gave to Performance faculty for sparking their academic interests bolsters the literature on the critical nature of faculty interaction to this population (Longwell-Grice \& Longwell-Grice, 2008; Grayson 2011).

Most poignantly, participants in the current study described uncovering deeper collegiate purpose through participation in out-of-class activities. From on-campus employment opportunities to participation in student-run organizations, the sense of purpose that the first-generation participants gleaned from extra-curricular involvement undergirds the literature on the importance of these experiences to non-majority populations in general (Kinzie et al., 2008) and first-generation students specifically (Pike \& Kuh, 2005). Indeed, when extra-curricular involvement includes activities that are tied to critical institutional functions like peer mentoring, these experiences are particularly powerful in promoting institutional commitment (Kuh \& Love, 2000). 
Shaped by pre-college assets and obstacles and facilitated by experiences of institutional culture, the participants' descriptions of navigating the Performance environment are tied to the literature on organizational culture and first-generation persistence. Bolstered by their experiences of care within the Performance community, participants describe adjustment to a new environment that relates to the literature on the importance of orientation programs (Pascarella \& Terenzini, 2005) and the critical nature of socialization for new organizational members (Tierney, 1997). Aided by experiences of inclusion, participants' accounts of overcoming social isolation undergird the literature on encouraging student involvement (Astin, 1984); creating conditions for engagement (Pike \& Kuh, 2005); and fostering cultural enclaves for non-majority students (Kuh \& Love, 2000). And facilitated by experiences of achievement born from challenge, participants' descriptions of facing academic difficulties and uncovering deeper purpose are linked to the literature on role of critical thinking for first-generation students (Pascarella et al., 2004) as well as the importance of role models (Stuber, 2011), faculty interaction (Longwell-Grice \& Longwell-Grice, 2008) and meaningful co-curricular experiences (Pike \& Kuh, 2005; Kuh \& Love, 2000).

\section{Summary}

This chapter synthesized the results of the current study into a conceptual model of first-generation student persistence at Performance University and linked the major constructs of the model (first-generation assets and obstacles; experiences of institutional culture; navigation of institutional culture) to the literature on persistence and organizational culture. The college-going assets described by the participants affirm the 
empirical literature on the positive influences of family members within first-generation households as well as the theoretical literature on cultural influences within these contexts. In turn, the college-going obstacles described by the participants mirror previous investigations on the first-generation student experience and are linked to sociological and psychological literature on collegiate success. The participants' experiences of the institutional culture of Performance relate to the literature on organizational culture within postsecondary institutions as well as sociological and psychological influences within the first-generation context. Finally, participants' accounts of their navigation of the Performance environment are tied to the empirical literature on first-generation student success as well as literature on organizational culture within postsecondary institutions. 


\section{CHAPTER VI \\ DISCUSSION AND IMPLICATIONS}

Filtering the constructs of Tinto's (1993) interactionalist theory of student persistence through the lens of organizational culture grounded in the sociological tradition, the purpose of this study was to explore first-generation students' experiences of a small, privately-controlled institution. According to Kuh and Whitt (1988), organizational culture from the sociological tradition centers on institutional structures and environmental conditions; the formation and sustainability of organizational subcultures; the processes by which new members are socialized within the organization; and, most critically, the products and processes of members creating meaning through the process of social construction (Crotty, 1998). Long applied to the study of postsecondary management and leadership (see Dill, 1992; Chaffee \& Tierney, 1988; Rhoades \& Tierney, 1992), organizational culture is a useful framework for examining how Tinto's (1993) constructs of entry characteristics; postsecondary goals and commitments; institutional environments; and social and academic integration intersect at the individual student level to influence postsecondary outcomes like degree persistence. While acknowledging that factors like student entry characteristics, prior family and educational experiences, and goals and commitments influence degree completion, this study focused on the role that tangible and intangible elements of institutional culture play in firstgeneration student integration within the academic and social communities of their 
institution. Specifically, this study emphasized how the first-generation research participants' pre-matriculation characteristics and contexts shaped not only their postsecondary goals and commitments but also their post-matriculation interpretations of the structural elements, environmental conditions, and community members of the case study institution. More critically, this study examined what participants' interpretations meant for their desire and ability to navigate the institution's organizational milieu and persist to degree completion.

Through the qualitative investigation of three research questions, a model of successful first-generation student degree persistence at Performance University emerged (see Figure 1). Inquiry within Research Question 1 (i.e., How do external forces influence first-generation students' experiences of a small, privately-controlled institution?) revealed pre-matriculation characteristics and experiences that served as antecedents to participants' collegiate experiences. Chief among these characteristics and experiences were a strong work ethic instilled within the family context and robust support for postsecondary attendance among immediate and extended family. Inquiry within Research Question 2 (i.e., How do first-generation students interpret the functional aspects of their institution's culture?) cataloged first-generation participants' discernment of institutional values through their experiences of the tangible and intangible elements of Performance's culture. As a collective, participants experienced a sense of care through their perception of the value of community, a sense of inclusion through their perception of the value of diversity, and a sense of achievement through their perception of the value of challenge. Finally, inquiry within Research Question 3 (i.e., What do these interpretations mean for first-generation students' ability to navigate the functional 
aspects of their institution's culture?) revealed how first-generation participants' experiences of institutional values-in-action facilitated their adjustment to the collegiate environment, their ability to overcome social and academic challenges, and their discovery of a deeper sense of purpose in their collegiate career.

While remaining a "near paradigmatic" (Braxton \& Hirschy, 2005, p. 61) theory of student persistence, Tinto's (1993) interactionalist theory is problematic, particularly as it relates to historically under-represented populations within traditional institutions. For example, Tierney (1992) offers a cultural critique of the interactionalist model, positing that Tinto incorrectly operationalizes an anthropological construct in his conception of academic and social integration. Tinto's conception of academic and social integration is based in part on anthropologist Van Gennep's (1960) inquiry into the rites of passage among indigenous populations. For Van Gennep, a "rite of passage" is an intra-cultural event that marks the ending of one developmental stage and the ushering in of another within a single culture. To that end, Tierney (1992) maintains that Tinto incorrectly conceptualizes integration as an inter-cultural event in which students from one culture (i.e., their home cultures) traverse developmental stages within another culture (i.e., the culture of their colleges and universities). This misapplication of anthropological theory is particularly salient for historically under-represented populations like first-generation students who may not share - or even be familiar with the values of the dominant culture. Indeed, Tierney maintains that Tinto's interactionalist model ignores the fact that most colleges and universities are mirrors of the dominant culture, containing Caucasian, middle- and upper-class, Judeo-Christian forms and values with which students from historically under-represented populations may lack familiarity. 
Most troubling, Tierney asserts that the language of academic and social integration problematizes those from historically under-represented student populations like firstgeneration students, ignoring the possibility that their inability to achieve academic and social integration stems not from within these populations, but from issues within traditional institutional environments that reflect a dominant culture. In this way, higher education scholars' and practitioners' steadfast adherence to the interactionalist model not only marginalizes the experiences of historically under-represented students but also calls into question the continued relevance of traditional colleges and universities within a rapidly changing postsecondary landscape.

Tierney's (1992) cultural critique reveals that the interactionalist model of student persistence lacks substantive focus on the potentially critical role that colleges and universities can play in cultivating institutional programs, policies and environments that promote the success of all students, including first-generation students. Grounded in the findings of the current investigation, what follows are implications for faculty and administrators at privately-controlled institutions interested in leveraging the power of institutional culture to improve first-generation student success and degree completion.

\section{Channeling the Strength of Cultures of Origin}

Within their critique of the interactionalist theory of student persistence (Tinto, 1993), Kuh and Love (2000) offer a number of cultural propositions relating to students' decisions to stay or leave their postsecondary institutions. According to Kuh and Love, the actual properties of a particular culture of immersion (i.e., the structural and organizational forms that compose the institutional environment) are secondary to students' interpretations of that culture with regard to the affective and behavioral 
responses related to persistence. In other words, the environmental properties of a college or university's environment are not as significant to persistence as the meaning that students attach to those properties. In addition, Kuh and Love assert that students' interpretation of their culture of immersion is filtered through their experiences of their cultures of origin, or pre-matriculation familial, educational and community contexts. Some students' cultures of origin may attach significant importance to attending college, while college attendance is stressed to a lesser extent in other home cultures. Similarly, some students' cultures of origin may be rich in familiarity with the collegiate environment and in the cultural capital crucial for collegiate navigation (Bourdieu, (1979/1984), while other students (namely students who are the first in their families to attend college) hail from home cultures where collegiate familiarity and navigational resources are less well developed.

Consistent with empirical investigations into familial support for college-going among first-generation students (Saenz et al., 2007; Irlbeck et al., 2014), participants in the current study described cultures of origin that contain robust supports for postsecondary education. For example, participants described parents who framed postsecondary attendance as compulsory, a life decision that is critical to material success in uncertain economic times. The parents of participants often presented attending college as a foil to their own life decisions, stressing postsecondary education as a way of ensuring that their children have a better life than they had. Upon matriculation, participants described parents who continued to be strong advocates for postsecondary education even as they were unsure how to provide specific and actionable assistance as the result of being unfamiliar with the collegiate context. Similarly, extended family 
members within participants' cultures of origin were strong advocates of postsecondary education, namely grandparents and siblings. In addition to encouraging participants to attend college, grandparents often provided the financial means to make collegiate aspirations a reality. For their part, older siblings served as both models and foils for collegiate success, providing pre-matriculation knowledge about college life for participants and, in some instances, emerging as examples of how not to approach college.

Viewing first-generation students' cultures of origin as reservoirs of strength is in opposition to the latent cultural deficit discourse that undergirds the interactionalist theory of student persistence (Tinto, 1993) and that permeates the discussion on minority student collegiate success. A cultural deficit worldview problematizes the context of students who hail from non-majority cultures, framing their perceived lack of academic success not as the result of the educational environment or even as deficiencies inherent to the students themselves, but as the result of minority students' home cultures which lack sufficient support for academic endeavors (Valencia, 2010). According to the cultural deficit worldview, academic success for non-majority students like firstgeneration students is achieved through the rejection of their cultures of origin and the embracing of the dominant cultural values of their colleges and universities. Conversely, negative phenomena like attrition are not attributed to systemic societal forces or institutional programs, policies or environments, but to departing students' failure to reject their "deficient" cultures of origin and acclimate to the dominant culture of their college or university. In this way, the onus for minority student persistence is shifted away from postsecondary institutions and is placed squarely on the shoulders of the 
students (Tierney, 1999).

As inquiry within the current study revealed, cultural deficit discourse is not only detrimental to the first-generation student experience, it is categorically inaccurate, with nearly all participants pointing to pre-college environments as sources of energy for collegiate effort. As such, colleges and universities interested in bolstering the degree completion rates of their first-generation students should view this population's cultures of origin as critical sources of strength. Tierney (1999) advocates for a commitment to cultural integrity, or strategies that engage students' home cultures in pedagogy and program development. In addition to acknowledging the considerable support for academic success inherent within non-majority cultures, cultural integrity involves bolstering the cultural capital available to students within their cultures of origin by engaging family members and secondary educators. This engagement should involve not only off-campus programs and services within students' communities (e.g., mentoring programs that pair former first-generation students with rising first-generation students; in-services for high school teachers and counselors from majority-minority schools), but also in re-imagining campus-based programs and pedagogies. Upon students' matriculation, a commitment to cultural integrity means continued engagement with those within students' cultures of origin, including communication modes and strategies that are readily accessible to all communities. By employing cultural integrity-based programmatic and communication strategies, institutional leaders arm their strongest allies in first-generation persistence - those within students' cultures of origin - with the tools necessary to translate their encouraging sentiment into actionable support. 


\section{Leveraging the Allure of the Culture of Immersion}

Even as they characterized their cultures of origin in primarily positive ways, first-generation participants in the current investigation voiced a desire to leave their familiar home environments in pursuit of new opportunities and experiences. Indeed, some participants described attending college as an opportunity to create distance between themselves and their cultures of origin, most often with hometown peers with whom they perceived emerging differences. In their pursuit of new experiences, the firstgeneration participants were drawn to Performance University. Far from passive receptacles of dominant institutional values and norms, the first-generation participants infused new life into their new culture of immersion, interpreting the Performance culture through their unique contexts while simultaneously altering the culture through their unique perspectives (Tierney, 1997). While acknowledging that life in the "PerformaBubble" was not perfect, on the whole the participants experienced a caring community, an overarching respect for difference and being true to one's self, and an environment that challenged them to a explore new possibilities and achieve their highest potential. Through this experience and re-creation of culture, participants learned to overcome difficulties, develop lasting relationships and foster new interests and purposes.

Colleges and universities like Performance can cultivate the success of firstgeneration students by capitalizing on the allure of the culture of immersion that attracts this population while embracing the invigoration that emerges from their participation in the academic and social life of the campus. For example, with multiple participants in the current investigation citing their initial campus visit as a pivotal moment, college and university leaders should ensure that these pre-matriculation events are shining examples 
of the institutional experience. Similarly, orientation programming and early curricular and co-curricular experiences should be purposeful exercises in values-in action, providing students with exposure to those ideals which the institution finds important and to which students are drawn. Whether through performance learning-based curricular experiences that instill the importance of achievement or through co-curricular experiences like First Week that promote the significance of community, ensuring that early institutional experiences are positive creates a force to which all students are drawn and through which the institution is continually reinvented.

\section{Culling the Power of Cultural Values}

The current study examined first-generation students' interpretations of the cultural phenomenon of a small, privately controlled institution, including institutional structures, processes, and environmental conditions; faculty, staff, and student subcultures; and the ways that new members are socialized within the institution (Kuh \& Whitt, 1988). Secondary to the actual properties of these cultural phenomena are the meanings that students attach to them and the values that they infer from their interpretations. As a group, the first-generation participants in the current investigation articulated institutional values that mirror Performance's own articulation of its mission, vision and values. For example, participants' experience of the Performance values of community, diversity and inclusion paralleled the university's explicit value of "a diverse and inclusive community” (Mission and Values, 2015). In addition, participants' description of the emphasis placed on individuality mirrored Performance's explicit value of "dignity and respect for the individual" (Mission and Values, 2015). Finally, participants' experience of the importance of personal responsibility and challenge was 
aligned with Performance's mission to prepare students for personal and professional success, with its vision to be a leader in performance learning, and with its value statement on "integrity and responsibility" (Mission and Values, 2015).

Beyond first-generation participants' explicit articulations of institutional values, participants' impressions of cultural elements also aligned with Performance's explicit value statements. Within symbols like the Green Roll mascot, participants found the value of community. Within their representations of the faculty subculture and curriculum, participants perceived an embrace of challenge that mirrored Performance's mission to prepare students for success as well as a sense of positivity-in-action that reflects the university's value of "passion and enthusiasm" (Mission and Values, 2015). And in their experiences of a student subculture that embraced uniqueness, participants discerned the Performance value of inclusivity. In these ways, explicitly stated institutional values were reflected in each student's experience of institutional culture.

The alignment between a college or university's aspirational mission, vision and value statements and students' interpretations of the collegiate environment has positive implications for success within the institutional environment. In general, institutions that articulate a clear philosophy of education like performance learning and strong institutional values exert a strong "cultural pull” for students (Kuh, 2001-2002, pg. 27). Indeed, when institutional values include the value of community, this "pull" is particularly strong (Kuh, 2001-2002). In the current investigation, participants' experiences of care through the value of community, inclusion through the value of individuality, and achievement through the value of challenge facilitated a number of critical navigational tasks. Through their experiences of care, participants found 
adjustment to an unfamiliar collegiate environment. Through their experiences of inclusion, participants overcame initial feelings of isolation. And through their experiences of achievement, participants overcame academic and social obstacles to uncover deeper purpose in their collegiate pursuits. Collectively, these cultural experiences bolster the ability of all students to persist to degree completion, particularly for populations like first-generation students who are navigating unchartered and unfamiliar institutional waters.

What should colleges and universities like Performance - small, privatelycontrolled, residentially-based institutions that excel with the "traditional" college population while struggling to support "non-traditional" populations like first-generation students - consider as they contemplate the power of culture in promoting degree persistence? Inquiry within the research questions of the current investigation offered a number of insights in capitalizing on the potency of organizational culture, channeling the power of cultural windows and harnessing the power of cultural ambassadors.

\section{Capitalizing on the Potency of Organizational Culture}

In their discussion of organizational culture within colleges and universities, Kuh and Whitt (1988) describe the notion of potency, or the degree to which norms, values, practices and beliefs are uniform across the institution and exert a normative influence on institutional members. According to Kuh and Whitt, the institutional culture of small colleges and universities is more potent than the culture of larger institutions due to their reduced layers of administrative structure. Indeed, the current investigation revealed a strong sense of shared purpose and potent cultural values among participants at Performance. As such, small institutions interested in utilizing the power of their 
institutional values to bolster student success should capitalize on the potency of their organizational cultures and ensure that their aspirational values are critically examined, strongly articulated, and widely enacted.

\section{Channeling the Power of Cultural Windows}

In his discussion of the abstract nature of organizational culture in postsecondary institutions, Masland (1985) identifies a number of cultural windows that provide insight into a college or university's values, norms and shared beliefs. One type of cultural window is the symbol, or material manifestation of organizational values that are apparent to those inside and outside of the institution. Often, a symbol is presented as metaphor, or the personification of organizational values. Indeed, articulating understanding of an organization metaphorically is one way of effectively capturing its complex, multi-faceted nature (Morgan, 2006). Another cultural window is an institution's myriad of rituals, or repeated actions and ceremonies that serve as values-inaction (Masland, 1985).

The current investigation revealed strong institutional symbols, metaphors and rituals that served as cultural guideposts for first-generation Performance University students who had limited exposure to the academy. For example, participants described the Green Roll athletic mascot as a symbol of the value of community that was revered at Performance. In addition, participants utilized the metaphors of home and family to relate their experiences of a caring, if not always perfect, institutional environment. Finally, participants described the Candlelight Ceremony during First Week as an emotionally-charge ceremony in which participants were made to feel welcomed into the saga of an institution rich with history (Clark, 1972). Colleges and universities like 
Performance with rich institutional histories and potent organizational cultures should utilize their cultural windows to convey the norms, values and beliefs that are crucial to success within an academic environment, particularly for first-generation students who have limited experience with the academy

\section{Harnessing the Power of Cultural Ambassadors}

In addition to being represented in institutional structures, processes, and environmental conditions, cultural values are embodied in institutional members, both in the words and actions of individual actors as well as in institutional subcultures comprised of multiple actors with shared backgrounds, beliefs, norms and values (Kuh \& Whitt, 1988). Viewed in this light, individual actors and subcultures are cultural ambassadors: gatekeepers of cultural knowledge and history as well as transmitters of cultural norms, beliefs and values. For first-generation students with limited prior exposure to the collegiate context, cultural ambassadors are critical guideposts for making sense of an unfamiliar environment. In the current investigation, individual actors within the Performance community as well was as subcultures within the institution served as cultural ambassadors for the first-generation participants. From individual actors like the Director of the Center for Engagement and Inclusivity, participants gleaned the institutional values of community and inclusion. From the overarching student subculture, participants discerned an emphasis on individuality and a focus on personal development. And from the faculty subculture, participants experienced the importance of challenge and of positive regard for others. Taken together, participant reported that their interactions with Performance's cultural ambassadors were more important to their regard for the institution than their experiences 
of the inanimate elements of the institutional environment. Clearly, colleges and universities focused on the institutional experiences of historically under-represented populations like first-generation students cannot ignore the powerful influence of human capital.

\section{Fostering Cultural Enclaves}

Kuh and Love (2000) utilize cultural distance to characterize the degree of relative alignment between students' cultures of origin and their culture of immersion with regard to the importance attached to collegiate attendance and the resources brought to bear on collegiate navigation. Kuh and Love posit that student departure is more likely when students - and, more critically, postsecondary institutions - fail to bridge the cultural distance between their cultures of origin and the institutional culture of immersion, resulting in the experience of cultural stress. According to Kuh and Love, bridging cultural distance and staving off cultural stress requires employing one of two strategies. First, students can reject the values and behavioral norms of their cultures of origin and embrace the dominant values and norms of their college or university. Alternately, students can seek membership within cultural enclaves, or institutional student subcultures with similar backgrounds, interests, values and/or behavioral expectations. Echoing Tierney's (1992) critique of persistence models like the interactionalist theory (Tinto, 1993) that place the burden of collegiate acclimation squarely on students, Kuh and Love (2000) advocate for fostering cultural enclaves in which students are able to re-frame their culture of immersion in familiar ways and successfully navigate the institution.

In the current investigation, cultural enclaves were a consistent theme in 
participants' attempts to navigate an unfamiliar collegiate environment. For example, multiple participants described overcoming initial social isolation through campus involvement within subcultures of likeminded students. Some students characterized their campus involvement as joining subcultures based on shared interests (e.g., Tom's participation on the football team), while others described joining subcultures that shared their beliefs (e.g., Cassie and the Wiccans she encountered in Unity) and values (e.g., Beth and her involvement with fellow First-Year Experience mentors). Still others cited involvement in subcultures that shared a common racial and ethnic heritage (e.g., Jordan and her multicultural sorority). Regardless of whether they were based on shared interest, beliefs, values or background, these cultural enclaves were critical to successful navigation of the institution. Indeed, multiple participants characterized their Performance "arrival moment" as establishing membership in a subculture of similar peers.

The presence (or, more accurately, the absence) of cultural enclaves within postsecondary institutions has implications for non-dominant populations like firstgeneration students. Indeed, the lack of physical and cultural spaces at small, privatelycontrolled colleges and universities may account for lagging persistence rates at these institutions (Davis, 2010). To that end, postsecondary institutions seeking to improve the degree completion rates of first-generation students must focus on what Kuh and Love (2000) characterize as enclave extension. Whether through spearheading the development of new student groups or supporting the efforts of existing groups, college and university leaders should concentrate on enclave extension efforts that embrace what Tierney (1993) characterizes as communities of difference, or subcultures that share 
cultural values that might not mirror the values of the dominant culture. When appropriately nurtured from the outside as well as the inside, cultural enclaves provide organic navigational assistance by "scaling down" the institution for students that might not share the same backgrounds, values and beliefs of the dominant culture (Attinasi, 1989). Moreover, cultural enclaves like the First-Year Experience Mentors groups and the resident assistant community are particularly impactful because these subcultures are legitimized by the institution and entrusted with work critical to institutional functioning (Kuh \& Love, 2000). In this way, college and university leaders focused on the success of first-generation students should concentrate not simply on accepting the presence of communities of difference, but on bringing these groups into the institutional fold by affirming their importance to the life of the institution and entrusting them with meaningful responsibilities.

\section{Implications for Practice}

Grounded in the results of the current study, what follows are practical considerations for leaders of small, privately-controlled institutions like Performance University seeking to leverage cultural strategies in support of the degree completion for all students, including first-generation students. These strategies include reimagining the campus visit; revitalizing orientation programming; revamping communication strategies; reinforcing cultural ambassadors; and rediscovering the culture of the college or university.

\section{Reimagining the Campus Visit}

With the bulk of the first-generation participants in the current study citing their initial campus visit as a pivotal moment in their collegiate experiences, leaders of small, 
privately-controlled institutions would do well to attend to the overt structure of their campus visit programs as well as the covert messages that are transmitted during these events. Structurally, campus visit programs should center not only on visitors' interactions with the physical campus, but also on their interactions with institutional members. Although some participants did cite the aesthetics of Performance University as important to their campus visit experience, they were more likely to cite their experiences of welcoming students, faculty and staff as the highlight of their campus visit. As such, leaders of institutions like Performance should plan campus visit programs around sustained, meaningful engagement with students, faculty and staff. In addition to attending to program structure, campus leaders should ensure that campus visit programs are shining examples of institutional values-in-action, including considering the prominence of institutional symbols, ceremonies and traditions within these programs and what they might mean to a student who is not only unfamiliar with the institution, but unfamiliar with the trappings of the academy. For example, admission directors scripting campus tours might consider how first-generation students and their families would react to phrases like "the quad" or notions like faculty office hours and help tour guides frame these concepts for those who may lack familiarity with them. Attending to the explicit and implicit elements of the campus visit - including what these elements might mean to first-generation college students and their families - ensures that these programs are exemplars of cultural beliefs, norms and values that support student success.

\section{Revitalizing Orientation Programming}

In addition to the campus visit, the majority of first-generation participants in the current study cited their orientation experience as a pivotal moment in their time at 
Performance, most notably the way that orientation helped them acclimate to their new environment and to form critical campus relationships. As such, campus leaders at institutions like Performance should examine their orientation programs and processes with an eye toward how programs and processes might be experience by historically under-represented populations like first-generation students.

One orientation element for culturally-minded college and university leaders to consider is family member participation. From a cultural integrity standpoint (Tierney, 1999), college and university leaders should acknowledge the critical nature of orientation programming for non-majority students and their family members. While mandating orientation participation for non-students is neither feasible nor appropriate, extending a personalized orientation invitation to first-generation family members that acknowledges the importance of their engagement to student success would be an important step. In addition, campus leaders at traditional colleges and universities should ensure that family orientation programs are not merely focused around the policies and procedures of an unfamiliar dominant culture, but allow non-majority students and their families the opportunity to engage in activities and spaces that reflect familiar norms and values. In these ways, postsecondary leaders leverage the power of first-generation students' cultures of origin to promote success.

While the majority of the first-generation participants expressed appreciation for the structured, mandated nature of Performance's orientation program, some participants - primarily those who maintained significant off-campus responsibilities like work found the rigid nature of First Week to be frustrating and stress-inducing. When designing their orientation programming, college and university leaders at traditional 
institutions like Performance should consider the circumstances of non-traditional student segments like first-generation students. For example, allowances should be made for students to opt out of orientation programming that interferes with external obligations critical to a student, such as work or caregiving responsibilities. Campus practitioners might consider offering critical orientation programming at multiple times and in a variety of modalities (e.g., online modules) to accommodate the needs of students who, for a variety of legitimate reasons, cannot attend specific on-campus sessions. In this way, campus leaders simultaneously acknowledge the differing circumstances of nontraditional students and convey their commitment to all students, regardless of their life circumstances.

In addition to expanding orientation to include first-generation students' family members and building flexibility into orientation processes, college and university leaders operating from a cultural integrity standpoint (Tierney, 1999) should infuse their orientation programs with elements that promote access to the cultural capital necessary for collegiate navigation. Orientation programming should explicitly recognize the unique assets and challenges of historically under-represented populations like firstgeneration students while simultaneously developing cultural capital within these communities. Orientation sessions specifically for historically under-represented students and their family members on financial aid literacy; the expectations of college faculty; the vernacular of the institution and the academy writ large; and on- and offcampus navigational resources are just a few programmatic initiatives that institutional leaders can employ to ensure that their orientation processes capitalize on the strength of students' cultures of origin. 
Finally, practitioners at institutions like Performance should consider the timing of their social and academic orientation programming. In the current study, multiple first-generation participants described feelings of social isolation that extended beyond their First Week orientation and, in some cases, beyond their first year. Furthermore, multiple participants described academic difficulties that did not emerge until well after their initial days and weeks on campus. While front-loading programming and support services is a common practice among student affairs and academic support professionals, college and university leaders should ensure that these programs and services do not stop abruptly at the end of the formal orientation program. Instead, college and university leaders should ensure that social and academic acclimation is a sustained process that is responsive to the unique needs of different student segments, including first-generation students.

\section{Revamping Communication Strategies}

Upon students' matriculation, institutional commitment to cultural integrity (Tierney, 1999) involves continued engagement with those within students' cultures of origin, including utilizing communication modes and strategies that are readily accessible to those at home. For colleges and universities leaders, this communication strategy entails a focus on medium (e.g., utilizing a mix of social media like Twitter and Facebook and more traditional communication like letters and emails) and message (e.g., examining language for academic jargon and/or campus acronyms that might be unfamiliar to firstgeneration families). In addition, meaning-rich cultural windows should be central to institutions like Performance University's print and web-based marketing, with an eye toward invitational, communal images for populations like first-generation students that 
may be intimidated by these unfamiliar cultural forms. Upon matriculation, internal communiques should continue to utilize these cultural images to reinforce the importance of the values that they embody as students continually create and re-create meaning from their institutional experiences throughout their college career.

\section{Reinforcing Cultural Ambassadors}

Colleges and universities focused on the institutional experiences of historically under-represented populations like first-generation students cannot ignore the powerful influence of human capital. For their part, institutional leaders should ensure that faculty and staff embrace their roles as cultural ambassadors by creating opportunities for these subcultures to demonstrate institutional values-in-action. For faculty, these opportunities can be created by encouraging pedagogies that reflect diversity and inclusion (institutional values that must emerge as new voices join the academy) and by promoting the critical thinking skills necessary for collegiate success. For staff, these opportunities can be created by supporting sustained, positive interaction with students as well as supporting efforts to engage all students (particularly those historically marginalized within the academy) in activities that embody institutional values. In these ways, faculty and staff serve as cultural guideposts, modeling institutional values and providing a critical frame of reference from which first-generation students can create meaning from their institutional experiences.

\section{Rediscovering Institutional Culture}

In order to leverage the power of institutional culture to promote student achievement, colleges and universities must be able to discern and articulate cultural beliefs, norms and values. Far from being a static and rational construct, a college or 
university's culture is continually evolving in unpredictable ways, created and re-created as members move in and out of the organization (Tierney, 1997). Rather than assuming that they "know" their colleges or universities, campus leaders should engage in periodic formal study of the cultural beliefs, norms and values of their institution. Specifically, a cultural audit would assist postsecondary leaders at small institutions in gaining greater insight into their institutional environments and leveraging the potent nature of their organizational cultures to support student success (Kuh, Schuh \& Whitt, 1991; Kuh, 2001-2002).

Traditional institutions like Performance University can utilize cultural strategies to promote the achievement of contemporary student populations, including firstgeneration students. Whether these strategies involve re-engineering campus visit and orientation programs to consider how historically under-represented population experience these events; fine-tuning communication to enhance the accessibility of institutional values to diverse populations; empowering faculty and staff to serve as cultural ambassadors; or formally examining institutional culture to capitalize on its potential, campus leaders can leverage the power of institutional culture to improve student outcomes like degree completion.

\section{Conclusion}

As findings in the current study demonstrated, the experiences of a college or university's culture can have positive implications for postsecondary outcomes such as persistence. Filtered through pre-college contexts that include supportive family members, students create meaning from cultural forms like the campus environment, cultural experiences like institutional ceremonies, and cultural ambassadors like faculty 
and student bodies. Students' impressions of these forms, events and ambassadors can have positive effects, providing a frame of reference through which to create meaning of the collegiate context and to navigate the unfamiliar institutional milieu. In this way, institutional leaders seeking to improve student outcomes like degree completion would do well to attend to institutional culture, ensuring that college and university environments reflect cultural values that are compatible with the success of all students. As first-generation, low-income, and non-White students enter postsecondary education in greater numbers, strategies for improving outcomes that center on institutional culture become increasingly critical. As these historically underserved populations enter new cultures of immersion, college and university leaders must simultaneously acknowledge the strength of these populations' cultures of origin while employing strategies that build capacity within them. At small, private institutions in particular, the potent nature of culture inherent within institutional forms, processes and members has the potential to convey norms and values consistent with achievement. Most critically, these institutions must employ cultural strategies that help minority students navigate complex organizations that continue to reflect dominant cultural values. These strategies should be aimed at fostering cultural enclaves: physical and cultural campus spaces through which under-represented find common ground with others with whom they share common values and through which these students can make sense of their collegiate environment.

In closing, it is important to acknowledge how the dynamic nature of institutional culture within colleges and universities bolsters the highest aim of a liberal arts education. An institution's culture must not be conceived as a fixed phenomenon that 
new organizational members absorb passively through a series of scripted learning activities. Instead, culture is fluid, constantly changing as members move in and out of the organization (Tierney, 1997). As college and university leaders of traditional institutions employ cultural strategies aimed at helping historically under-represented students navigate their institutional environments, they will find that their institutional cultures are enhanced by these students' contributions. As those historically shut out of the academy create meaning from the elements, processes and people around them, they simultaneously enrich their collegiate environment, providing fresh perspectives and new ways of knowing. This revitalization of institutional culture that incorporates the gifts of previously unheard voices fosters the ideals of higher education in the liberal arts tradition: embracing new ways of knowing and fostering dialogue across disparate worldviews. 


\section{REFERENCES}

Alliance for Excellent Education. (May 2011). Saving now and saving later: How high school reform can reduce the nation's wasted remediation dollars. Washington, DC: Alliance for Excellent Education. Retrieved from http://www.all4ed.org/files/SavingNowSavingLaterRemediation.pdf

Ancis, J.R., Sedlacek, W.E., \& Mohr, J.J. (2000). Student perceptions of campus cultural climate by race. Journal of Counseling and Development, 78, 180-185.

Aries, E., and Seider, M. (2005). The interactive relationship between class identity and the college experience: The case of lower income students. Qualitative Sociology, 28(4), 419-433.

Aronson, J., \& Inzlicht, M. (2004). The ups and downs of attributional ambiguity: Stereotype vulnerability and the academic self-knowledge of African-American college students. Psychological Science, 15, 829-836.

Aschaffenburg, K., and Maas, I. (1997). Cultural and educational careers: The dynamics of social reproduction. American Sociological Review, 62(4), 573-587.

Aspelmeier, J.E., Love, M. M., McGill, L. A., Elliott, A. N., \& Pierce, T. W. (2012). Self-esteem, locus of control, college adjustment, and GPA among first- and continuing-generation students: A moderator model of generational status. Research in Higher Education, 53, 755-781. 
Astin, A.W. (1984). Student Involvement: A developmental theory for higher education. Journal of College Student Personnel, 25(4), 297-308.

Astin, A. W. (1993). What matters in college? Four critical years revisited. San Francisco: Jossey-Bass.

Astin, A. W., and Oseguera, L. (2004). The declining "equity" of American higher education. Review of Higher Education, 27(3), 321-341.

Attewell, P., Heil, S., Reisel, L. (2012). What is academic momentum? And does it matter? Educational Evaluation \& Policy Analysis, 34(1), 27-44.

Attinasi, L.C. (1989). Getting in: Mexican-Americans' perceptions of university attendance and the implications for freshman year persistence. Journal of Higher Education, 60, 247-277.

Aud, S., Hussar, W., Johnson, F., Kena, G., \& Roth, E. (2012). The condition of education 2012 (NCES 2012-045). Washington, DC: U.S. Department of Education, National Center for Education Statistics. Retrieved from http://nces.ed.gov/pubs2012/2012045.pdf

Awbrey, S. M. (2005). General education reform as organizational change: Integrating cultural and structural change. The Journal of General Education, 54 (1), 1-21.

Bailey, T., Jeong, D.W., \& Cho, S. (2010). Referral, enrollment, and completion in developmental education sequences in community colleges. Economics of Education Review, 29(2), 255-270.

Baird, L. L. (2000). College climate and the Tinto model. In J. M. Braxton (Ed.), Reworking the student departure puzzle (pp. 62-80). Nashville, TN: Vanderbilt University Press. 
Bandura, A. (1997). Self-efficacy: The exercise of control. New York: W.H. Freeman.

Barnett, M. (2004). A qualitative analysis of family support and interaction among Black college students at an Ivy League university. Journal of Negro Education, 73(1), 53-68.

Barry, L. M., Hudley, C., Cho, S., \& Kelly, M. (2008). College students' perceptions of parental support: Differences and similarities by first-generation status. Southeastern Teacher Education Journal, 7(1), 101-108.

Baum, S., Little, K., \& Payea, K. (2011). Trends in community college education: Enrollment, prices, student aid, and debt levels (Trends in Higher Education Series). College Board Advocacy \& Policy Center. Retrieved from http://advocacy.collegeboard.org/sites/default/files/11b_3741_CC_Trends_Brief_ WEB_110620.pdf

Bean, J. P. \& Eaton, S. B. (2000). A psychological model of college student retention. In J. M. Braxton (Ed.), Reworking the student departure puzzle (pp. 48-61). Nashville, TN: Vanderbilt University Press.

Berger, J. B. (2000). Optimizing capital, social reproduction, and undergraduate persistence. In J. M. Braxton (Ed.), Reworking the student departure puzzle (pp. 95-124). Nashville, TN: Vanderbilt University Press.

Bergquist, W. H. (1992). The four cultures of the academy. San Francisco: Jossey-Bass. Bergquist, W.H. \& Pawlak, K. (2008). Engaging the six cultures of the academy. San Francisco: Jossey-Bass. 
Bolton, C.D., \& Kammeyer, K.C.W. (1972). Campus cultures, role orientations, and social types. In K. Feldman (Ed.), College and students: Selected readings in the social psychology of higher education (pp. 377-391). New York: Pergamon Press.

Bourdieu, P. (1979/1984). Distinction: A social critique of the judgment of taste. R. Nice (Trans.). Cambridge, MA: Harvard University Press.

Bowen, W. G., Chingos, M. M., \& McPherson, M. S. (2009). Crossing the finish line: Completing college at America's public universities. Princeton, NJ: Princeton University Press.

Braxton, J. M. \& Hirschy, A. S. (2005). Theoretical developments in the study of college student departure. In A. Seidman (Ed.), College student retention: Formula for success (61-87). West Port, CT: Praeger Publishers.

Brown, P. A. (2008). A review of the literature on case study research. Canadian Journal for New Scholars in Education, 1(1), 1-13.

Bryk, A. S., Gomez, L. M., \& Grunow, A. (2011). Getting ideas into action: Building networked improvement communities in education. In M. T. Hallinan (Ed.), Frontiers in sociology of education (pp. 127-162). New York: Springer.

Cabrera, A. F., Nora, A. \& Castañeda, M. B. (1992). The role of finances in the persistence process: A structural model. Research in Higher Education, 33(5), $571-593$

Cataldi, E.F., Green, C., Henke, R., Lew, T., Woo, J., Shepherd, B., \& Siegel, P. (2011). 2008-09 Baccalaureate and beyond longitudinal study (B\&B:08/09): First Look (NCES 2011-236). U.S. Department of Education. Washington, DC: National Center for Education Statistics. Retrieved from http://nces.ed.gov/pubsearch 
Carnevale, A. P., Jayasundera, T., \& Cheah, B. (2012). The college advantage:

Weathering the economic storm. Washington, D.C., Georgetown Public Policy Institute Center on Education and the Workforce. Retrieved from http://www9.georgetown.edu/grad/gppi/hpi/cew/pdfs/CollegeAdvantage.FullRepo rt.081512.pdf

Ceja, M. (2006). Understanding the role of parents and siblings as information sources in the college choice process of Chicana students. Journal of College Student Development, 47(1), 87-104.

Chaffee, E.E. \& Tierney, W.G. (1988). Collegiate culture and leadership strategies. New York: American Council on Education and MacMillan Publishing.

Chen, X. (2005). First-generation students in postsecondary education: A look at their college transcripts (NCES 2005-171). Washington, DC: U.S. Department of Education, National Center for Education Statistics. Retrieved from http://nces.ed.gov/pubs2005/2005171.pdf

Chickering, A. W., \& Gamson, Z. F. (1987). Seven principles for good practice in undergraduate education. AAHE Bulletin, 39(7), 3-7.

Choy, S. P. (2001). Students whose parents did not go to college: Postsecondary access, persistence, and attainment (NCES 2001-126). Washington, DC: U.S. Department of Education, National Center for Education Statistics. Retrieved from http://nces.ed.gov/pubs2001/2001126.pdf

Clark, B. R. (1970). The distinctive college. Chicago: Aldine Publishing Company. Clark, B. R. (1972). The organizational saga in higher education. Administrative Science Quarterly, 17(2), 178-184. 
Clark, B. R., \& Trow, M. (1966). The organizational context. In T. Newcomb \& E.K. Wilson (Eds.), College peer groups: Problems and prospects for research (pp. 17-70). Chicago: Aldine.

Collier, P. (2008). "Is that paper really due today?”: Differences in first-generation and traditional college students' understandings of faculty expectations. Higher Education, 55(4), 425-446.

Complete College America. (September 2011). Time is the enemy: The surprising truth about why today's college students aren't graduating ... and what needs to change. Washington, DC: Complete College America. Retrieved from http://www.completecollege.org/docs/Time_Is_the_Enemy.pdf

Complete College America. (April 2012). Remediation: Higher education's bridge to nowhere. Washington, DC: Complete College America. Retrieved from http://www.completecollege.org/docs/CCA-Remediation-final.pdf

Considine, M. (2006). Theorizing the university as a cultural system: Distinctions, identities, emergences. Educational Theory, 56 (3), 255-270.

Consumer Financial Protection Bureau (May, 2013). Student loan affordability: Analysis of public input on impact and solutions. Washington, DC: Consumer Financial Protection Bureau. Retrieved from http://files.consumerfinance.gov/f/201305_cfpb_rfi-report_student-loans.pdf

Corbin, J., \& Strauss, A. (2007). Basics of qualitative research: Techniques and procedures for developing grounded theory ( $3^{\text {rd }}$ ed.). Thousand Oaks, CA: Sage.

Creswell, J. W. (2013). Qualitative inquiry and research design: Choosing among five approaches $\left(3^{\text {rd }} \mathrm{ed}\right)$. Thousand Oaks, CA: Sage. 
Crotty. M. (1998). The foundations of social research. London: Sage.

Dana, N. F., Kelsay, K. L., Thomas, D. \& Tippins, D. J. (January 1992). Qualitative interviewing and the art of questioning: Promise, possibilities, problems, and pitfalls. Paper presented at the meeting of the Qualitative Research in Education Conference, Athens, GA.

Davis. J. (2010). The first-generation student experience: Who they are, their characteristics, and strategies for improving their persistence and success. Sterling, VA: Stylus.

Delpit, L. (1996). Other people's children: Cultural conflict in the classroom. New York: New Press.

Dill, D. D. (1982). The management of academic culture: Notes on the management of meaning and social integration. In M. C. Brown (Ed.), ASHE reader on organization \& governance in higher education ( $5^{\text {th }}$ ed.) (pp. 261-272). Boston: Pearson Custom Publishing.

DiMaggio, P. J. \& Powell, W. W. (1983). The iron cage revisited: Institutional isomorphism and collective rationality in organizational fields. American Sociological Review, 48(2), 147-160.

Durkheim, E. (1951). Suicide: A study in sociology (translated by J.A. Spaulding \& G. Simpson). Glencoe, IL: The Free Press.

Dwyer, R. E., Hodson, R. \& McCloud, L. (2012). Gender, debt, and dropping out of college. Gender \& Society, 20(10), 1-26. 
Engle, J., \& Tinto, V. (2008). Moving beyond access: College success for low-income, first-generation students. Washington, DC: Pell Institute for the Study of Opportunity in Higher Education.

Feldman, K. A., \& Newcomb, T. M. (1969). The impact of college on students. San Francisco: Jossey-Bass.

Fenske, R. H., Porter, J. D., \& DuBrian, C. P. (2000). Tracking financial aid and persistence of women, minority and needy students in science, engineering and mathematics. Research in Higher Education, 41(1), 67-93.

Forbus, P. R., Ncwbold, J. J., \& Mehta, S. S. (2011). First-generation university students: Motivation, academic success, and satisfaction with the university experience. International Journal of Education Research, 6(2), 34- 55.

Fordham, S. \& Obgu, J. U. (1986). Black students' school success: Coping with the burden of 'acting White.' Urban Review, 18, 176-206.

Freire, P. (2000). Pedagogy of the oppressed. New York: Continuum.

Frye, M. (1983). Oppression. In The politics of reality: Essays in feminist theory. Trumansburg, NY: The Crossing Press.

Fugazzotto, S.J. (2012). Mission statements, physical space, and strategy in higher education. Innovative Higher Education, 34, 285-298.

Gallant, T. B. \& Drinan, P. (2006). Organizational theory and student cheating: Explanation, responses, and strategies. The Journal of Higher Education, 77 (5), 839-860.

Geertz, C. (1973). The interpretation of cultures. New York: Basic Books. Glaser, B.G., \& Strauss, A. (1967). The discovery of grounded theory. Chicago: Aldine. 
Gloria, A. M., \& Castellanos, A. J. (2012). Desafíos y bendiciones: A multiperspective examination of the educational experiences and coping responses of firstgeneration college Latina students. Journal of Hispanic Higher Education, 11(1), 82-89.

Gofen, A. (2009). Family capital: How first-generation higher education students break the intergenerational cycle. Family Relations, 58(1), 104-120.

González, K. P. (2002). Campus culture and the experiences of Chicano students in a predominantly White university. Urban Education, 37(2), 193-218.

Gorden, R. L. (1975). Interviewing: Strategy, techniques, and tactics. Homewood, IL: Dorsey Press.

Goyette, K. A., and Mullen, A. L. (2006). Who studies the arts and sciences? Social background and consequences of undergraduate field of study. Journal of Higher Education, 77(3), 497-539.

Grayson, P. J. (2011). Cultural capital and academic achievement of first-generation domestic and international students in Canadian universities. British Educational Research Journal, 37(4), 605-630.

Hale-Benson, J. (1986). Black children: Their roots, culture and learning styles. Baltimore, MD: Johns Hopkins University Press.

Hellman, C. M. (1996). Academic self-efficacy: Highlighting the first-generation student. Journal of Applied Research in the Community College, 4, 69-75.

Herndon, M. K., \& Hirt, J. B. (2004). Black students and their families: What leads to success in college. Journal of Black Studies, 34(4), 489-513. 
Hermes, J. (2012). States trend toward performance funding. Community College Journal, 82(4), 26-29.

Horn, L., \& Carroll, C.D. (2007). Placing college graduation rates in context: How 4year college graduation rates vary with selectivity and the size of low-income enrollment (NCES 2007-161). Washington, DC: U.S. Department of Education, National Center for Education Statistics. Retrieved from http://nces.ed.gov/pubs2007/2007161.pdf

Horn, L, Kojaku, L.K., \& Caroll, C.D. (2001). High school academic curriculum and the persistence path through college: Persistence and transfer behavior of undergraduates three years after entering 4-year institutions (NCES 2001-163). Washington, DC: U.S. Department of Education, National Center for Education Statistics. Retrieved from http://nces.ed.gov/pubs2001/2001163.pdf

Hurtado, S., \& Carter, D. F. (1997). Effects of college transition and perceptions of the campus racial climate on Latino college students' sense of belonging. Sociology of Education, 70, 324-345.

Hussar, W. J., \& Bailey, T. M. (2013). Projections of Education Statistics to 2021 (NCES 2013-008). Washington, DC: U.S. Department of Education, National Center for Education Statistics. Retrieved from http://nces.ed.gov/pubs2013/2013008.pdf Illinois Board of Higher Education. (2008). The Illinois public agenda for college and career success. Springfield, IL: Illinois Board of Higher Education. Retrieved from http://www.ibhe.state.il.us/masterPlanning/materials/070109_PublicAgenda.pdf 
Illinois Board of Higher Education. (2011). Databook on Illinois higher education.

Retrieved from http://www.ibhe.state.il.us/Data/Bank/DataBook

Integrated Postsecondary Education Data System. (2016). Performance University.

Retrieved January 28, 2016 from https://nces.ed.gov/ipeds/datacenter/

Irlbeck, E., Adams, S., Akers, C., Burris, S., \& Jones, S. (2014). First generation college students: Motivations and support systems. Journal of Agricultural Education, $55(2), 154$.

Ishitani, T. T. (2003). A longitudinal approach to assessing attrition behavior among firstgeneration students: Time-varying effects of pre-college characteristics. Research in Higher Education, 44(4), 433-449.

Ishitani, T. T. (May, 2005). Studying educational attainment among first-generation students in the United States. Paper presented at the $45^{\text {th }}$ Annual Forum of the Association for Institutional Research, San Diego, CA.

Ishitani, T. T. (2006). Studying attrition and degree completion behavior among firstgeneration college students in the United States. Journal of Higher Education, 77, 861-885.

Jenkins, Y., Miyazaki, A. L., \& Janosik, S. M. (2009). Predictors that distinguish firstgeneration college students from non-first generation college students. Journal of Multicultural, Gender, and Minority Studies 3(1), 1-9.

Johnson, N. (2012). The Institutional Costs of Student Attrition. Washington, D.C., Delta Cost Project at the American Institute for Research. Retrieved from http://www.deltacostproject.org/resources/pdf/Delta-Cost-Attrition-ResearchPaper.pdf 
Johnson, R. B. (1997). Examining the validity structure of qualitative research. Education, 118, 282-292.

Kanter, M., Ochoa, E., Nassif, R., \& Chong, F. (2011). Meeting President Obama's 2020 college completion goal. US Department of Education.

Karp, M. M., Hughes, K.L., \& O’Gara, L. (2010-2011). An exploration of Tinto’s integration framework for community college students. Journal of College Student Retention: Research, Theory \& Practice, 12(1), 69-86.

Katchadourian, H.A., \& Boli, J. (1985). Careerism and intellectualism among college students. San Francisco: Jossey-Bass.

Kena, G., Hussar W., McFarland J., de Brey C., Musu-Gillette, L., Wang, X., ... Dunlop Velez, E. (2016). The condition of education 2016 (NCES 2016-144). Washington, DC: U.S. Department of Education, National Center for Education Statistics. Retrieved from http://nces.ed.gov/pubs2016/2016144.pdf

Kinzie, J., Gonyea, R., Shoup, R., \& Kuh, G.D. (2008). Promoting persistence and success of underrepresented students: Lessons for teaching and learning. New Directions for Teaching and Learning, 115, 21-38.

Knapp, L. G., Kelly-Reid, J. E., \& Ginder, S. A. (2012). Enrollment in postsecondary institutions, fall 2011; financial statistics, fiscal year 2011; and graduation rates, selected cohorts, 2003-2008: First look (preliminary data) (NCES 2012-174). Washington, DC: U.S. Department of Education, National Center for Education Statistics. Retrieved from http://nces.ed.gov/pubs2012/2012174.pdf 
Kuh, G. D. (2001-2002). Organizational culture and student persistence: Prospects and puzzles. Journal of College Student Retention: Research, Theory \& Practice, 3(1), 23-39.

Kuh, G. D. (2003). What we're learning about student engagement from NSSE. Change, $35(2), 24-32$.

Kuh, G. D. (2009). The National Survey of Student Engagement: Conceptual and empirical foundations. New Directions for Institutional Research, 141, 5-20.

Kuh, G. D., Kinzie, J., Cruce, T., Shoup, R. \& Gonyea, R. (2007). Connecting the dots: Multi-faceted analyses of the relationships between student engagement: Results from the NSSE, and the institutional practices and conditions that foster student success. Retrieved from nsse.iub.edu/pdf/Connecting_the_Dots_Report.pdf

Kuh, G. D., \& Love, P. G. (2000). A cultural perspective on student departure. In J. M. Braxton (Ed.), Reworking the student departure puzzle (pp. 196- 212). Nashville, TN: Vanderbilt University Press.

Kuh, G. D., Schuh, J.H., Whitt, E.J. and associates (1991). Involving colleges: Successful approaches to fostering student learning and development outside the classroom. San Francisco: Jossey-Bass.

Kuh, G. D. \& Whitt, E. J. (1988). The invisible tapestry: Culture in American colleges and universities (ASHE-ERIC Higher Education Report No. 1). Washington, D.C.: Association for the Study of Higher Education.

Kuo, H. (2009). Understanding relationships between academic staff and administrators: An organizational culture perspective. Journal of Higher Education Policy and Management, 31(1), 43-54. 
Laden, B. V., Milem, J. F., \& Crowson, R. L. (2000). New institutional theory and student departure. In J. M. Braxton (Ed.), Reworking the student departure puzzle (pp. 235- 256). Nashville, TN: Vanderbilt University Press.

Lareau, A., \& Weininger, E. B. (2003). Cultural capital in educational research: A critical assessment. Theory and Society, 32, 567-606.

Lee, J., Donlan, W., \& Brown, E.D. (2010-2011). American Indian/Alaskan Native undergraduate retention at predominantly white institutions: An elaboration of Tinto's theory of college student departure. Journal of College Student Retention: Research, Theory \& Practice 12(3), 257-276.

Lingenfelter, P. E. (2008). The financing of public colleges and universities in the United States. In H. F. Ladd \& E.B. Fiske (Eds.), Handbook of research in education finance and policy (pp. 651-670). New York: Routledge.

Liu, S. (2011, May). An analysis of first-generation college student experiences and their educational growth. Presented at the Annual Conference of Maryland Association for Institutional Research, Baltimore, Maryland.

Lohfink, M. M., \& Paulsen, M. B. (2005). Comparing the determinants of persistence for first-generation and continuing-generation students. Journal of College Student Development, 46(4), 409-428.

London, H. B. (1989). Breaking away: A study of first-generation college students and their families. American Journal of Education, 97, 144-170.

Longwell-Grice, R., \& Longwell-Grice, H. (2008). Testing Tinto: How do retention theories work for first-generation, working-class students? Journal of College Student Retention, 9(4), 407-420. 
Masland, A. T. (1985). Organizational culture in the study of higher education. In C. Brown (Ed.), Organization \& governance in higher education, 5th ed. (pp. 145152). Boston: Pearson Custom Publishing.

Matthews, D. (2016). A stronger nation through higher education: How and why Americans must achieve a Big Goal for college attainment. Indianapolis, IN: Lumina Foundation. Retrieved from https://www.luminafoundation.org/files/publications/stronger_nation/2016/A_Str onger_Nation-2016-Full.pdf

McClusky, H. Y. (1974). Education for aging: The scope of the field and perspectives for the future. In S. Grabowski \& W. D. Mason (Eds.), Learning for aging (pp. 324355). Washington, DC: Adult Education Association of the USA.

McCormick, A.C., Moore, J. V., \& Kuh, J. D. (2010). Working during college: Its relationship to student engagement and educational outcomes. In L.W. Perna (Ed.), Understanding the working college student. (pp. 179-212). Sterling, VA: Stylus.

McNay, I. (1995). From the collegial academy to the corporate enterprise: The changing cultures of universities. In T. Schuller (ed.), The changing university? (pp. 105115). Buckingham: Open University Press.

Mehta, S., Newbold, J. J., \& O’Rourke, M. A. (2011). Why do first-generation students fail? College Student Journal, 45(1), 20-35.

Merriam, S. B. (1998). Qualitative research and case study applications in education. San Francisco: Jossey-Bass. 
Merriam, S. B. (2009). Qualitative research: A guide to design and implementation. San Francisco: Jossey-Bass.

Merwin, J. C. (1969). Historical review of changing concepts of evaluation.” In R. L. Tyler (Ed.), Educational Evaluation: New Roles, New Methods: The Sixty-Eighth Yearbook of the National Society for the Study of Education, Part II (p. 295). Chicago: University of Chicago Press.

Meyer, J. W. (1970). The charter: Conditions of diffuse socialization in schools. In W. R. Scott (Ed.), Social processes and social structures: An introduction to sociology (pp.564-578). New York: Henry Holt.

Meyer, J. W., \& Rowan, R. (1977). Institutionalized organizations: Formal organizations as myth and ceremony. American Journal of Sociology, 83, 340-363.

Mintzberg, H. (1979). The professional bureaucracy. In C. Brown (Ed.), Organization \& governance in higher education, 5th ed. (pp. 50-70). Boston: Pearson Custom Publishing.

Mission and Values. (2015). Retrieved from http://www. performance.edu/about/missionvalues

Morgan, G. (2006). Images of organization. Thousand Oaks, CA: Sage.

Mortenson, T. (January, 2012). The inconvenient truth: Family income and educational attainment: 1970 to 2010. Postsecondary Education Opportunity, 235, 1-16.

Nelson Laird, T.F., Chen, D., \& Kuh, G.D. (2008). Classroom practices at institutions with higher-than-expected persistence rates: What student engagement data tell us. New Directions for Teaching and Learning, 115, 85-99. 
Newcomb, T.M., Koenig , K.E., Flacks, R. \& Warwick , D.P. (1967). Persistence and change: Bennington College and its students after twenty-five years. New York: Wiley.

Núñez, A. M. (2009). Modeling the effects of diversity experiences and multiple capitals on Latina/o college students' academic self-confidence. Journal of Hispanic Higher Education, 8(2), 179-196.

Núñez, A. \& Cuccarco-Alamin, C. D. (1998). First generation students: Undergraduates whose parents never enrolled in postsecondary education (NCES 98-082). Washington, DC: U.S. Department of Education, National Center for Education Statistics. Retrieved from http://nces.ed.gov/pubs98/98082.pdf

Offenstein, J., Moore, C., \& Shulock, N. (2010). Advancing by degrees: A framework for increasing college completion. Sacramento, CA: Institute for Higher Education Leadership and Policy and The Education Trust.

Office of Institutional Research (2016). Pell and first-generation student outcomes. Performance University.

Oliff, P., Palacios, V., Johnson, I. \& Leachman, M. (2013). Recent state higher education cuts may harm students and the economy for years to come. Washington, DC: Center on Budget and Policy Priorities. Retrieved from http://www.cbpp.org/files/3-19-13sfp.pdf

Pace, C. R. (1990). The undergraduates: A report of their activities and college experiences in the 1980s. Los Angeles: Center for the Study of Evaluation, UCLA Graduate School of Education. 
Pascarella, E. T., Pierson, C. T., Wolniak, G. C., \& Terenzini, P. T. (2004). Firstgeneration college students: Additional evidence on college experiences and outcomes. The Journal of Higher Education, 75 (3), 249-284.

Pascarella, E. T., \& Terenzini, P. T. (1991). How college affects students: Findings and insights from twenty years of research. San Francisco: Jossey-Bass.

Pascarella, E. T., \& Terenzini, P. T. (2005). How college affects students, Volume 2: A third decade of research. San Francisco: Jossey-Bass.

Patton, M. Q. (2002). Qualitative research and evaluation methods ( $3^{\text {rd }}$ ed.). Thousand Oaks, CA: Sage.

Pearce, R. R., \& Lin, Z. (2005). Cultural capital and postsecondary educational attainment among White and Chinese Americans: An analysis of NELS 19882000. Educational Review, 1(59), 19-36.

Performance Learning. (2015). Retrieved from http://www.peformance.edu/performance Performance University. (2015). Retrieved from http://nces.ed.gov/collegenavigator Peterson, M. W., \& Spencer, M.G. (1990). Understanding academic culture and climate. In W. G. Tierney, (Ed.), Assessing academic climates and cultures [New Directions for Institutional Research, 68, Winter 1990] (pp. 3-18). San Francisco: Jossey-Bass.

Pettigrew, A. M. (1979). On studying organizational cultures. Administrative Science Quarterly, 24, 570-581.

Pike, G. R., \& Kuh, G.D. (2005). First- and second-generation college students: A comparison of their engagement and intellectual development. Journal of Higher Education, 76(3), 276-300. 
Próspero, M., Russell, A. M., \& Vohra-Gupta, S. (2012). Effects of motivation on educational attainment: Ethnic and developmental differences among firstgeneration students. Journal of Hispanic Higher Education, 11(1), 100-119.

PU History. (2015). Retrieved from https://www.performance.edu/about/missionvalues/pu-history

Radford, A. W. (April, 2013). Social class and the college choice process: How poverty shapes where even valedictorians attend. Paper presented at the meeting of the American Educational Research Association, San Francisco.

Rhoades, G. (2012). Closing the door, increasing the gap: Who's not going to (community) college. Center for the Future of Higher Education. Retrieved from http://futureofhighered.org/uploads/ClosingTheDoorFINAL_ALL32812.pdf

Rhoades, G., \& Tierney, W. G. (1992). Cultural leadership in higher education. University Park, PA: National Center on Postsecondary Teaching, Learning, and Assessment.

Richardson, R. C., \& Skinner, E. F. (1992). Helping first-generation minority students achieve degrees. In L. S. Zwerling \& H. B. London (Eds.), First generation students: Confronting the cultural issues (pp. 29-43). New Directions for Community College, 80, San Francisco: Jossey-Bass.

Roscigno, V. J., and Ainsworth-Darnell, J. W. (1999). Race, cultural capital and educational resources: Persistent inequalities and achievement returns. Sociology of Education, 72(3), 158-178.

Rodney, B.D., \& Stephan, L. (2012). An analysis of Barack Obama's dual language game on education. Journal of Philosophy and History of Education, 62. 29-40. 
Saenz, V. B., Hurtado, S., Barrera, D., Wolf, D., \& Yeung, F. (2007). First in my family: A profile of first generation college students at four-year institutions since 1971. Los Angeles: UCLA, Higher Education Research Institute.

Sánchez, B., Reyes, O., \& Singh, J. (2006). Makin' it in college: The value of significant individuals in the lives of Mexican-American adolescents. Journal of Hispanic Higher Education, 5(1), 48-67.

Sanford, N., \& Adelson, J. (1962). The American college. Hoboken, NJ: Wiley.

Saunders, D. B. (2010). Neoliberal ideology and public higher education in the United States. Journal for Critical Education Policy Studies, 8(1), 42-77.

Schein, E.H. (2010). Organizational culture and leadership (4th ed). San Francisco: Jossey-Bass.

Schneider, M. (2010). Finishing the first lap: The cost of first-year student attrition in America's four-year colleges and universities. Retrieved from http://www.air.org/files/AIR_Schneider_Finishing_the_First_Lap_Oct101.pdf

Seidman, A. (2005). College student retention: Formula for student success. Westport, CT: Praeger Publishers.

Silver, H. (2003). Does a university have a culture? Studies in Higher Education, 28 (2), 157-169.

Smircich, L. (1983). Concepts of culture and organizational analysis. Administrative Science Quarterly, 28(3). 339-358. 
Snyder, T.D., de Brey, C., and Dillow, S.A. (2016). Digest of education statistics 2014 (NCES 2016-006). Washington, DC: U.S Department of Education, National Center for Education Statistics. Retrieved from http://nces.ed.gov/pubs2016/2016006.pdf

Snyder, T.D., \& Dillow, S.A. (2011). Digest of education statistics 2010 (NCES 2011015). Washington, DC: U.S. Department of Education, National Center for Education Statistics. Retrieved from http://nces.ed.gov/pubs2011/2011015.pdf

Somers, P., Woodhouse, S., \& Cofer, J. (2004). Pushing the boulder uphill: The persistence of first-generation college students. NASPA Journal, 41(3), 418-435. Spady, W. G. (1971). Dropouts from higher education: An interdisciplinary review and synthesis. Interchange, 1, 64-85.

St. John, E. P., Cabrera, A. F., Nora, A. \& Asker, E. H. (2000). Economic influences on persistence reconsidered: How can finance research inform the reconceptualization of persistence models? In J. M. Braxton (Ed.), Reworking the student departure puzzle (pp. 29 - 47). Nashville, TN: Vanderbilt University Press.

St. John, E. P., Paulsen, M. B. \& Starkey, J. B. (1996). The nexus between college choice and persistence. Research in Higher Education, 37(2), 175-220.

Stake, R. E. (2005). Qualitative case studies. In N.K. Denzin \& Y.S. Lincolon (Eds.), The Sage handbook of qualitative research $\left(3^{\mathrm{rd}} \mathrm{Ed}.\right)(\mathrm{pp} .443-466)$. Thousand Oaks, CA: Sage. 
State of Illinois Board of Higher Education. (2009). The Illinois public agenda for college and career success. Retrieved from http://www.ibhe.org/masterplanning/materials/070109_PublicAgenda.pdf

State of Illinois Board of Higher Education. (2011). Databook on Illinois higher education. Retrieved at http://www.ibhe.state.il.us/data bank/databook/2011/databook2011.pdf

Stebleton, M., \& Soria, K. (2012). Breaking down barriers: Academic obstacles of firstgeneration students at research universities. Learning Assistance Review, 17(2), $7-$ 19.

Stephens, N. M., Fryberg, S., Markus, H., Johnson, C., Covarrubias, R. (2012). Unseen disadvantage: How American universities' focus on independence undermines the academic performance of first-generation college students. Journal of Personality \& Social Psychology, 102(6), 1178-1197.

Stephens, N. M., Townsend, S.S.M., Markus, H. R., Phillips, L. T. (2012). A cultural mismatch: Independent cultural norms produce greater increases in cortisol and more negative emotions among first-generation college students. Journal of Experimental Social Psychology, 48(6), 1389-1393.

Stierlin, H. (1974). Separating parents and adolescents. New York: Quadrangle.

Strage, A. (1999). Social and academic integration and college success: Similarities and differences as a function of ethnicity and family educational background. College Student Journal, 33, 198-205.

Strayhorn, T. L. (2006). Factors influencing the academic achievement of firstgeneration college students. NASPA Journal, 43(4), 82-111. 
Strayhorn, T. L. (2012). Satisfaction and retention among African-American men at twoyear community colleges. Community College Journal of Research \& Practice, $36(5), 358-375$.

Strother, S., Van Campen, J. \& Grunow, A. (2013). Community college pathways: 2011-2012 descriptive report. Stanford, CA: Carnegie Foundation for the Advancement of Teaching. Retrieved from http://www.carnegiefoundation.org/sites/default/files/CCP_Descriptive_Report_Y ear_1.pdf

Stuber, J. M. (2011). Integrated, marginal and resilient: Race, class, and the diverse experiences of white first-generation students. International Journal of Qualitative Studies in Education, 24(1), 117-136.

Swail, W. S., Cabrera, A.F., Lee, C., \& Williams, A. (2005). Part I: From middle school to the work force: Latino students in the educational pipeline. Washington, DC: The Educational Policy Institute. Retrieved from http://educationalpolicy.org/pdf/LatinoI.pdf

Sy, S. R., Fong, K., Carter, R., Boehme, J. \& Alpert, A. (2011-2012). Parent support and stress among first-generation and continuing-generation female students during the transition to college. Journal of College Student Retention: Research, Theory \& Practice, 13(3), 383-398.

Tate, K. A., Williams, C. \& Harden, D. (2013). Finding purpose in pain: Using logotherapy as a method for addressing survivor guilt in first-generation college students. Journal of College Counseling, 16(1), 79-92. 
Terenzini, P.T., Pascarella, E.T., \& Blimling, G.S. (1996). Students' out-of-class experiences and their influences on learning and cognitive development: A literature review. Journal of College Student Development, 37(2), 149-162.

Terenzini, P. T., Springer, L., Yaeger, P. M., Pascarella, E. T., \& Nora, A. (1996). Firstgeneration college students: Characteristics, experiences and cognitive development. Research in Higher Education, 37, 1-22.

Thelin, J.R. (2004). American higher education. Baltimore, MD: The John Hopkins University Press.

Thorton, C. H. \& Jaeger, A. J. (2006). Institutional culture and civic responsibility: An ethnographic study. Journal of College Student Development, 47 (1), 52-68.

Thorton, C. H. \& Jaeger, A. J. (2007). The ceremonies and symbols of citizenship. About Campus, March/April, 15-20.

Tierney, W. G. (1988). Organizational culture in higher education: Defining the essentials. Journal of Higher Education, 59(1), 2-21.

Tierney, W. G. (1992). An anthropological analysis of student participation in college. Journal of Higher Education, 64, 604-618.

Tierney, W. G. (1993). Building communities of difference: Higher education in the twenty-first century. Westport, $\mathrm{CN}$ : Bergin \& Garvey.

Tierney, W. G. (1997). Organizational socialization in higher education. Journal of Higher Education, 68(1), 1-16.

Tierney, W. G. (1999). Models of minority college-going and retention: Cultural integrity versus cultural suicide. Journal of Negro Education, 68(1), 80-91. 
Tierney, W. G. (2002). Parents and families in precollege preparation: The lack of connection between research and practice. Educational Policy, 4(16), 588-606.

Tierney, W. G. \& Minor, J. T. (2004). A cultural perspective on communication and governance. New Directions for Higher Education, 127, 85-94.

Tinto, V. T. (1993). Leaving college: Rethinking the causes and cures of student attrition. Chicago: The University of Chicago Press.

U.S. Department of Education. (2014). Progress for America's children. Retrieved from http://www.ed.gov/priorities

Valencia, R. R. (2010). Dismantling contemporary deficit thinking: Educational thought and practice. New York: Routledge.

Valentine, J. C., Hirschy, A. S., Bremer, C. D., Novillo, W., Castellano, M., \& Banister, A. (2011). Keeping at-risk students in school: A systematic review of college retention programs. Educational Evaluation and Policy Analysis, 33(2), 214-234.

van der Velden, G. (2012). Institutional level student engagement and organizational cultures. Higher Education Quarterly, 66(3), 227-247.

Van Gennep, A. (1960). The rites of passage. M. Vizedone \& G. Caffee (Trans.). Chicago: University of Chicago Press.

Wang, C. D. C, \& Castañeda-Sound, C. (2008). The role of generational status, selfesteem, academic self-efficacy, and perceived social support in college students' psychological well-being. Journal of College Counseling, 11(2), 101-118.

Wang, T. (2012). Understanding the memorable messages first-generation college students receive from on-campus mentors. Communication Education, 61(4), 335357. 
Warburton, E. C., Bugarin, R. B., Nunez, A. (2001). Bridging the gap: Academic preparation and postsecondary success of first-generation students (NCES 2001153). Washington, DC: U.S. Department of Education, National Center for Education Statistics. Retrieved from http://nces.ed.gov/pubs2001/2001153.pdf

Weber, M. (1968). Economy and society. New York: Bedminster Press.

Wei, C. C., \& Horn, L. (2013). Federal student loan debt burden of noncompleters (NCES 2013-155). Washington, DC: U.S. Department of Education, National Center for Education Statistics. Retrieved from http://nces.ed.gov/pubs2013/2013155.pdf

Weick, K. E. (1976). Educational organizations as loosely coupled systems. In C. Brown (Ed.), Organization \& governance in higher education, 5th ed. (pp. 36-49). Boston: Pearson Custom Publishing.

Weick, K. E. (1988). Enacted sensemaking in crisis situations. Journal of Management Studies, 25(4), 305-317.

Winkle-Wagner, R. (2010). Cultural capital: The uses and abuses of a key theoretical concept in educational research. ASHE Higher Education Report Series, 36(1).

Woosley, S.A., \& Shepler, D.K. (2011). Understanding the early integration experiences of first-generation college students. College Student Journal, 45(4), 700-714.

Yin, R. K. (2003). Case study research: Design and methods ( $3^{\text {rd }}$ Ed.). Thousand Oaks, CA: Sage. 
Young Invincibles. (May 2013). Borrower in distress: A survey on the impact of private student loan debt. Washington, DC: Center for Community of Change. Retrieved from http://younginvincibles.org/wpcontent/uploads/2013/05/Borrower-in-Distress-5.8.13.pdf

Zucker, L. G. (1987). Institutional theories of organization. Annual Review of Sociology, $13,443-464$. 


\section{APPENDIX A}

\section{SURVEY INVITATION}

Are you (or you and your siblings) the first in your family to attend college? If so, we are interested in YOUR story.

A researcher from Illinois State University is investigating the first-generation student experience at colleges and universities like Performance. You can improve our understanding of what it's like to be the first person in your family to attend college including Performance's role in shaping your experience - by completing the following survey:

https://www.surveymonkey.com/s/mufgs

Participation in this research is voluntary and will remain confidential.

Your input is valuable! Thank you for taking the time to help us understand the firstgeneration student experience at Performance.

Dean of Student Development 


\section{APPENDIX B}

\section{SURVEY PROTOCOL}

\section{Performance First-Generation Student Survey}

\section{Demographic Questions}

- Year in school: (first year, second year, etc.) (open-ended response)

- Did either of your parents/primary caregivers ever attend college? (Y or N response)

\section{External Influences (Research Question \#1)}

- Describe how your prior educational experiences (i.e., your experiences in grade school, middle school, and/or high school) did or did not prepare you for college. (open-ended response)

- Describe your family's involvement in your decision to attend Performance. (open-ended response)

- Describe your family's involvement in your education today. (open-ended response)

\section{Interpretation of Institutional Culture (Research Question \#2)}

- What is unique about what Performance represents? (open-ended response)

- What is unique about the way the Performance campus looks and feels? (openended response)

- What is unique about the things that people at Performance care about and the way that they act? (open-ended response)

Navigation of Institutional Culture (Research Question \#3)

- Did you feel prepared for the challenges of college life? Please explain. (openended response)

- Do you feel like you fit in at Performance? Please explain. (open-ended response)

- Do you feel supported by Performance to reach your educational goals? Please explain. (open-ended response)

- As of today, do you intend to graduate from Performance? If so, why are you staying? If not, why are you leaving? (open-ended response)

\section{Invitation to Interview}

- Would you consider having a confidential conversation with someone outside of Performance about your college experience? (Y or N response)

- [If Y above] Please enter your first name. (open-ended response)

- [If Y above] Please enter the email address at which you would like to be contacted about the possibility of a confidential conversation centering on your 
college experience. (open-ended response) 


\section{APPENDIX C INTERVIEW INVITATION}

Thank you for completing the First-Generation Student Survey. Your responses shed an illuminating light on the Performance student experience. Please know that your survey responses will not be linked to you in the write-up of results.

You indicated that you might be interested in a follow-up conversation. If you are still interested, I would like to schedule this conversation at your convenience. I plan to be on campus on Wednesdays and Thursdays during the month of [November/December/January/February]. Is there a time on either one of those days that would work for a meeting (no longer than an hour, likely less than an hour)? Please let me know by replying to this email.

I look forward to the opportunity to hear your story in person.

Josh Hayes, Illinois State University 


\section{APPENDIX D}

\section{INTERVIEW PROTOCOL}

\section{External Influences (Research Question \#1)}

- What did you know about college life before arriving on campus?

- Tell me about the person or group of people who was most influential in your decision to attend college. How and why did they influence your thinking?

- Tell me about the moment that you knew that you wanted to attend college.

- Tell me about the moment that you knew you wanted to attend Performance?

- What words or phrases would your family and friends at home use to describe Performance?

\section{Interpretation of Institutional Culture (Research Question \#2)}

- What did you know about Performance before you enrolled? Did this knowledge connect with you? Why or why not?

- Tell me about your first days on campus. Who was there? What were the major activities? What were you thinking and feeling in these initial moments? What did these early days on campus tell you about the college experience ahead?

- Tell me about the moment that you felt like you had finally "arrived" at Performance. What was the setting? Who else was there? What were you doing? What were you thinking and feeling in the moment?

- Faculty, staff and students at Performance gather for ceremonies and special events outside of class time. Tell me about a Performance event or ceremony that stands out to you, including why you feel it is distinctive.

- Tell me about a time that you participated in a Performance tradition, or a time that you observed other Performance students participating in this tradition. How did you feel as you participated or observed this tradition?

- All colleges and universities have symbols that represent what they value as an institution. What symbol (person, animal, object) best represents Performance? Why do you think that?

- Who is the person or group of people that best represents Performance? What is it about this person or group that makes him/her/them a good representation of Performance?

\section{Navigation of Institutional Culture (Research Question \#3)}

- If you live on campus, tell me about your first residence hall experience at Millkin. 
- Talk about your first class experiences at Performance. Was it was what you expected? Why or why not? Without revealing names, tell me about your favorite and least favorite instructor at Performance. What makes him or her your favorite/least favorite instructor?

- Without revealing names, talk about your closest on-campus friends. How did you meet them? How do you spend your time? What distinguished your closest oncampus friends from other people that you have met during your time at Performance?

- Without revealing names, who is your "go to" person at Performance when you need help? Tell me about the last time you sought this person's assistance. What were the circumstances? How did this person help? What was the result?

- Describe the most significant challenge or challenges that you faced adjusting to life at Performance. What were the circumstances? If you have overcome these challenges, how did you do it? 


\section{APPENDIX E \\ STATEMENT OF INFORMED CONSENT}

Dear

I am a graduate student under the direction of Dr. Dianne Gardner Renn in the College of Education at Illinois State University. I am conducting a research study to explore how college students' experiences and views of their institution have affected their desire and ability to persist towards graduation. I am requesting your participation, which will involve one interview with me that will take place at a campus location convenient to you and last about 45-60 minutes. The interview will be audio taped, with your permission.

Your participation in this study is voluntary. If you choose not to participate or to withdraw from the study at any time, there will be no penalty of any kind. Your decision to participate or not to participate will not affect your standing at [insert name of institution] in any way. The results of the research study may be published, but your name will not be used. Although the use of an interview method raises risks concerning confidentiality, I will take all precautions to maintain your confidentiality (e.g., your name will not be used, and the transcript from our interview will not be shared with anyone). In addition, pseudonyms will be used during the interview and the final report. And of course, you may choose not to answer any question asked of you during the interview.

There are minimal physical, psychological or social risks to this research study. Although some interview questions may remind you of negative experiences, the likelihood of this is low and the potential negative effects (e.g., disappointment in your institution) are likely to be minor. Please be assured that your identity will not be revealed to any [insert name of institution] faculty member, staff member, administrator or student in the write-up of this interview. In addition, you have the right to refuse to answer any interview question and to discontinue your participation in the study at any point before, during or after the interview session. Should you decide to participate, you will be given a copy of this consent form to keep.

Although there may be no direct benefit to you, the possible benefit of your participation would be to reflect on your collegiate accomplishments and those factors that have contributed to you success. 
If you have any questions concerning the research study, please call me at (XXX) XXXXXXX, or Dr. Dianne Gardner Renn at (XXX) XXX-XXXX.

By my signature, I affirm that I have been given the opportunity to ask questions and consent to participate in the interview. I understand that my interview will be audiotaped.

Signature

Date

Co-PI Signature

Date

If you have any questions about your rights as a subject/participant in this research, or if you feel you have been placed at risk, you can contact the Research Ethics \& Compliance Office at Illinois State University at (309) 438-2529. 